\title{
R\&D alliances, knowledge flows, and innovation : three studies on the value of collaborative R\&D
}

Citation for published version (APA):

Frankort, J. T. W. (2010). R\&D alliances, knowledge flows, and innovation : three studies on the value of collaborative R\&D. [Doctoral Thesis, Maastricht University]. Maastricht University Press. https://doi.org/10.26481/dis.20100618jf

Document status and date:

Published: 01/01/2010

DOI:

10.26481/dis.20100618jf

Document Version:

Publisher's PDF, also known as Version of record

\section{Please check the document version of this publication:}

- A submitted manuscript is the version of the article upon submission and before peer-review. There can be important differences between the submitted version and the official published version of record.

People interested in the research are advised to contact the author for the final version of the publication, or visit the DOI to the publisher's website.

- The final author version and the galley proof are versions of the publication after peer review.

- The final published version features the final layout of the paper including the volume, issue and page numbers.

Link to publication

\footnotetext{
General rights rights.

- You may freely distribute the URL identifying the publication in the public portal. please follow below link for the End User Agreement:

www.umlib.nl/taverne-license

Take down policy

If you believe that this document breaches copyright please contact us at:

repository@maastrichtuniversity.nl

providing details and we will investigate your claim.
}

Copyright and moral rights for the publications made accessible in the public portal are retained by the authors and/or other copyright owners and it is a condition of accessing publications that users recognise and abide by the legal requirements associated with these

- Users may download and print one copy of any publication from the public portal for the purpose of private study or research.

- You may not further distribute the material or use it for any profit-making activity or commercial gain

If the publication is distributed under the terms of Article $25 \mathrm{fa}$ of the Dutch Copyright Act, indicated by the "Taverne" license above, 


\section{R\&D ALLIANCES, KNOWLEDGE FLOWS, AND INNOVATION}

THREE STUDIES ON THE VALUE OF COLLABORATIVE R\&D 
R\&D Alliances, Knowledge Flows, and Innovation Three Studies on the Value of Collaborative R\&D

(c) H. T. W. Frankort, London 2010

All rights reserved. No part of this publication may be reproduced in any form or by any means without prior written consent by the author.

ISBN 9789052789538

Print: Datawyse/Universitaire Pers Maastricht 


\title{
R\&D ALLIANCES, KNOWLEDGE FLOWS, AND INNOVATION
}

\section{THREE STUDIES ON THE VALUE OF COLLABORATIVE R\&D}

\author{
DISSERTATION \\ to obtain the degree of Doctor at Maastricht University, \\ on the authority of the Rector Magnificus, Prof. Dr. G. P. M. F. Mols, \\ in accordance with the decision of the Board of Deans, \\ to be defended in public on Friday June 18, 2010, at 14:00 hours \\ by \\ Johannes [Hans] Theresia Wilhelmus Frankort \\ born in Heerlen, the Netherlands \\ on August 27, 1981
}

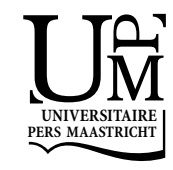




\section{Supervisor:}

Prof. Dr. John Hagedoorn

\section{Co-supervisor:}

Dr. Wilko Letterie

\section{Assessment committee:}

Prof. Dr. Martin A. Carree (chair)

Dr. Joanne E. Oxley (Rotman School of Management, University of Toronto) Prof. Dr. Franz C. Palm 
IF you can keep your head when all about you

Are losing theirs and blaming it on you;

If you can trust yourself when all men doubt you,

But make allowance for their doubting too:

If you can wait and not be tired by waiting,

Or being lied about, don't deal in lies,

Or being hated don't give way to hating,

And yet don't look too good, nor talk too wise;

If you can dream - and not make dreams your master;

If you can think - and not make thoughts your aim,

If you can meet with Triumph and Disaster

And treat those two impostors just the same:

If you can bear to hear the truth you've spoken

Twisted by knaves to make a trap for fools,

Or watch the things you gave your life to, broken,

And stoop and build 'em up with worn-out tools;

If you can make one heap of all your winnings

And risk it on one turn of pitch-and-toss,

And lose, and start again at your beginnings

And never breathe a word about your loss:

If you can force your heart and nerve and sinew

To serve your turn long after they are gone,

And so hold on when there is nothing in you

Except the Will which says to them: 'Hold on!'

If you can talk with crowds and keep your virtue,

Or walk with Kings - nor lose the common touch,

If neither foes nor loving friends can hurt you,

If all men count with you, but none too much:

If you can fill the unforgiving minute

With sixty seconds' worth of distance run,

Yours is the Earth and everything that's in it,

And - which is more-You'll be a Man, my son!

by Rudyard Kipling

from Rewards and Fairies (1910)

pp. 181-182

Doubleday, Page \& Company, Garden City, New York 



\section{Acknowledgments}

John Hagedoorn provided encouragement and direction. Many thanks go to John for his incredible effort and for setting the example of working dreadfully hard, with dedication and wit. He never lacked the energy to discuss. I am also thankful for important doors he opened for me; by generously sharing data; by initiating the contacts for my stay at UC Berkeley; by inviting me as his co-author on the paper published in the 2008 volume of Advances in Strategic Management; and for the suggestion to take aboard Wilko Letterie during my project. I especially thank Wilko for encouraging me to develop my ideas and for sharing his insights into econometrics. Wilko always pushed me to clarify my thoughts. Working with John and Wilko is inspiring and, above all, much fun.

I wish to thank the members of the reading committee, Martin Carree, Joanne Oxley, and Franz Palm, for their feedback and effort. Martin has always supported my attempts to get to grips with panel data econometrics. Joanne has provided sharp feedback that has in the meantime helped me further develop the ideas as pitched in especially chapter 4. Franz Palm provided meticulous comments and questions on econometrics and beyond.

I was fortunate to have three magnificent roommates in B2.10. Danielle Cloodt, Andrea Guenster, and Daniela Kirchberg, thanks for being so nice to me and for sitting through many terrible jokes. Adela Buttolo and Kitty van Straaten provided much valued time, support, and a place to blow off steam. Marc van Ekert generously shared his deep insights into the R\&D alliance data. Thanks also to all the other colleagues in the department and to the $\mathrm{PhD}$ students that were around when I was.

In 2007, I visited the Walter A. Haas School of Business at UC Berkeley. Thanks go to David Mowery for sponsoring my stay, to David Teece and Pat Murphy for hosting me, and to Anita Stephens for the work she did to help me get through the administrative burden necessary to work on U.S. soil. I also thank Josef Chytry, Oliver Gassmann, and Anne Koch for their interest and collegiality. Emily Choi and Chris Rider invited me to join their weekly $\mathrm{PhD}$ seminar, which I appreciated very much.

During my last year in the PhD program, I went on the job market and accepted a job at Cass Business School. I am grateful to Joel Baum, Martin Carree, and Oliver Gassmann for supporting my applications. I wish to thank Head of Faculty David Sims for the trust he put in me; Strategy subject leader Charles Baden-Fuller for expert advice, support, and inspiration; Santi Furnari for endless chats about research; and Gianvito Lanzolla for kind guidance and numerous pleasant lunches. Finally, my thanks go in particular to Caroline Wiertz for her as always generous advice and friendship, which has made work and life in London most enjoyable. 
Sjoerd Beugelsdijk, Boris Blumberg, Dries Faems, Victor Gilsing, Koen Heimeriks, Justin Jansen, Tom Mom, Arjen Slangen, Roger Smeets, Omar Solinger, Wouter Stam, Brian Tjemkes, Diederik van Liere, Pepijn van Neerijnen, Woody van Olffen, and Paul Vlaar all took part in two discussion groups that I have been involved in since 2008. Many thanks for all the interesting discussions and, not in the least, for the nice dinners. Diederik and Michiel, thank you for all the fun moments at conferences and elsewhere. I especially thank the two of you for supporting me during my dissertation defense.

Dear mom and dad, thank you for your unconditional love and encouragement, and for your understanding. You have always been there for me, but especially when I needed it most. Dear Peter and Marie-Claire, thanks for your interest and support. Thanks also go to my in-laws for support and curiosity. Many thanks to all my friends for all the good times we have had together, but especially to Charli, Frank, John, and Koen.

I saved the greatest 'thank you' for the most important person in my life. Dear Jessica, thank you for your love, support, and friendship.

Hans Frankort

London, April 2010 


\section{Table of Contents}

List of Tables and Figures $\quad$ xi

\section{Introduction}

1.1 Introduction

1.2 Research questions

1.3 Across the chapters

1.4 Outline

2. R\&D Alliance Portfolios and the Inflow of Technological Knowledge

2.1 Introduction

2.2 R\&D portfolios inside the firm

2.3 From internal to external R\&D portfolios

2.3.1 Portfolio size

2.3.2 R\&D alliance portfolios and the focus on research 11

$\begin{array}{ll}\text { 2.3.3 Combining novel and repeat partners } & 13\end{array}$

2.4 Method

2.4.1 Data and sample

2.4.2 Dependent variable 16

$\begin{array}{ll}2.4 .3 \text { Independent variables } & 17\end{array}$

$\begin{array}{ll}2.4 .4 \text { Control variables } & 18\end{array}$

$\begin{array}{ll}2.4 .5 \text { Statistical analysis } & 20\end{array}$

$\begin{array}{ll}2.5 \text { Results } & 20\end{array}$

2.5.1 Control variable results 20

2.5.2 Hypotheses $\quad 21$

$\begin{array}{ll}2.5 .3 \text { Robustness } & 25\end{array}$

2.6 Discussion and conclusion $\quad 27$

\section{Partner Effects on Firm Innovation:}

Concurrent Effects of Technological Resources and Structural Holes

3.1 Introduction 31

3.2 Firm effects on innovation 32

3.3 Partner effects on firm innovation 34

3.3.1 Partners' technological resources and firm innovation 34

3.3.2 Partners' structural holes and firm innovation 35

$\begin{array}{ll}3.4 \text { Method } & 39\end{array}$

3.4.1 Data and sample $\quad 39$

$\begin{array}{ll}\text { 3.4.2 Network definition } & 40\end{array}$

3.4.3 Dependent variable $\quad 41$

3.4.4 Independent variables $\quad 42$

$\begin{array}{ll}3.4 .5 \text { Control variables } & 43\end{array}$

3.4.6 Statistical analysis $\quad 44$ 
3.5 Results 46

3.5.1 Control variable results $\quad 46$

3.5.2 Hypotheses 49

3.6 Discussion and conclusion 51

4. Technological Dynamism and the Performance of R\&D Alliances

4.1 Introduction $\quad 55$

4.2 R\&D alliances, structural governance, and performance 56

4.3 Technological dynamism, flexibility, and performance $\quad 58$

4.3.1 Organizational commitment and technological dynamism $\quad 60$

4.3.2 Hierarchical organization and technological dynamism $\quad 62$

4.4 Method 64

4.4.1 Data and sample $\quad 64$

4.4.2 Dependent variables 65

4.4.3 Governance and dynamism variables 66

4.4.4 Control variables $\quad 68$

4.4.5 Statistical analysis $\quad 69$

4.5 Results $\quad 72$

4.5.1 Dyad models $\quad 72$

4.5.2 Firm models $\quad 75$

$\begin{array}{ll}\text { 4.5.3 Supplementary analysis } & 80\end{array}$

4.6 Discussion and conclusion 83

5. Conclusions

5.1 Introduction $\quad 89$

5.2 Major findings 90

$\begin{array}{ll}\text { 5.2.1 Study } 1 & 90\end{array}$

5.2.2 Study 2

5.2.3 Study $3 \quad 92$

5.3 Implications $\quad 93$

5.3.1 Theoretical implications 93

5.3.2 Methodological implications $\quad 94$

5.3.3 Managerial implications $\quad 96$

$\begin{array}{ll}5.4 \text { Limitations and suggestions for further research } & 97\end{array}$

Literature $\quad 99$

Nederlandse Samenvatting (Dutch Summary) 111

Biographical Sketch 113 


\section{List of Tables and Figures}

\section{Tables}

Table 2.1 Descriptive statistics $\quad 21$

Table 2.2 Correlations 22

Table 2.3 Conditional FE negative binomial estimates of knowledge inflows

Table 3.1 Descriptive statistics and correlations

Table 3.2 Unconditional FE negative binomial estimates of firm innovation

Table 4.1 Descriptive statistics and correlations for dyad analysis

Table 4.2 Descriptive statistics and correlations for firm analysis

Table 4.3 Robust probit estimates of dyad governance structure

Table 4.4 Poisson QML conditional FE panel estimates of dyad knowledge flows

Table 4.5 Poisson QML conditional FE panel estimates of firm innovative performance

Table 4.6 Negative binomial estimates of firms' new product announcements

\section{Figures}

Figure 2.1 Portfolio size, research focus, and inward knowledge flows 24

Figure 2.2 Portfolio novelty and inward knowledge flows 25

Figure 3.1 Structural holes of A's partners B and E 37

Figure 3.2 Partners' technological resources and firm innovation 49

Figure 3.3 Firm and partner structural holes, and firm innovation $\quad 50$

Figure 4.1 Rate and unpredictability of technological change in IT, 1978-1999

Figure 4.2 Rate of technological change, dyad JV-share, and dyad knowledge flows

Figure 4.3 Unpredictability of technological change, dyad JV-share, and dyad knowledge flows

Figure 4.4 Rate of technological change, portfolio JV-share, and firm innovation

Figure 4.5 Unpredictability of technological change, portfolio JV-share, and firm innovation

Figure 4.6 Rate of technological change, portfolio JV-share, and new product launch

Figure 4.7 Unpredictability of technological change, portfolio JV-share, and new product launch 



\section{ONE}

\section{Introduction}

\subsection{Introduction}

This dissertation presents three essays concerning interfirm R\&D alliances and their relation to interfirm flows of technological knowledge and firm innovation. My overall research question is this: how do R\&D alliances affect the interfirm flow of technological knowledge and firms' innovative performance?

R\&D alliances are interfirm cooperative agreements aimed at joint research and development relating to new technologies, products and processes (Hagedoorn 1993). Over the past decades, but especially since the mid-1980s, firms have increasingly engaged in such R\&D alliances, reflecting that the sources necessary to innovate are no longer found within the boundaries of single firms (Cloodt, Hagedoorn, \& Roijakkers 2006; Contractor \& Lorange 2002; Gay \& Dousset 2005; Hagedoorn 1993, 2002; Hagedoorn \& Narula 1996; Harrigan 2003 [1985]; Iyer, Lee, \& Venkatraman 2006; Miles et al. 1997; Parise \& Henderson 2001; Powell \& Grodal 2005; Powell, Koput, \& Smith-Doerr 1996; Powell, White, Koput, \& Owen-Smith 2005; Rosenkopf \& Schilling 2007; Teece 1992). In fact, R\&D alliances are but one of a broader range of manifestations of firms' increased preparedness to connect their innovation processes with external players, a tendency compellingly summarized and illustrated by Henry Chesbrough in his 2003 book entitled Open Innovation. Overall, R\&D alliances represent an important form of coordinated interfirm exchange, highlighting the intricacy of technology-related connections among firms (cf. Stuart 1998; Stuart \& Podolny 1996, 1999).

Descriptive evidence on the steep increase in R\&D alliance activity abound. At the aggregate level, Hagedoorn (2002) showed that though only few R\&D alliances were formed in the 1960s and 1970s, in the 1990s many hundreds of R\&D alliances were formed annually. Further, his data indicated that the dramatic increase in firms' engagement in R\&D alliances was largely concentrated in a small number of high tech industries such as information technology, pharmaceutical biotechnology, and aerospace and defense (cf. Schilling 2009). At the firm level, numbers of R\&D alliances have also increased markedly over time. For example, Cloodt et al. (2006) indicated that though IBM formed only 7 R\&D alliances in computers during the first half of the 1980s, it formed as many as 27 computers-related R\&D alliances during the second half of the 1990s. More broadly, IBM formed as many as 335 new R\&D alliances with 163 unique partners in the 1990s alone, across a broad range of industries (Hagedoorn \& Frankort 2008). Furthermore, interestingly, despite a good deal of path-dependence in firms' partnering preferences (e.g., Gulati 1995a; Gulati \& Gargiulo 1999), the R\&D al- 
liance portfolios of individual firms have changed noticeably over time, reflecting that R\&D alliances provide flexible, temporary means of tapping divergent sources of knowledge. For example, comparative statistics presented by Hagedoorn and Frankort (2008) reveal that of all of IBM's R\&D alliance partners during the first half of the 1990s, only about $15 \%$ still appeared to serve as IBM's R\&D partner during the second half of the 1990s.

Along with firms' increased engagement in R\&D alliances, scholarly interest in their determinants and success factors has flourished. By now, there is a fair body of research addressing a range of factors deemed crucial for choosing alliance partners (Gulati 1995a; Harrigan 2003 [1985]), designing alliances (Gulati 1995b; Oxley 1997; Pisano, Russo, \& Teece 1988), and drawing their contractual foundations (Hagedoorn \& Hesen 2007). Furthermore, beyond research on partner choice and alliance architecture, much work has sought to identify the performance benefits accruing to partner firms (Ahuja 2000a; Baum, Calabrese, \& Silverman 2000; Hagedoorn \& Schakenraad 1994; Powell, Koput, Smith-Doerr, \& Owen-Smith 1999; Shan, Walker, \& Kogut 1994; Soh 2003; Stuart 2000). This dissertation aligns with the latter string of work to spell out conditions under which $R \& D$ alliances are beneficial to the firms involved, both in terms of sparking interfirm knowledge flows as well as affecting firm innovation.

\subsection{Research questions}

In broad terms, the studies reported here are attempts at developing an understanding of the contingent value of $R \& D$ alliances. Most prior studies have by now come to agree that $R \& D$ alliances need not unconditionally help firms forward. Rather, in order to reap innovative benefits, firms would seem to have to attend to certain alliance and partner contingencies (e.g., Baum et al. 2000; Gomes-Casseres, Hagedoorn, \& Jaffe 2006; Mowery, Oxley, \& Silverman 1996; Oxley \& Wada 2009; Rowley, Behrens, \& Krackhardt 2000; Sampson 2004, 2007; Stuart 2000). Unfortunately, therefore, decisions concerning $R \& D$ alliances are multifaceted and require significant insights on the part of firms' decision makers. Not surprisingly, designing alliance strategy represents a formidable management challenge.

The studies here aim to speak to the multifaceted nature of interfirm R\&D. In addressing the main research question, I therefore divide my attention across three sub questions that deliberately take a multifaceted view of R\&D alliances. First, at the firm level, firms' accumulated R\&D alliances culminate into portfolios of external ties. In chapter 2 , I probe the applicability of theory on internal R\&D portfolios (e.g., Nelson 1961) to portfolios of external R\&D partnerships by asking:

How do compositional features of firms' $R \mathcal{E} D$ alliance portfolios influence the rate of technological knowledge flowing into these firms? 
At its essence, this first question addresses the extent to which firms stand to benefit from taking a portfolio view of their external contacts, an issue of significant interest to practitioners (e.g., Bamford \& Ernst 2002) and academics alike (e.g., Lavie 2007).

Second, prior work has argued that resource profiles of a firm's alliance partners influence the extent to which it stands to benefit from its R\&D alliances (e.g., Stuart 2000). An adjacent literature has studied how the structural characteristics of the network formed by firms' accumulated R\&D alliance activities impact performance (e.g., Ahuja 2000a). Yet, scant attention has been paid to the joint effects of resource profiles and network structure (but see Baum et al. 2000). In chapter 3, I therefore seize recent calls for more careful analyses of partner attributes (Gulati 2007; Lavie 2006) and juxtapose resource and network structural effects at the partner level by asking:

Does partners' position in the RED alliance network influence firm innovation net of the effects of partners' technological resources on firm innovation?

In broad terms, this second question seeks to clarify if it pays for firms to look beyond technological resources in choosing their exchange partners. In other words, if indeed networks matter for outcomes, they may actually constitute an important factor in selecting partners (cf. Jensen 2008). Chapter 3 also moves beyond the widely held conception of resource profiles as the endogenous resultants of network structure, by addressing the endogeneity issue and in turn studying the concurrent effects of exogenous resource and network structural effects.

Third, the substantive focus of chapter 4 concerns the relation between R\&D alliance governance and innovation-related outcomes. Prior work indicates that, on the average, equity joint ventures should contribute a variable amount more to knowledge flowing between partnered firms and to partner firms' innovative performance than nonequity contractual agreements. But some scholars have argued that, in certain situations, contractual agreements might be relatively more productive than joint ventures (Harrigan 2003 [1985]; Kale \& Puranam 2004; Sampson 2007). Chapter 4 takes issue with one such situational factor by investigating the industry contingency of R\&D alliance governance effects. In particular, I ask:

How does technological dynamism at the industry level moderate the relation between RED alliance governance and dimensions of firm innovation?

Essentially, chapter 4 contrasts results of alliance performance studies showing joint ventures' broad superiority for sparking interfirm knowledge flows (e.g., Gomes-Casseres et al. 2006; Mowery et al. 1996; Oxley \& Wada 2009) and firm innovation (e.g., Rothaermel \& Deeds 2006; Sampson 2007) with results of alliance formation studies showing that firms in fact tend to form 
nonequity contractual R\&D agreements in dynamic environments (e.g., Hagedoorn, Cloodt, \& van Kranenburg 2005; Santoro \& McGill 2005; van de Vrande, Vanhaverbeke, \& Duysters 2009). In other words, does it turn out wise for firms to have followed a seemingly counterintuitive governance strategy?

\subsection{Across the chapters}

Before turning to the three empirical chapters, it is helpful to spell out some of their key features and scope conditions.

Perspectives. I invoke a number of theoretical perspectives to formulate presumptions concerning the links between firms' patterns of R\&D alliances on the one hand, and outcomes on the other. As such, the mechanisms I propose linking cooperation to outcomes connect logics across theoretical discussions in the literature. For example, though elements of transaction costs economics theory and a knowledge-based perspective inform some of the discussion in chapter 4, theory drawn from social-psychological literatures also proves of some interest to the proposed mechanisms. Across single chapters, theoretical perspectives diverge as well: the consecutive chapters take a portfolio view, a network view, and a relational view, respectively, of R\&D alliances. Together, the joint use of multiple perspectives reflects my belief that, to the extent R\&D alliances are multifaceted entities, it is unlikely that one perspective alone explains their inner workings and performance consequences.

Setting. The studies reported here concern the innovative activities of firms engaged in R\&D alliances related to information technology (IT) during 1975-1999. IT includes industry segments for communications, computer hardware and software, computer peripherals, information storage, and semiconductors (patent class subcategories 21-24 and 46 in Hall, Jaffe, \& Trajtenberg 2002). Firms active in IT-related R\&D have both actively patented their innovations (Griliches 1990; Hall et al. 2002) and widely formed R\&D alliances (Hagedoorn 2002), thus making them suitable subjects for the current dissertation.

Alliance types. In line with Hagedoorn $(1993,2002)$, R\&D alliances as discussed here are either nonequity contractual agreements or equity joint ventures. More specifically, nonequity contractual agreements are either joint research pacts or joint development agreements, and equity joint ventures are either research corporations or research joint ventures. Since my focus is explicitly on interfirm alliance relations aimed at joint research and development relating to new technologies, products and processes, a range of other interfirm exchange forms such as unilateral licensing, customersupplier relationships, and research contracts are beyond the scope of my theory and empirics.

Conditional sampling. All analyses assume partner choice exogenous and, more broadly, take interfirm cooperation as a given. In other words, I ana- 
lyze data conditional on (1) the sample firms having decided on their exchange partners and (2) the planned R\&D alliances taking place. All results should therefore be taken as evidence supporting the effects of R\&D alliances on firms engaged in at least one $R \& D$ alliance during the sample period. This form of selective sampling is common but has often remained implicit in prior research (e.g., Ahuja 2000a; Stuart 2000). Nevertheless, per classic selection arguments (e.g., Aldrich \& Ruef 2006), it is well conceivable that firms that do engage in interfirm R\&D alliances have systematically different characteristics than those that do not. For example, they may have different strategic intentions (cf. Hamilton \& Nickerson 2003; Hennart 1991); they may have different, possibly better relational capabilities (cf. Dyer \& Singh 1998; Heimeriks, Duysters, \& Vanhaverbeke 2007), differential resource endowments making them more attractive as exchange partners, or they may be better able to interpret and process external knowledge (e.g., Ahuja 2000b; Cohen \& Levinthal 1990; Dutta \& Weiss 1997; Zhang, BadenFuller, \& Mangematin 2007). Regardless, such heterogeneity imposes bounds on generalizing implications to the broader population of firms. These issues are consciously put to one side in the current dissertation but should be kept in mind in speculating beyond the current study setting.

Causality. My goal is to establish causal relationships congruent with Stinchcombe (1987: ch. 2). He outlines four necessary and, jointly, sufficient conditions for establishing causality. First, the causal variable must take on different values in the sample. Absent cross-sectional or, in this dissertation, longitudinal variation on the causal variable, inferring causality is impossible. Second, for a causal relation to be present, the dependent variable should vary with changes in the causal variable. Third, covariation should be nonspurious, i.e. alternative explanations should be eliminated. Lastly, we must observe temporal precedence of the causal variable to the dependent variable.

Though the first and second conditions are rather straightforward, the latter two conditions are often difficult to establish. Yet, with the luxury of panel data - i.e. cross-sectional, time-series data - I am in a comfortable position to try to address them empirically. Overall, I believe that the analyses broadly illustrate the toolkit that alliance researchers can use in order to get a more solid grip on the cause-effect relations proposed in emergent theory. Issues of confounded nodal and relational effects, unobserved heterogeneity, endogeneity, and network autocorrelation pop up in many alliance studies and can be addressed sufficiently with relatively simple but very effective tools. Examples of substantive applications in the alliance literature can be found in Anand and Khanna (2000), Baum, Rowley, Shipilov, and Chuang (2005), Gulati (1995a), Leiblein, Reuer, and Dalsace (2002), Lincoln, Gerlach, and Takahashi (1992), and Stuart (1998). Generally, I believe there is opportunity in the literature to specify models more carefully in order to test theoretical claims more convincingly. Actually, the management, strategy, and 
adjacent literatures have seen a growing concern for valid inference convergent with frameworks like Stinchcombe's (e.g., Bascle 2008; Beck, Brüderl, \& Woywode 2008; Durlauf 2002; Edwards \& Parry 1993; Greve \& Goldeng 2004; Halaby 2004; Hamilton \& Nickerson 2003; Jacobson 1990; Lincoln 1984; Manski 1993; Mouw 2006; Oxley 2009; Reagans, Zuckerman, \& McEvily 2007; Shaver 1998; Stuart 2007), perhaps reflecting the increased legitimacy and maturation of the field broadly construed.

\subsection{Outline}

Each of chapters 2, 3, and 4 deals with one of the three sub research questions introduced in the above. The chapters each introduce a theoretical background drawing on extant work, followed by methodological and econometric notes, empirical results, and a discussion of the main findings. Importantly, all three empirical chapters are fully self contained and so all information relevant to individual chapters is enclosed within them. Consequently, they can (but, obviously, need not) be read as separate studies. Chapter 5 revisits the overall research question and takes a broader view in looking across the chapters to spell out some implications shared by the individual studies. 


\title{
R\&D Alliance Portfolios and the Inflow of Technological Knowledge ${ }^{1}$
}

\begin{abstract}
This chapter asks how compositional features of firms' R\&D alliance portfolios influence the rate of technological knowledge flowing into these firms. I theorize that R\&D alliance portfolios - firms' collections of R\&D alliancesperform an information-gathering role, allowing firms to deal with technological uncertainties. Using longitudinal data on the innovative activities of firms engaged in information technology-related R\&D alliances between 1975 and 1999, I study how inflows of technological knowledge vary with (1) the size of portfolios, (2) their focus on research versus development, and (3) the mix of novel and recurrent partners. Results show that portfolio composition crucially conditions knowledge inflows, over and above portfolio size alone.
\end{abstract}

\subsection{Introduction}

Firms' innovative outputs increasingly rely on external relationships (Ahuja 2000a; Hagedoorn \& Schakenraad 1994; Powell, Koput, Smith-Doerr, \& Owen-Smith 1999; Shan, Walker, \& Kogut 1994; Soh 2003; Stuart 2000). In high tech industries in particular, the requisite knowledge to develop novel technologies, products, and processes has become ever more scattered across industry segments, which has tremendously increased firms' proclivity to enter into interfirm R\&D alliances (Hagedoorn 2002). Many firms have compiled portfolios of R\&D alliances to scan multiple external sources of knowledge, access complementary technologies, and reduce their innovation time span (Laursen \& Salter 2006; Leiponen \& Helfat 2005). Extant theory argues that the crucial mediating mechanism connecting R\&D alliance portfolios to firms' innovative performance is the incidence of technological knowledge flows between partnered firms. These flows of technological knowledge are the material indicators that recipient firms learn from the innovative experience of their partners.

1. This chapter is based on collaborative work with John Hagedoorn and Wilko Letterie, who both played an important role in developing the ideas in this chapter. I further thank Sjoerd Beugelsdijk and seminar participants at Copenhagen Business School, Heriot-Watt University, London Business School, London School of Economics and Political Science, and ICS (Utrecht University) for many helpful suggestions. 
To date, two broad lines of empirical research have spoken to the link between interfirm alliances and technological knowledge flows. First, some contributions infer the effects of alliance portfolios on technological knowledge flows from the widely observed association between alliance portfolios and innovation (e.g., Ahuja 2000a; Hagedoorn \& Schakenraad 1994; Soh 2003; Stuart 2000). In particular, if technological knowledge underlies innovations and if alliance portfolios increase firms' innovative output, dimensions of such portfolios should also be at the root of technological knowledge flows. Second, a number of large-scale studies using patent citation data present more direct evidence that interfirm alliances spark knowledge flows in dyadic alliances (Almeida, Song, \& Grant 2002; Gomes-Casseres, Hagedoorn, \& Jaffe 2006; Mowery, Oxley, \& Silverman 1996; Oxley \& Wada 2009; Rosenkopf \& Almeida 2003).

Overall, while research focusing on alliance portfolios presents indirect empirical evidence of knowledge flows, research with closer evidence of alliance-related knowledge flows has largely focused on firm-partner dyads. Lacking in the literature is a study that directly relates compositional characteristics of firms' R\&D alliance portfolios to technological knowledge flows. Such a study is essential because alliance portfolios exhibit aggregate properties that can be distinct from properties of single alliances (Faems, Van Looy, \& Debackere 2005; Gulati 2007; Hoffmann 2007; Lavie 2007). These aggregate properties reflect synergies and spillover effects that one can only partly trace to separate individual alliances. Thus, the literature needs an account of how aggregate properties of R\&D alliance portfolios influence the rate at which technological knowledge flows into firms. My aim is to provide arguments and evidence toward addressing this need.

I define an R\&D alliance portfolio as a firm's collection of alliances formed with other firms to perform joint R\&D, share existing technologies, and develop new technologies, products, and processes. I derive testable hypotheses of R\&D alliance portfolios as determinants of the magnitude of technological knowledge flows - the knowledge flows related to the development of firms' technological innovations. Grounding my arguments in the early literature on parallel R\&D inside firms, I argue that, in a high tech industry rife with uncertainties, R\&D alliance portfolios are knowledgegathering conduits that help firms to hedge their bets concerning which technologies will dominate in the future. I test my predictions using comprehensive longitudinal data on the innovative activities of firms that engaged in IT-related R\&D alliances between 1975 and 1999.

\subsection{R\&D portfolios inside the firm}

The selection of promising internal R\&D projects is crucial for firms' innovative success (Krishnan \& Ulrich 2001). The classical project selection model suggests a sequential innovation strategy where firms bet all resources on one 'best evidence' $R \& D$ project and only consider alternative projects if the 
initial investments have proven unsuccessful. However, in the face of significant uncertainty -i.e. when the project concerns novel, cutting-edge technologies and the competitive environment forces short development cycles-such a sequential strategy is risky. Betting on the wrong approach means that firms lose costly time and resources by sequentially investing in new projects after earlier projects failed.

Seminal contributions to the innovation literature by Abernathy and Rosenbloom (1969) and Nelson (1961) criticize the sequential project selection model. They show that, when a firm faces high levels of technological uncertainty, it can benefit from investing in a portfolio of parallel R\&D projects to gain information on a range of $R \& D$ options. In so doing, the firm avoids the risks of a priori decision making about uncertain R\&D projects, potentially cutting off promising options. Instead of picking a winner early on, a firm picks several potential winners. Nelson (1961) demonstrates that such a parallel investment approach can be cost-effective in the long run because it leads to a better-informed investment decision when, compared to the later stages of product development, the costs of R\&D are still relatively low. Parallel projects thus generate information about the future value of products and technologies, which decreases follow-up investments for failed individual initiatives. Hence, though seemingly more complex, the concurrent evaluation of various alternatives eventually leads to superior performance (Eisenhardt 1989; Nutt 1998; Vishwanath 1992; Wheelwright \& Clark 1992).

A portfolio of various $R \& D$ projects enables a firm to hedge against the risk of project failure (Childs \& Triantis 1999; Scherer 2007). Indirect benefits of a portfolio approach surface when parallel R\&D projects stimulate internal competition and broaden a firm's technological competencies (Abernathy \& Rosenbloom 1969: 486). For a multi-product, multi-technology firm, this approach can lead to an R\&D portfolio with a large number of projects for a range of new products and technologies. For example, during the early 1990s even a specialized firm like Intel, a dominant firm in the IT industry, switched from a single R\&D team to as many as four R\&D teams working on the design of its next generation microprocessors (Economist 1993). The information flow generated in this parallel approach halved the processor's development time and saved significant financial resources because the four parallel teams communicated and compared their findings to arrive at the optimal solutions. This improved success and avoided unnecessary costs associated with follow-ups to failed initiatives.

\subsection{From internal to external R\&D portfolios}

The parallel $R \& D$ approach has received wide attention in the context of firms' internal R\&D projects. Here, I contend that its main premise - that parallel investments can be used to hedge bets concerning which technologies will be successful in the future - is equally relevant for firms' external R\&D 
alliances. To be sure, scholars and practitioners alike are increasingly aware that alliance portfolios, rather than individual alliances, are an important level of analysis (e.g., Bamford \& Ernst 2002; Gulati 2007; Lavie 2007; Mahnke, Overby, \& Nielsen 2006; Munson \& Spivey 2006; Parise \& Sasson 2002; Reuer \& Ragozzino 2006). Like internal portfolios of projects, external alliance portfolios are combinations of individual alliances that exhibit aggregate compositional properties. Recent evidence suggests that firms indeed invest strategically in their alliance portfolios (Reuer \& Ragozzino 2006), while also considering complementarities among firms in such a portfolio (Hoffmann 2007; Lavie 2007; Lavie \& Singh 2008). Moreover, a portfolio of alliances is a key learning conduit for firms in notoriously uncertain technological environments (Hagedoorn 2002; Powell et al. 1996).

Despite increasing awareness that alliance portfolios provide a valuable level of analysis, extant empirical research does not reveal whether external $R \& D$ alliances, as a portfolio, serve a hedging, knowledge-gathering function. This is surprising because the motives and benefits of a portfolio of internal R\&D projects-long run cost efficiency, information gains, hedging against the risk of individual project failure, generating competing perspectives on novel technologies, and boosting technological competencies-also appear highly relevant for a portfolio of external R\&D alliances.

There are exceptions in adjacent descriptive studies. Harrigan (2003 [1985]) provided early indications that firms in embryonic, high tech industries hedged their bets concerning which firms and technologies would become successful in the future by forming spider's webs of knowledgegathering alliances. Some other literatures hold related premises. For example, Cohen and Levinthal (1990: 132) noted that "under conditions of rapid and uncertain technical change (...), it is best for the organization to expose a fairly broad range of prospective receptors to the environment." Similarly, Winter (1984: 293) argued that firms can complement the information they hold internally by searching their environments for "...fragments of knowledge of possible usefulness ..." These fragments are perhaps useless in isolation but become meaningful when a firm integrates them across a portfolio of external contacts. Finally, Helper, MacDuffie, and Sabel (2000: 471) noted that "the experience of firms in technologically sophisticated industries with extremely short product life cycles shows (...) that pursuit of many alternatives is the best way of understanding the advantages and disadvantages of each, and so contributes to selection of the best current possibilities." Here, I seek broader empirical evidence for these suggestions.

\subsubsection{Portfolio size}

It is likely that firms increase the inflow of technological knowledge by extending their portfolio of $R \& D$ alliances. Firms in turn use these inward flows of technological knowledge to improve their estimates of potentially valuable technologies. Moreover, firms with a portfolio of R\&D alliances de- 
velop capabilities to learn from a range of partners, which decreases the likelihood that they fail to locate relevant technological knowledge and in turn increases their ability to compare the value of divergent bits of knowledge (Gnyawali \& Madhavan 2001; Powell et al. 1996). Overall, a basic test of the hedging function of an R\&D alliance portfolio is this: if the size of a firm's $R \& D$ alliance portfolio indexes the effectiveness of an external portfolio strategy, increases in the size of an R\&D alliance portfolio should increase the rate of knowledge inflow. Consequently:

Hypothesis 1. The larger a firm's RED alliance portfolio, the larger the inward flow of technological knowledge from its partners.

\subsubsection{RED alliance portfolios and the focus on research}

The literature on parallel $R \& D$ suggests that the main effect of parallel $R \& D$ alliances may hide an important contingency. Endogenous technological uncertainty is a key factor that determines the value of a parallel R\&D approach and it varies across the different stages of the innovation process (Abernathy \& Rosenbloom 1969; Nelson 1961; Wheelwright \& Clark 1992). Specifically, it should decrease over time (Roberts \& Weitzman 1981). Consequently, I expect to observe differences between, on the one hand, firms that focus on early-stage experimental, basic or applied research in their $R \& D$ alliance portfolios and, on the other hand, firms that mainly focus on alliances aimed at the further development of extant technologies.

Early-stage experimental and applied research is rife with uncertainties. Firms face many technological options and, therefore, many different directions for potential research projects (Freeman \& Soete 1997; Nelson 1961 1982). Across options, the information availability ranges from no information to crude ideas about various technological attributes and their relation to economic payoffs. The sequencing of research steps is unclear ex ante as means-ends connections await establishment and concrete performance information is lacking (Van de Ven \& Polley 1992). Behavioral tendencies of key $R \& D$ managers further aggravate the uncertainty because of incentives to over-estimate the rates of return to favored technological paths (Freeman \& Soete 1997). Therefore, even although decision makers may have crude estimates about the merits of several potential research projects early on, these estimates are often highly unreliable. In short, a priori decision making about which research projects to pursue is a misfortune if unreliable estimates can only improve ex post, i.e. during the actual project when additional information is being gathered (Roberts \& Weitzman 1981).

In contrast, development projects are far less uncertain in technological terms because they often start from a set of decisions about which technologies will be developed to commercial ends. These decisions in turn define stricter boundary conditions within which further efforts are to be expended. During development, firms work increasingly toward the imple- 
mentation of innovations and, eventually, the introduction of new products and processes. Prior technological choices thus lock firms into development trajectories that become more proprietary and firm specific over time.

With the distinction in mind between basic and applied research on the one hand, and development on the other, I expect that a parallel, portfolio approach to external $R \& D$ alliances is most useful if the alliances in such a portfolio focus strongly on basic and applied research. A portfolio of parallel R\&D alliances geared toward performing joint research - rather than development-will increase the reliability of estimates of total effort, timeline, costs, and performance prospects of the various technological options, before irreversible investments in downstream development are made. Over time, firms in turn weed out the options with poor prospects and continue to develop the most promising ones. In line with Nelson (1961), I expect that the parallel pursuit of a number of joint R\&D projects gravitating toward joint research is effective to hedge against decision intricacies when firms' knowledge about the future is fuzzy.

Because the early stages of research are notoriously uncertain, they offer the cleanest motivation for uncertainty reduction. For two reasons, they also seem to offer the best opportunities to reduce uncertainties. First, early-stage basic and applied research has fewer immediate implications for interfirm rivalry in downstream product markets than more close-to commercial activities such as the development and commercialization of concrete technologies, products, or processes (Harrigan 2003 [1985]: 380). Firms thus tend to be more open - perceptive to external knowledge sources-during the early stages of research, whereas toward development, they become increasingly secretive (Faems, Janssens, \& Van Looy 2007).

The second opportunity factor is cost related. The early stage of an R\&D effort (i.e. the R-stage) tends to be significantly less costly than the later stage of an R\&D effort (i.e. the D-stage). Parallel efforts early in a research trajectory therefore reduce uncertainty in a cost-effective way. For example, data on US industrial R\&D expenditures compiled by the US National Science Foundation show that, during the period 1975-1999, only 23 to $31 \%$ of firms' total R\&D costs related to basic and applied research, whereas roughly 70 to $80 \%$ was dedicated to development activities (National Science Foundation 2006: table 32). Similarly, Freeman and Soete (1997) indicate that the costs of basic and applied research are comparatively low in relation to the total costs of an innovation trajectory. A range of additional activities related to development-e.g., engineering, prototyping, and design - create major expenses at the later stages of the innovation process.

To summarize, convergent with the logic justifying hypothesis 1 , I expect that firms with a portfolio of parallel R\&D alliances experience increasing benefits from these alliances if they concern basic and applied research, rather than development. As running parallel alliances enables information gathering and as information gathering in turn counters endogenous tech- 
nological uncertainties (Nelson 1961; Pindyck 1991; Roberts \& Weitzman 1981), an R\&D alliance portfolio should be most effective early in the innovation process, when uncertainty is highest. Empirical corroboration of these arguments would be fully congruent with descriptive work by Hagedoorn (1993), indicating that firms in high tech environments seem to decrease technological uncertainties disproportionally through a range of researchfocused interfirm alliances. Therefore:

Hypothesis 2. The positive effect of a firm's RED alliance portfolio size on the inward flow of technological knowledge from its partners increases with the research focus of the RED alliances in the portfolio.

Together, hypotheses 1 and 2 express that a portfolio of R\&D alliances should give firms a firmer grip on uncertain developments in the industry and, furthermore, on endogenous uncertainties related to the innovation process. In particular, a portfolio helps in identifying new opportunities and, furthermore, it provides additional informational advantages to the extent firms focus on joint early-stage research. In addition to the number and research focus of R\&D alliances, particular types of partners may contribute significantly to the flows of technological knowledge into the focal firm.

\subsubsection{Combining novel and repeat partners}

Prior work documents that firms in an uncertain environment tend to engage in alliances with firms with whom they have collaborated before (Gulati 1995a; Podolny 1994). This reflects that partner selection is costly and timeconsuming, especially in the face of uncertainty. Prior partners with known reputation are thus likely subjects of new alliances, as relational trust becomes increasingly embedded in prior ties (e.g., Gulati 1995b), which in turn leads to more cohesive alliances. Repeated engagements with prior partners also spark the development of cooperative routines, especially in the area of R\&D in which tacit knowledge sharing requires rich interactions among the personnel of the sponsoring firms (Zollo, Reuer, \& Singh 2002). It is thus plausible that, due to evolving relational routines, the flow of technological knowledge drawn from R\&D partners increases in the advent of repeat engagements.

Although repeat collaboration might initially increase knowledge inflows into the focal firm, prior work has also documented that there would appear to be decreasing marginal returns to repeated engagements with prior partners. For example, Gulati (1995a) shows that the relation between prior alliances and future alliance formation at the dyad level is an inverted shaped one, which is congruent with firms' expectation of decreased marginal benefits. The implication is that beyond a certain threshold, additional information benefits of alliances with repeat partners dry up. Convergent with this claim, Hagedoorn and Frankort's (2008) mapping of the R\&D part- 
nering behavior of IBM in the 1990s indicates that IBM's intricate engagements with firms like Apple, Siemens, Toshiba, and HP appeared to have eventually exhausted opportunities for interfirm learning. This led IBM to engage in alliances with a new set of firms that had not featured prominently in its R\&D alliance portfolio before.

Hence, a focus on repeat partners alone would eventually lead to vanishing informational returns and overdependence on prior partners. In high tech industries characterized by unstable populations owing to the exit and entry of firms, useful sources for novel perspectives will simply not infinitely reside within a firm's group of repeat partners. Then, cooperation with R\&D partners that have no prior alliances to the firm creates important conduits generating novel technological perspectives (Lavie \& Rosenkopf 2006). Novel, previously unconnected partners with unknown reputations can thus be valuable additions to firms' R\&D alliance portfolios. New perspectives drawn from such novel partners in turn increase the diversity of information to which firms are exposed and enrich the opportunity set they face vis-à-vis their competitors. As such, drawing knowledge from a richer opportunity set allows firms to reduce technological uncertainty and increase the prospects for promising technologies.

The cost of collaboration with novel partners is that their reputation is unknown compared to prior partners. Even if opportunism does not operationalize, firms' expectation of opportunism might lead them to be less forthcoming in sharing knowledge. Fear for opportunistic behaviors would therefore be an impediment to freely sharing technological knowledge. In addition, it takes time to develop cooperative routines and shared understandings of intricate technological problems. In short, a focus on novel partners alone would expose a firm to excessively high levels of exchange hazards, eventually deteriorating any informational benefits.

At the portfolio level, these arguments would imply that though repeat alliances are valuable due to higher trust levels and increasingly solid information exchange routines, novel alliances are valuable as they infuse the firm with new information with higher marginal benefits. Hence, a firm maintaining a portfolio with both repeat partners and novel ones would balance the informational benefits of relational routines constraining opportunism with higher marginal returns of information drawn from novel partners. Whereas repeat alliances would predominantly deepen a firm's technological understanding, novel alliances would predominantly enrich the focal firms' perspectives on new technologies (Lavie \& Rosenkopf 2006). As excessive depth would lock a firm into one technological direction and excessive breadth would challenge the cognitive abilities of a firm to make sense of disparate bits of technological knowledge, either extreme would render additional knowledge inflows uncalled-for. In short, I expect that R\&D alliance portfolios that mix novel and recurrent partners create the largest inflow of technological knowledge. Consequently: 
Hypothesis 3. The inward flow of technological knowledge is curvilinearly (inverted U-shaped) related to the share of novel partners in a firm's RED alliance portfolio.

\subsection{Method}

\subsubsection{Data and sample}

I use data from a database developed by researchers from Brandeis University and Maastricht University (for detailed information, see GomesCasseres et al. 2006). This database contains data on R\&D alliances, patents and patent citations in the IT industry for the period 1975-1999. For the current chapter, I added information from CATI, Osiris, Datastream, and firms' annual reports. The Brandeis-Maastricht database is a merger of parts of the CATI database on R\&D alliances (Hagedoorn 2002), the NBER patent data file (Hall, Jaffe, \& Trajtenberg 2002), and Standard \& Poor's COMPUSTAT database. CATI contains detailed information on interfirm R\&D alliances starting in 1960, including partner identities, organizational form, and other specifics of the alliances. The NBER patent data file contains detailed information on all utility patents granted by the USPTO since 1963, the citations among them (1975-2002), and information about inventors and firms. COMPUSTAT contains a wide range of firm-level financial variables.

IT includes sectors such as computers, semiconductors, and communications, corresponding to patent classes for communications, computer hardware and software, computer peripherals, information storage and semiconductor devices (patent class subcategories 21-24 and 46 in Hall et al. 2002). I use two rules sequentially for including firms in the estimation sam-

ple. First, a firm is included if it had at least one patent in patent classes for communications, computer hardware and software, computer peripherals, information storage and semiconductor devices in 1975-1999. Second, of the selected firms I include only those that had at least one R\&D alliance in IT, devised to perform joint R\&D and/or joint technology development. These two rules ensure that firms in the sample are, at a minimum, at risk of citing (or being cited by) a partner. The alliance/patent sample contains 152 firms, organized as an unbalanced panel of 1,836 firm-years.

The longitudinal nature of the data necessarily leads to missing values for some of the key control variables. I include only those firm-years for which both firm- and partner-specific data are complete and delete others listwise. In addition, the lagging of independent variables and restrictions imposed by the count data models discard additional firm-year records from the analyses. Taken together, these steps lead to an effective sample size of 1,030 firm-years. Below, I probe the sensitivity of the analyses to this reduction in sample size. Further, the design might raise concerns of left censoring, as some sample firms were already in business prior to the sampling window. However, the sample firms' R\&D alliance activity prior to 1975 was 
negligible. In fact, R\&D partnering did not take serious shape until the second half of the eighties, although the IT industry took an early lead (Hagedoorn 2002).

\subsubsection{Dependent variable}

Following recent work by Almeida et al. (2002), Gomes-Casseres et al. (2006), Rosenkopf and Almeida (2003), and Singh (2005), I use patent citations to proxy the inflows of technological knowledge between firms engaged in interfirm R\&D alliances. Patent citations indicate that existing patents, representing 'prior art', were relevant for a new patent and, therefore, they likely represent the flow of knowledge between the citing and cited party. Some survey-based results indeed indicate that the flow of technological knowledge between actors is significantly larger when they cite each other's patents (Duguet \& MacGarvie 2005; Jaffe, Trajtenberg, \& Fogarty 2000). Jaffe et al. (2000) conclude that aggregated, actor-centric citation flows can proxy for the intensity of knowledge flow between actors.

I recognize that patents embody codified knowledge, whereas much of the technological knowledge in the innovation process is tacit (cf. Appleyard 1996). Yet, tracing tacit knowledge empirically is nearly impossible, especially given the longitudinal design. Instead, I align with Almeida et al. (2002: 152), Mowery et al. (1996: 83), and Patel and Pavitt (1997: 143) and assume that flows of codified and tacit knowledge are closely related and complementary. I thus abstract from the codified-tacit distinction and use the pattern of citations between firms' patents to identify the magnitude of inflows of technological knowledge.

Nevertheless, some recent work has called for caution when using patent citations to proxy flows of technological knowledge (Alcácer \& Gittelman 2006). For instance, part of the citations on a patent may be 'strategic', to avoid litigation only. More importantly, however, patent examiners or a firm's lawyers might add citations to the patent that the inventors were not aware of themselves. Only since the 2001 change in U.S. patent reporting do patents contain a separate listing of inventor- and examiner-inserted citations. My sampling period (1975-1999) thus precludes the use of a more finegrained proxy that excludes examiner-inserted citations.

Despite these potential issues, I have five reasons to expect that patent citations are useful in my analyses of technological knowledge flows in the context of interfirm R\&D alliances. First, interfirm R\&D alliances serve as embedded mechanisms in which human capital intervenes to transfer technological knowledge (Autant-Bernard 2001; Singh 2005). As such, cooperating firms are most likely cognizant of partners' relevant lines of research and pending patents. Second, violating a partner's interests by wittingly excluding citations may harm a firm's reputation as a trustworthy partner and, hence, restrict future cooperative possibilities. Drawing from in-depth field studies, Harrigan (2003 [1985]: 342) concludes that “...if a trusted partner 
chose to betray its partner by pirating intellectual property, word went out in the industry." Third, closely related to the second point, to protect its interests a firm has an incentive to monitor the applications of its partners and, if necessary, suggest citations to its own patents. Fourth, I have no reason to expect that examiners pattern their interventions on characteristics of an applicant's R\&D alliance portfolio. Hence, in the current setting, examinerinserted citations should only add noise to the knowledge flow measures, without systematically (dis-)favoring particular firms. Finally, examinerinserted citations appear especially troublesome for analyzing self-citations (Alcácer \& Gittelman 2006), which are beyond my theoretical and empirical focus.

Besides these five reasons, I also cover an important historical period in which the use of R\&D alliances flourished (Hagedoorn 2002), generating important cross-sectional and longitudinal variation. Given the large number of patents and citations in the data, I expect that the annual firm-level citation count reveals a meaningful signal about the magnitude and direction of technological knowledge flows between partnered firms.

My hypotheses concern inflows of knowledge as the by-products of technology access. I therefore specify Inward knowledge flows as the aggregate annual number of patent citations by the focal firm to patents of its R\&D partners. To evade simultaneity, this dependent variable takes a one-year lead to the independent variables and covariates.

\subsubsection{Independent variables}

Portfolio size. A firm's Portfolio size is the count of R\&D alliances it maintains in $t$.

Portfolio research focus. Whereas much of the academic work so far has distinguished R\&D alliances from a variety of other alliance types such as second-sourcing deals, marketing, licensing, royalty and sales agreements (e.g., Lavie 2007; Robinson \& Stuart 2007), I identify an R\&D alliance's research focus (I split the R from the D). What results is a more granular picture of $R \& D$ alliances.

Convergent with the OECD's guidelines for distinguishing types of R\&D (OECD 2002: 77-82), I distinguish alliances that focus on basic and applied research on the one hand from those focusing on development activities on the other. I exploit the granular categorical information about the cooperative forms of the alliances contained in CATI. In particular, I consider alliances that fall into one of four categories: (1) joint research pacts, (2) joint development agreements, (3) joint ventures, and (4) research corporations. Categories (1) and (4) unambiguously indicate a focus on basic and applied research. Category (2) unambiguously indicates a focus on development. But category (3) is ambiguous. For example, detailed inspection of alliance announcements reveals that this category contains alliances that may focus on either research or development. Therefore, I label alliances in category (3) as 
research focused only if the public announcement clearly indicated that the alliance focuses on basic and/or applied research activities rather than the development of existing technologies.

To summarize, I code an alliance as research focused if it is a joint research pact, a research corporation, or if it is a joint venture with an explicit focus on research. Using this dyad-level coding, I calculate Portfolio research focus as a firm's share of alliances with a distinctive research focus in $t$. To test hypothesis 2, I calculate the interaction term of Portfolio size and Portfolio research focus. A positive sign for the interaction coefficients would be in line with my predictions.

Portfolio novelty. I measure Portfolio novelty as a firm's share of partners in $t$ that it has never collaborated with before. This measure ranges between 0 and 1 and a higher value indicates that a firm maintains more alliances with firms it has never previously collaborated with. For example, a value of 0.4 means that $40 \%$ of all partners in a firm's portfolio are novel to the firm and the other $60 \%$ are repeat partners. To test hypothesis 3, I include the main effect, for which I expect a positive coefficient, and its squared term, for which I expect a negative coefficient. The findings are robust to redefining portfolio novelty to include all current partners that a firm has not otherwise collaborated with in the past five years (rather than ever).

\subsubsection{Control variables}

I test the hypotheses net of a rich control model of knowledge inflows. This model reflects that knowledge inflows are a function of firm, partner, and relational properties (cf. Argote, McEvily, \& Reagans 2003; Greve 2005; Kalaignanam, Shankar, \& Varadarajan 2007) and I include a full set of year dummies (1975-1998, omitting 1999) that capture unobserved temporal effects.

Firm controls. The variable Size is the logarithm of a firm's total sales in $t$ (using values in millions of U.S. dollars). I control for firm size as larger firms tend to have more financial and managerial resources, and more alliances than smaller ones. This in turn influences their investments and attractiveness for cooperation in R\&D alliances. I define the variable Profitability as the ratio of a firm's operating income to its sales in $t$. A firm's profitability possibly signals that it successfully commercialized new technologies. In addition, the firm can use profits to invest in new technological activities.

To control for the confounding effects of innovativeness, I include the variable $R \mathcal{E} D$ intensity as the ratio of a firm's R\&D spending to its sales in $t$. A firm's innovativeness likely reflects its absorptive capacity (Cohen \& Levinthal 1990), which should ease the assimilation of externally generated technological knowledge. In addition, increases in firms' technological inputs broaden the scope for complementarities to exploit, which may lead to the formation of additional alliances (Cassiman \& Veugelers 2002). Patent stock measures the size of a firm's patent stock in $t$. To control for a firm's 
overall patent citing activity, I include total inward citations, indexing the total number of patent citations made by the focal firm in a given year.

I include the variable Partnering experience that measures the count of $R \& D$ alliances a firm has entered by $t$. Evolutionary accounts of technological development stress that a firm's past pursuit of technological knowledge is important in guiding new searches (Nelson \& Winter 1982). Hence, a firm's partnering experience may ease the search for knowledge. Further, more experienced firms tend to develop a dedicated alliance management function, enabling the coordination of cooperative activities across a portfolio of alliances (Heimeriks, Duysters, \& Vanhaverbeke 2007; Kale, Dyer, \& Singh 2002; Sarkar, Aulakh, \& Madhok 2009).

Partner controls. I include a number of partner-specific measures that capture their potential value as sources of knowledge. Partner size is the mean value of partners' logged sales in $t$. Partner profitability measures the mean value of partners' operating income divided by sales in t. Partner RED intensity is the mean value of partners' R\&D spending divided by sales in $t$. I include three measures for the age profiles of partners' patent stocks, i.e. the average count of partners' patents that are 0-2 years old, 3-7 years old, and older than 7 years, respectively. This follows prior work indicating that patents of 3 to 7 years old have a higher citation probability than older or younger ones (Jaffe \& Trajtenberg 1996). Finally, to control for a partners' overall numbers of received patent citations, I include a variable for the total number of patent citations made to partner firms in a given year, averaged across a firm's partners.

Relational controls. Bilateral competition enumerates a firm's proportion of partners active in its own primary 3-digit SIC in $t .^{2}$ Firms that cooperate in IT may nevertheless compete in product markets (Mowery et al. 1996). I thus control for the extent to which partners are active in primary product markets identical to the focal firm (cf. Lavie 2007). To account for the effects of equity alliances on technological knowledge flows (Almeida et al. 2002; Mowery et al. 1996), I include the variable Equity as the proportion of a firm's equity-based alliances (comprising joint ventures and research corporations). This variable is bounded by 0 and 1 , and a value closer to 1 indicates a higher share of equity-based alliances. I control for geographic explanations of technological knowledge flows and define the variable Regional concentration, which is the proportion of a firm's partners in its home region. This variable ranges from 0 to 1 , and a value closer to 1 indicates a higher share of intraregional alliances. I use the home country of a firm's headquarters to classify firms in one of four regions: the United States, Europe, Japan, and Other regions. ${ }^{3}$

2. Results of 4-digit SIC are identical; those based on 2-digit SIC are insignificant.

3. Re-specifying the default U.S.-region as NAFTA (U.S., Canada and Mexico) leads to identical results. 


\subsubsection{Statistical analysis}

The statistical model allows me to obtain estimates on the determinants of the expected amount of partner-related knowledge flowing into firm $i$ in year $t+1, K_{i t+1}$. Specifically, in my model

$$
E\left(K_{i t+1} \mid X_{i t}, C_{i t}, a_{t}, \delta_{i}\right) \propto \exp \left(\beta_{X} X_{i t}+\beta_{C} C_{i t}+\beta_{a} a_{t}+\delta_{i}\right),
$$

where $X_{i t}$ is a time-varying vector of independent variables and their interactions, characterizing firm $i ; C_{i t}$ is a time-varying vector of control variables characterizing firm $i ; a_{\mathrm{t}}$ is a vector of year dummies; and $\delta_{\mathrm{i}}$ represents unobserved time-invariant firm effects not captured by the independent and control variables. I use a conditional fixed effects negative binomial specification to estimate this model (Hausman, Hall, \& Griliches 1984). A Hausman (1978) specification test indicated that the use of a random effects specification would have generated parameter inconsistencies. The conditional fixed effects negative binomial estimator accommodates the integer, overdispersed nature of the dependent variable. Further, it partials out time-invariant unobserved firm heterogeneity (i.e. $\delta_{i}$ ) - by conditioning on firms' total count of alliance-related inward patent citations during the sampling window (Hausman et al. 1984: 923-924). This procedure drops firms for which the dependent variable is zero in the sampling period. However, even with this reduction of the sample, estimates remain consistent (for the proof, see Hausman et al. 1984: 935).

\subsection{Results}

Tables 2.1 and 2.2 show the descriptive statistics and correlations. Note that, on the average, $16 \%$ of firms' R\&D alliances focus on research. Interestingly, this is close to the breakdown of firms' average R\&D spending as reported by the National Science Foundation (NSF 2006: table 32), showing that only about 20 to $30 \%$ of the full R\&D budget of U.S. firms goes to basic and applied research. Table 2.3 shows, stepwise, the findings regarding inward knowledge flows. Models 2 through 5 all improve significantly $(p<0.001)$ upon the baseline estimates in model 1 and the subsequent models improve significantly $(p<0.001)$ on each prior model.

\subsubsection{Control variable results}

Inward knowledge flows increase with firm size, indicating that larger firms attract more knowledge. In addition, firms' total inward citations spark alliance-related inward knowledge flows. Inward knowledge flows also increase with the equity nature of the alliances of a firm, confirming previous findings by Mowery et al. (1996), who show that knowledge flows are more intense with increased equity investments by the partnering firms. Finally, firms with a high proportion of partners in their home region experience lower inward knowledge flows. This surprising yet consistent finding may 
reflect that firms' choice of foreign partners is endogenous to expected knowledge flows, which in turn explains why firms that do have international partners appear to face fewer difficulties in attracting external knowledge (cf. Lavie \& Miller 2008). Moreover, Peri (2005) shows that technological knowledge in especially the computer sector flows significantly farther internationally than in a number of other sectors.

Table 2.1 Descriptive statistics

\begin{tabular}{lcccc}
\hline Variable & Mean & SD & Minimum & Maximum \\
\hline Inward knowledge flows & 58.416 & 257.764 & 0 & 5,112 \\
Firm controls & & & & \\
Size & 3.438 & 0.888 & 0.930 & 5.188 \\
Profitability & 0.142 & 0.132 & -1.104 & 0.624 \\
R\&D intensity & 0.091 & 0.099 & 0 & 1.708 \\
Patent stock & 516.855 & $1,155.485$ & 1 & 12,352 \\
Total inward citations & 260.485 & 851.618 & 0 & 16,205 \\
Partnering experience & 7.528 & 14.336 & 1 & 141 \\
Partner controls & & & & \\
Size & 3.907 & 0.619 & 1.242 & 5.188 \\
Profitability & 0.148 & 0.079 & -0.560 & 0.482 \\
R\&D intensity & 0.086 & 0.056 & 0.003 & 0.893 \\
Patent stock 0-2 years old & 450.144 & 564.584 & 0 & 4,949 \\
Patent stock 3-7 years old & 590.827 & 811.520 & 0 & 6,724 \\
Patent stock > 7 years old & 492.710 & 570.392 & 0 & 3,569 \\
Total outward citations & 635.357 & $1,193.549$ & 0 & 11,378 \\
Relational controls & & & & \\
Bilateral competition & 0.185 & 0.305 & 0 & 1 \\
Joint venture & 0.152 & 0.265 & 0 & 1 \\
Regional concentration & 0.840 & 0.299 & 0 & 1 \\
Independent variables & & & & \\
Portfolio size & 4.387 & 5.611 & 1 & 36 \\
Portfolio research focus & 0.160 & 0.294 & 0 & 1 \\
Portfolio novelty & 0.369 & 0.415 & 0 & \\
\hline & & & & \\
\hline
\end{tabular}

\subsubsection{Hypotheses}

Table 2.3 shows that portfolio size generally increases inward flows of knowledge, supporting hypothesis 1 . In line with hypothesis 2 , models 3 and 5 reveal a positive and significant interaction effect of portfolio size and portfolio research focus on inward knowledge flows. The squared effect of portfolio novelty is significantly negative (models 4 and 5), while the main effect is significantly positive. These results support hypothesis 3 . 
R\&D Alliance Portfolios and Knowledge Inflows

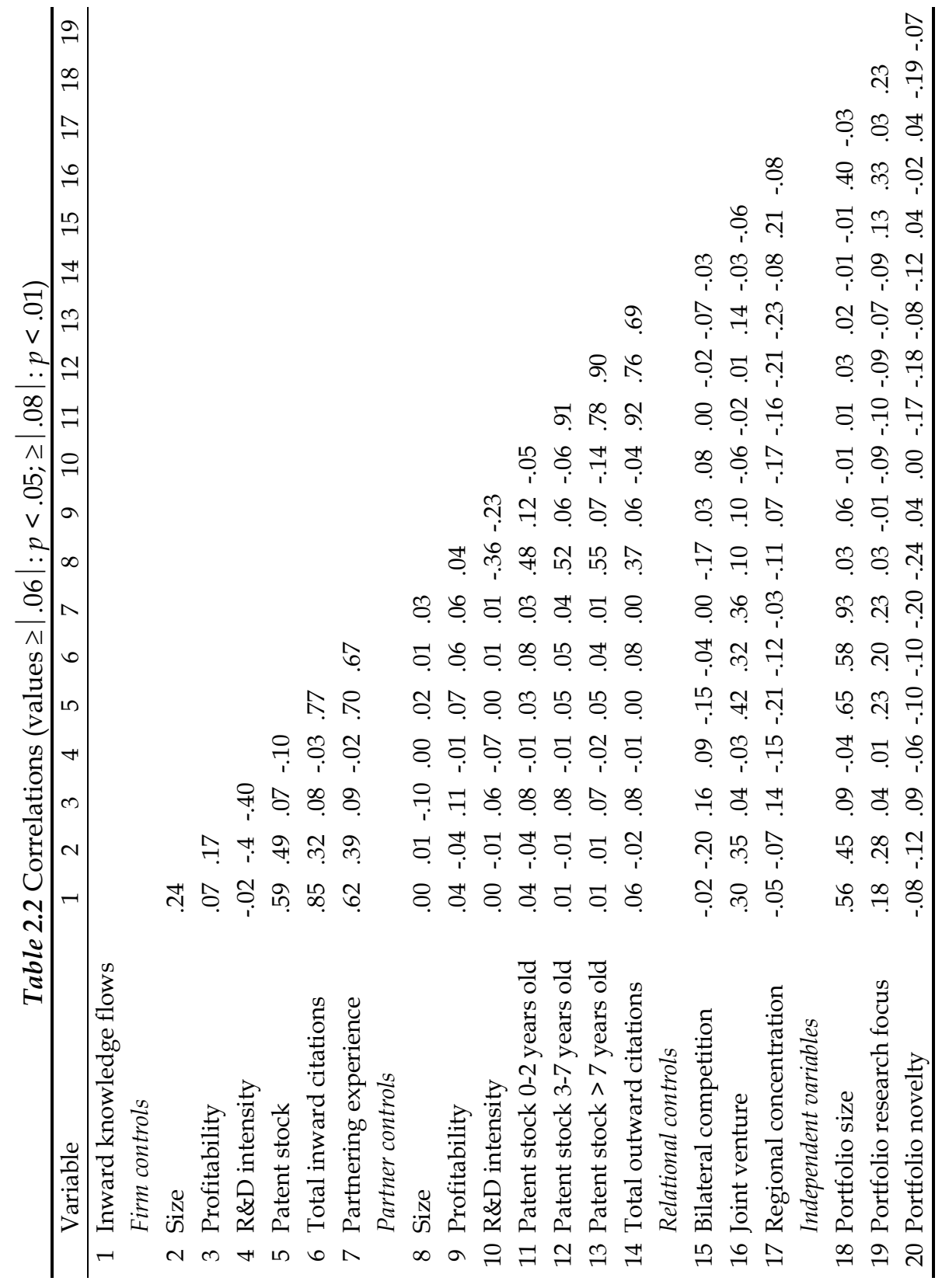


Table 2.3 Conditional FE negative binomial estimates of knowledge inflows

\begin{tabular}{|c|c|c|c|c|c|}
\hline Variable & (1) & (2) & (3) & (4) & (5) \\
\hline \multirow[t]{2}{*}{ Constant } & $-3.298^{* *}$ & $-2.843^{*}$ & $-2.463^{*}$ & -1.802 & -2.043 \\
\hline & $(1.235)$ & $(1.244)$ & $(1.252)$ & $(1.278)$ & $(1.275)$ \\
\hline \multirow[t]{2}{*}{ Firm size } & $.699^{* * *}$ & $.602^{* * *}$ & $.551^{* * *}$ & $.507^{* * *}$ & $.524^{* * *}$ \\
\hline & $(.100)$ & $(.104)$ & $(.105)$ & $(.107)$ & $(.106)$ \\
\hline \multirow[t]{2}{*}{ Firm profitability } & .573 & .425 & .568 & .508 & .613 \\
\hline & $(.456)$ & $(.456)$ & $(.446)$ & $(.447)$ & $(.447)$ \\
\hline \multirow[t]{2}{*}{ Firm R\&D intensity } & $1.804^{*}$ & 1.410 & 1.457 & 1.187 & 1.152 \\
\hline & $(.842)$ & $(.888)$ & $(.886)$ & $(.871)$ & $(.880)$ \\
\hline \multirow[t]{2}{*}{ Firm patent stock $\left(\times 10^{2}\right)$} & -.002 & -.001 & .000 & .004 & .005 \\
\hline & $(.004)$ & $(.005)$ & $(.004)$ & $(.004)$ & $(.004)$ \\
\hline \multirow[t]{2}{*}{ Firm total inward citations $\left(\times 10^{2}\right)$} & $.008^{* *}$ & $.011^{* * *}$ & $.009^{* * *}$ & $.008^{* *}$ & $.007^{* *}$ \\
\hline & $(.003)$ & $(.003)$ & $(.002)$ & $(.003)$ & $(.002)$ \\
\hline \multirow[t]{2}{*}{ Firm partnering experience } & $.007^{*}$ & -.007 & -.009 & -.003 & -.006 \\
\hline & $(.003)$ & $(.005)$ & $(.005)$ & $(.005)$ & $(.005)$ \\
\hline \multirow[t]{2}{*}{ Partner size } & -.024 & -.029 & -.048 & -.211 & -.129 \\
\hline & $(.141)$ & (.142) & (.145) & $(.146)$ & $(.145)$ \\
\hline \multirow[t]{2}{*}{ Partner profitability } & -.311 & -.531 & -.704 & -.710 & -.603 \\
\hline & $(.792)$ & $(.794)$ & $(.786)$ & $(.782)$ & $(.774)$ \\
\hline \multirow[t]{2}{*}{ Partner R\&D intensity } & -2.372 & -1.699 & -2.090 & -2.107 & -2.068 \\
\hline & $(1.858)$ & $(1.874)$ & $(1.853)$ & $(1.860)$ & $(1.847)$ \\
\hline \multirow[t]{2}{*}{ Partner patent stock $0-2$ yrs old $(\times 10)$} & .004 & .005 & .005 & .006 & .006 \\
\hline & $(.004)$ & $(.004)$ & $(.004)$ & $(.004)$ & $(.004)$ \\
\hline \multirow[t]{2}{*}{ Partner patent stock 3-7 yrs old $(\times 10)$} & .007 & .007 & .006 & .005 & .005 \\
\hline & $(.004)$ & $(.004)$ & $(.004)$ & $(.004)$ & $(.004)$ \\
\hline \multirow[t]{2}{*}{ Partner patent stock $>7$ yrs old $(\times 10)$} & -.003 & -.002 & -.001 & .001 & .001 \\
\hline & $(.003)$ & (.003) & $(.003)$ & $(.003)$ & $(.003)$ \\
\hline \multirow[t]{2}{*}{ Partner total outward citations $\left(\times 10^{2}\right)$} & -.008 & -.006 & -.008 & -.011 & -.009 \\
\hline & $(.010)$ & $(.010)$ & $(.010)$ & $(.010)$ & $(.010)$ \\
\hline \multirow[t]{2}{*}{ Bilateral competition } & .224 & .324 & .298 & .183 & .293 \\
\hline & $(.231)$ & $(.234)$ & $(.238)$ & $(.244)$ & $(.241)$ \\
\hline \multirow[t]{2}{*}{ Equity partnerships } & $1.116^{\star * *}$ & $1.058^{* * *}$ & $.989^{* * *}$ & $1.134^{* * *}$ & $1.034^{\star * *}$ \\
\hline & $(.212)$ & $(.212)$ & $(.213)$ & $(.214)$ & $(.215)$ \\
\hline \multirow[t]{2}{*}{ Regional concentration } & $-.573^{* *}$ & $-.712^{* * *}$ & $-.800^{* * *}$ & $-.735^{* * *}$ & $-.803^{* * *}$ \\
\hline & $(.196)$ & $(.200)$ & $(.196)$ & $(.199)$ & $(.198)$ \\
\hline \multirow[t]{2}{*}{ Portfolio size } & & $.051^{* *}$ & .027 & $.033^{*}$ & .009 \\
\hline & & $(.015)$ & $(.016)$ & $(.016)$ & $(.017)$ \\
\hline \multirow[t]{2}{*}{ Portfolio research focus } & & & -.093 & $.520^{* *}$ & -.055 \\
\hline & & & $(.250)$ & $(.184)$ & $(.254)$ \\
\hline \multirow[t]{2}{*}{ Portf. size $\times$ portf. research focus } & & & $.117^{* * *}$ & & $.110^{* *}$ \\
\hline & & & $(.032)$ & & $(.033)$ \\
\hline \multirow[t]{2}{*}{ Portfolio novelty } & & & & $1.441^{* * *}$ & $1.375^{* * *}$ \\
\hline & & & & $(.313)$ & $(.310)$ \\
\hline \multirow[t]{2}{*}{ (Portfolio novelty) $^{2}$} & & & & $-1.504^{* * *}$ & $-1.437^{* * *}$ \\
\hline & & & & $(.326)$ & $(.322)$ \\
\hline Log likelihood & $-2,692.09$ & $-2,686.61$ & $-2,676.79$ & $-2,672.10$ & $-2,666.76$ \\
\hline
\end{tabular}


A joint test of the main and squared effects of portfolio novelty in model 5 reveals a $\chi^{2}$-statistic of 19.08 ( $p<0.001 ; 2$ d.f.). A joint cross-hypothesis test using the coefficients of model 5 reveals a $\chi^{2}$-statistic of $59.41(p<0.001 ; 5$ d.f.). Thus, the effects as predicted in the hypotheses are jointly operative, meaning that firms that have an R\&D partnership portfolio with a large share of research-oriented alliances have greater inward knowledge flows when the portfolio simultaneously balances novel and repeat partners.

Figure 2.1 displays the size of the interaction effect between portfolio size and portfolio research focus, plotted around the means of the variables. When a firm focuses its portfolio on development rather than research (i.e. portfolio research focus $=0$ ), the multiplier of inward knowledge flows increases from around 1 to 1.1 when a portfolio grows from 1 single to 10 parallel alliances. Yet, for a portfolio containing $45 \%$ research alliances $(=\mu+\sigma)$, it increases from around 1 to 1.85 with a similar increase in the number of alliances. Thus, convergent with my theory, parallel alliances are significantly more valuable for knowledge inflows if the focus of these alliances leans toward research rather than development.

Figure 2.2 shows the portfolio novelty effect across its full range. The plot shows that the share of novel partners in an alliance portfolio first increases and then decreases the multiplier of knowledge inflows. Further, the inflection point lies well within one standard deviation above the mean, indicating that the inverted U-shaped effect materializes in the data.

Figure 2.1 Portfolio size, research focus, and inward knowledge flows

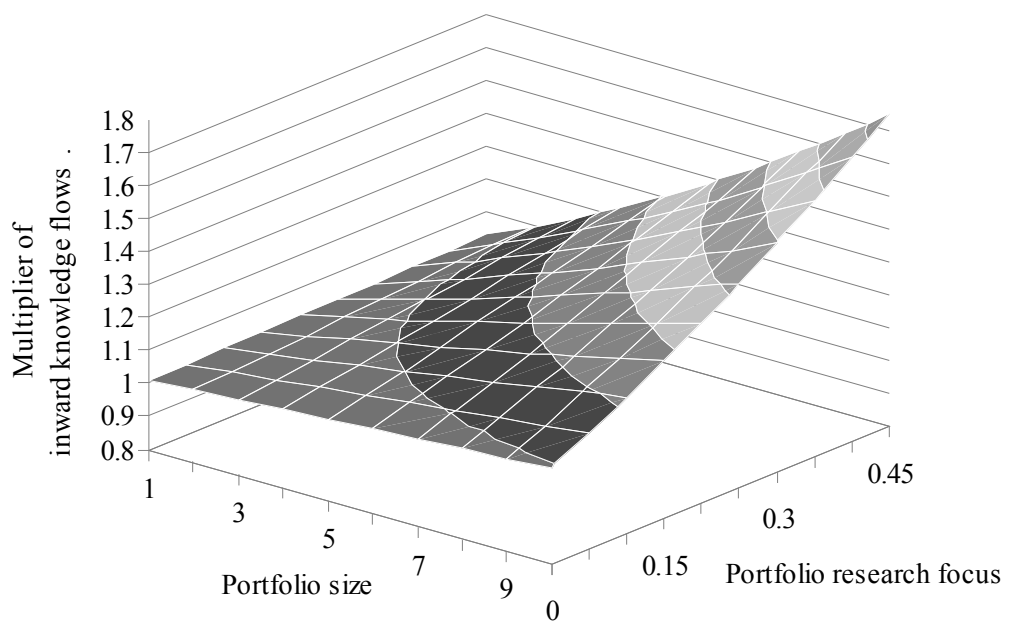


Figure 2.2 Portfolio novelty and inward knowledge flows

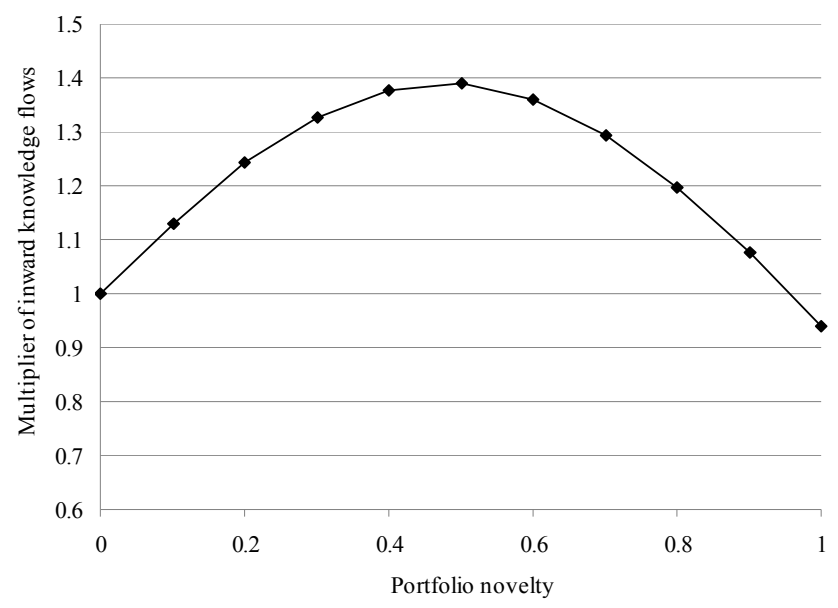

\subsubsection{Robustness}

First, as with any model relating interorganizational design to outcomes, endogeneity may affect the estimates (Bascle 2008). Specifically, knowledge inflows may systematically condition firms' R\&D alliance formation. Nevertheless, a generalized Durbin-Wu-Hausman $\chi^{2}$-test (Davidson \& MacKinnon 1993: 237-240) failed to reject the null hypothesis that the fixed effects negative binomial estimates of the three potentially endogenous alliance variables of interest (i.e. portfolio size, portfolio research focus, and portfolio novelty) were consistent. ${ }^{4}$ As only statistical proof of inconsistency would suggest endogeneity issues, I am confident that the focal independent variables can be treated as predetermined. This finding perhaps indicates that accounting for unobserved heterogeneity has reduced systematic endogeneity to random fluctuations (Heckman 1979), that there is no feedback, or that knowledge inflows affect R\&D alliance formation in multiple ways, culminating empirically into a net null effect. ${ }^{5}$

4. As instruments, I used the annual count of (1) alliance announcements in the IT industry, (2) research-focused alliances in the IT industry, and (3) new patents granted in patent class subcategories 21-24 and 46 in Hall et al. (2002: 452-453), plus the unpredictability measure as defined in chapter 4 (p. 67) of this dissertation.

5. To the extent that increases in the rate of knowledge inflow reflect firm-specific learning advantages, theory suggests systematic cause-effect relations from knowledge inflows to numbers of alliances formed (and, by implication, portfolio size). From a strategy view, firms with learning rate advantages may be motivated to seek more opportunities to learn, e.g. by expanding their portfolio of $R \& D$ alliances. Yet, it is equally plausible that others view fast learners (i.e. expropriators that absorb, rather than reveal, information) as suboptimal partners (Harrigan 2003 [1985]), which would shrink the fast learner's opportunity space of potential alliances, in turn coun- 
Second, I generated two sets of alternative estimates taking stricter issue with unobserved heterogeneity. In particular, I explored one extension and one alternative to Hausman et al.'s (1984) conditional effects model. First, in the spirit of Blundell, Griffith, and Van Reenen (1995) and Blundell, Griffith, and Windmeijer (2002), I added firms' pre-sample history of knowledge inflows to the conditional fixed effects models in table 2.3. Here, the underlying logic for pre-sample fixed effects is that any firm-specific dispositional differences should be manifest in firms' knowledge inflows prior to the study period, making a measure capturing such pre-sample inflows a suitable index of persistent unobserved firm differences (cf. Schilling \& Phelps 2007; Yayavaram \& Ahuja 2008; Ziedonis 2004). With this additional control complementing the conditional fixed effects estimator, the original results remained identical. ${ }^{6}$ Second, alternatively, I estimated an unconditional fixed effects negative binomial model-i.e. a cross-sectional negative binomial model with firm dummies. As Allison and Waterman (2002: 250-252, 255-256) argue, whereas Hausman et al.'s (1984: 922) parameterization of the negative binomial distribution might not eliminate all time-invariant firm effects, an unconditional estimator should be more effective to this end. Rather than eliminating $\delta_{i}$ from the likelihood function, this estimator captures $\delta_{i}$ through firm dummies. Admittedly inefficient, the unconditional estimator generated coefficients and significance levels that were broadly identical to the ones presented in table 2.3. Together, these two alternative specifications further increase my confidence in the main results, as the coefficients of interest (i.e. $\beta_{\mathrm{x}}$ ) do not appear to be systematic shadows of unobserved firm heterogeneity (i.e. $\delta_{\mathrm{i}}$ ).

terbalancing the portfolio-enlarging effect of its search motivation. Thus, theory runs in two directions, which perhaps explains the net null effect I find. The logic concerning a possible feedback effect of knowledge inflows to portfolio research focus runs along similar lines. Finally, the feedback effect to portfolio novelty is not obvious. I tested it nevertheless, as repeat partnering has been shown to be a systematic decision (Gulati 1995a). But in the current sample, the feedback mechanism (knowledge inflows conditioning shifts in the balance of novel vs. repeat partners) does not seem to explain firms' systematic preference for novel vs. repeat partnering.

6. Frank Windmeijer provided helpful comments on this pre-sample estimator. Blundell et al. $(1995,2002)$ originally used this approach to capture unobserved heterogeneity in dynamic patent rate models. Here, the pre-sample approach complements Hausman et al.'s (1984) conditioning procedure to weed out firm-level unobserved heterogeneity. In particular, I added the 4-year pre-sample mean of partner-specific inward patent citations in the analysis of inward knowledge flows. Patent citation data are not available prior to 1975 and, thus, a 4-year pre-sample period and a oneyear lead of the dependent variable only allowed me to predict knowledge inflows from 1980 onwards. Using a Hausman (1978) specification test, I compared the resulting coefficients to the ones of the models for 1980-1999 that omitted the presample mean estimator. With no exceptions, differences were non-systematic, increasing my confidence in the reported results. 
Third, some prior work has identified diminishing marginal returns to the number of concurrent R\&D alliances (e.g., Deeds \& Hill 1996). The data showed some support for such an effect. The inclusion of a squared portfolio size term in model 2 revealed decreasing marginal returns as the number of $R \& D$ alliances increased. Nevertheless, the squared effect was weakly significant and did not alter the shape of the portfolio size effect that I reported, as the inflection point fell well outside of the observed data range.

Finally, I investigated if the results were sensitive to the reduction in effective sample size due to missing values. I first ran the complete models excluding the controls with missing values. This increased the effective sample size to 1,322 firm-years. Though none of the coefficients changed direction, previously insignificant effects turned significant, underlining the importance of including the omitted controls nevertheless. Thus, I probed this issue further. Note that missing values may have biased the estimates if they occurred non-randomly. I tested for this potential selection bias by estimating a two-stage selection model (Allison 2001: 79-81; Heckman 1979). In the first stage, I estimated the probability of non-missing values in the full panel using probit regression. In the second stage, I estimated the full model including the inverse Mills ratio based on the first-stage probit estimates to correct for the probability of nonmissing values. Results remained identical, indicating that the coefficients are uncontaminated by missing values.

\subsection{Discussion and conclusion}

How do compositional features of R\&D alliance portfolios influence the flow of technological knowledge into firms? I have argued that R\&D alliance portfolios have aggregate properties with unique implications for understanding how technological knowledge 'flows' between firms and their R\&D portfolio partners. The results provide some evidence consistent with the view of R\&D alliance portfolios as knowledge-gathering conduits that help firms hedge their bets concerning which technologies will be relevant in the future. One of the strengths of this study is that it directly links R\&D alliance portfolios to technological knowledge flows. Thus, I move beyond conclusions about portfolios and knowledge flows deriving from studies connecting alliance portfolios to innovative outputs or those connecting alliance dyads to knowledge flows.

I find that larger portfolios tend to enhance inward flows of knowledge. More provocatively, when firms focus their joint R\&D activities on basic and applied research rather than development, a larger portfolio significantly enhances knowledge inflow. This finding mirrors early theory on internal R\&D project portfolios (Abernathy \& Rosenbloom 1969; Nelson 1961), indicating that parallel efforts comprising a portfolio show a larger effect during the early research stages of innovation projects. The results further reveal that firms that mix novel and recurrent partners accumulate knowledge at a higher rate. 
Broadly in line with early predictions by Abernathy and Rosenbloom (1969) and Nelson (1961), I identified the positive knowledge inflows resulting from a portfolio of parallel R\&D alliances during the research stages of firms' cooperative innovation activities. This is perhaps the clearest indication that portfolio strategies aimed at hedging risky bets concerning the dominance of future technologies play a salient role in firms' R\&D alliances. This finding also indicates a key challenge for managers faced with the design of cooperative R\&D strategies, because parts of the innovation inputs here, joint research and concurrent alliances - have a strong contingent value regarding knowledge assimilation. I therefore stress that it is important for such managers to develop an understanding of this counter-intuitive strategy aimed at improving prospects for future performance by investing in seemingly redundant hedging conduits in the present.

Mixing novel and recurrent partners generates increasing inflows of technological knowledge. This finding concerning the mixing of novel and recurring partners has at least two implications. First, although the engagement with novel R\&D partners is certainly risky, when combined with familiar partners, the payoffs in terms of knowledge flow increase significantly. Neither joint R\&D with mere recurring partners, nor that with novel partners alone is effective in a high tech environment where both firm-specific and industry-level uncertainties blur innovation-related decisions. Second, this finding also alludes to the broader notion that an R\&D portfolio may serve as an integrating mechanism joining novel and extant knowledge. This notion bears resemblance to Katila and Ahuja (2002), who suggest that useful innovations emerge when an integrating mechanism joins extant and novel perspectives. My findings provide a handle to further study the integrating function that seems to be endogenous to firms' investments in $R \& D$ alliance portfolios.

In addition to theoretical implications, my contribution offers a methodological contribution. I used data extracted from alliance announcements to identify each alliance's main R\&D aims - in terms of basic and applied research or development. Admittedly posing a research challenge when announcement data are scarce or dubious, I believe that decomposing R\&D alliances into joint research and joint development is necessary to arrive at a more fine-grained understanding of portfolio effects in firms' external alliance activities. I hope that the first look here spurs further study.

This chapter does not come without some caveats that might encourage further study beyond the above suggestions. Two stand out. First, measuring technological knowledge flows using patent citations has its shortcomings. Despite recent changes enabling the isolation of examiner-added citations, some degree of noise to the information caught in patent citations will remain. Obviously, standard single-respondent-per-firm survey research on such a complicated matter runs the risk of significant biases, in particular when technological knowledge flows have to be detected for firms with vast 
$R \& D$ resources and multiple $R \& D$ units and innovation centers. Although multiple-respondent-per-firm survey research could provide some additional insights, the cost of such research should not be underestimated. Also, for science-based industries such as IT, a combination of patent citations and bibliometric research on joint publications and scientific citations might reveal additional and more in-depth understanding of the technological knowledge flows between firms.

Second, I focused on one industry only, albeit a broad and influential one. The pattern of knowledge flow in relation to dimensions of firm's R\&D alliance portfolios may nevertheless reflect industry idiosyncrasies. An obvious question for further research is therefore if similar patterns emerge across a range of industries - from high tech industries to technologically less sophisticated ones.

Overall, this research has focused on the relationship between portfolios of interfirm R\&D alliances and the pattern of technological knowledge inflow. A next step is to establish a solid understanding of the coevolution of firms' alliance portfolios and their learning capabilities and, finally, how these generate firm-level innovations and economic performance. I hope these findings encourage initiatives to this end. 



\title{
THREE
}

\section{Partner Effects on Firm Innovation: Concurrent Effects of Technological Resources and Structural Holes ${ }^{7}$}

\begin{abstract}
This chapter examines how the technological resources and network positioning of a firm's R\&D alliance partners affect its innovation performance. Analyses of the innovative activities of firms active in IT-related R\&D alliances, 1978-1999, show that firm innovation increases with partners' technological resources at a gradually declining rate, but decreases strongly and monotonically if partners span structural holes in their network. Theoretically, the results suggest that partners' network structure is consequential for firm performance, net of resource effects. The concomitant strategy implication is that firms should attend not only to partners' resource profiles, but also to their positioning in social structure.
\end{abstract}

\subsection{Introduction}

In recent years, firms' engagement in interfirm $R \& D$ alliances has taken a quantum leap because the resources necessary to innovate no longer reside within the boundaries of single firms (Hagedoorn 2002). The corollary for researchers interested in the sources of firm innovation has been a shift from studying firms' internal resources to studying network resources - the "resources that accrue to a firm from its ties with key external constituents" (Gulati 2007: 3). Broadly speaking, the thrust of prior studies of R\&D network resources is that, all else equal, firm innovation is partly determined by partners' resource endowments (Stuart 2000), and by the focal firm's pattern of alliance ties (Ahuja 2000a; Baum, Calabrese, \& Silverman 2000; Rowley, Behrens, \& Krackhardt 2000).

Although prior studies demonstrate that R\&D alliances impact firm performance, they have not systematically attended to performance effects of

7. A predecessor of this chapter received the 2008 Robert J. Litschert Award and appeared in the 2008 AOM Best Paper Proceedings. Earlier versions were presented at the 2008 Academy of Management Meeting (Anaheim, CA) and research seminars at Cass Business School (City University London), the Haas School of Business (UC Berkeley), Maastricht University, and RSM Erasmus University. For their cogent comments and suggestions, I am grateful to Joel Baum, Ronald Burt, Waverly Ding, John Hagedoorn, Otto Koppius, Wilko Letterie, Christine Moorman, Woody Powell, Adam Tatarynowicz, Diederik van Liere, and Marc van Wegberg. Martin Carree shared his econometric insights. 
network structure beyond the firm's own R\&D alliances. In their focus on how firms reach the resources of their partners, prior work has mostly ignored how partners in turn reach the resources of their own partners and, thus, the focal firm. Yet, the key premise of a network approach to interfirm relations is that the network spanned through firms' engagement in R\&D alliances enables and constrains networked firms at both ends of an alliance (see Burt 2005; Galaskiewicz 1985; Podolny \& Page 1998). In other words, it is possible that any action undertaken and any benefit derived by partners spills over to or constrains the focal firm. Beyond their resource endowments, partners' patterns of alliance ties might therefore be of considerable interest to the performance of the focal firm.

In this chapter, I explore the additive effects on firm performance of both partners' resource endowments as well as their network positions. In so doing, I juxtapose a nodal with a network structural perspective on partner influence, recognizing that "it is likely that both perspectives are important" (Gomes-Casseres 2003: 332; cf. Lavie 2006: 650). I test nodal and structural partner influences on firm innovation in an analysis of the innovative activities of firms engaged in R\&D alliances related to information technology between 1978 and 1999. The models address issues related to unobserved heterogeneity and the potential endogeneity of network structure.

The chapter unfolds as follows. To set the stage for partner effects, I first discuss firm effects on firm innovation. Then I discuss the resource and network effects of partners on firm innovation. The following two sections describe method and results, and I close with a discussion of major implications.

\subsection{Firm effects on innovation}

Innovations arise from firms' accumulated skills, as they result in part from the recombination of extant technologies and concomitant capabilities (Cohen \& Levinthal 1994; Nelson \& Winter 1982; Pennings \& Harianto 1992). All else equal, to the extent a firm has accumulated a stock of technological knowledge, it has developed a set of skills necessary to produce new technologies. In the context of interfirm R\&D alliances, firms with a broad stock of technological resources are favorable partners, as parts of their knowledge base may form an important input to partners' $R \& D$ trajectories. This reflects that R\&D alliances are essentially access relationships (Stuart 2000). On the contrary, firms can use their extant knowledge base as a reference point for accumulating external knowledge from their partners. Specifically, to the extent firms have invested in a stock of technological resources, they should be in a good position to accumulate and make sense of external related knowledge (Cohen \& Levinthal 1994). Thus, technological resources make a firm attractive but also enable the inward accumulation of technological resources from partners at a higher rate. 
Apart from firms' accumulated stock of skills, firm innovation may additionally benefit from an appropriately structured R\&D alliance portfolio. Perhaps the most prominent of theories discussing the association of portfolio structure with firm benefits is Burt's (1992) structural holes theory. This theory argues that advantages from a firm's alliance portfolio derive from the disconnection among its direct partners, the so-called 'structural holes'. By virtue of bridging structural holes, a firm is positioned at the unique intersection of divergent, nonredundant flows of information and resources (Baum et al. 2000; Rowley et al. 2000). Hence, such a firm has timely access to novel combinations of divergent information, which in turn produces a competitive advantage. In particular, to the extent a firm is able to avail itself of a more diverse set of outside ideas, it will innovate more.

Moreover, structural holes endow the firm with the potential to control the flow of information and resources to serve its own interests. A firm bridging structural holes thus enjoys structural autonomy. Support for this theory abound. For example, Baum et al. (2000) show that, along a number of dimensions, Canadian biotech startups with structural holes in their alliance portfolio perform better than startups without such structural holes. Similarly, Rowley et al. (2000) found that semiconductor firms reach a higher return on assets with increases in the amount of structural holes in their alliance portfolio. ${ }^{8}$

In short, firms will experience additive benefits from having accumulated a stock of technological resources and from structural holes in their R\&D alliance portfolio. These issues have received a fair bit of attention in the literature. Relatively unexplored, however, are the resource and, more strikingly, network effects of partners on firm innovation. To the extent that $R \& D$ alliances are relations aimed at accessing partners' technologies, it is plausible that features of partners may affect the focal firm. Beyond investigating technological resources, I take an additional step in contrasting the resource effects with the potential structural effects of partners on the focal firm.

8. Ahuja (2000a) shows that firms in the (medium tech) international chemicals industry experience innovative advantages when the amount of structural holes among alliance partners decreases. However, he stresses that structural holes likely have a positive effect when "speedy access to diverse information is essential" (p. 451 ), so that structural holes are of prime importance in dynamic, high tech industries such as information technology (e.g., Rowley et al. 2000) or biotech (e.g., Baum et al. 2000). The IT industry I study is highly uncertain, dynamic, cross-disciplinary and knowledge is widely dispersed (Hall 2005). Thus, firms are forced "to monitor the evolution of scientific knowledge and complementary technologies across a broad spectrum" (Cloodt et al. 2006: 727), which creates a performance premium for firms that bridge structural holes (cf. Podolny 2001). 


\subsection{Partner effects on firm innovation}

\subsubsection{Partners' technological resources and firm innovation}

Firms that engage in R\&D alliances to access technological resources enjoy innovative benefits for at least two reasons. First, R\&D alliances ease the acquisition of tacit technological knowledge that would be costly to obtain through market transactions (Bae \& Gargiulo 2004; Gomes-Casseres, Hagedoorn, \& Jaffe 2006; Williamson 1991). They serve as embedded mechanisms to transfer difficult-to-codify knowledge (Mowery, Oxley, \& Silverman 1996) and other firms in the industry that are not linked to the focal firm's partners do not enjoy privileged access to the same technological knowledge. Thus, the more technological resources partners possess, the more the focal firm stands to benefit from its R\&D alliance portfolio.

Second, access to partners' technological resources infuses the firm's innovative efforts with relatively novel knowledge that would be hard to develop internally (Lavie, 2006; Rosenkopf \& Almeida, 2003; Stuart, 2000). This sparks innovation when partners' technologies are combined with a firm's internal technological resources. Moreover, as each firm's resource base is the unique result of path-dependent search efforts (Nelson \& Winter 1982; Stuart \& Podolny 1996), technological resources of different partners are likely distinct. Hence, a firm can also benefit from synergies arising from the combination of distinct technological resources of its partners. In short, the technological resources in a firm's R\&D alliance portfolio enrich the opportunity set it faces. Relatedly, partners that possess many technological resources enhance a firm's standing in the industry and endow it with legitimacy (Stuart 2000), sparking its capacity to attract more external knowledge from a variety of other parties, which in turn affects innovation.

Notwithstanding the expected positive consequences, partners with high levels of technological resources might also have adverse consequences for a firm's innovative performance. The literature identifies at least three reasons for this. First, resource-rich - and hence attractive-alliance partners are typically also the ones that are best equipped to exercise power and appropriate the lion's share of the value jointly created (Bae \& Gargiulo 2004; Katila, Rosenberger, \& Eisenhardt 2008; Lavie 2007). Indeed, it is a central tenet of resource-dependence theory (Pfeffer \& Salancik 1978) that the power of firm B over firm A stems from A's dependence on B for key resources. To the extent that the R\&D alliance partners of a firm hold the technological resources that the firm deems important, the former thus have the potential to exercise power over the latter. Ceteris paribus, excessive amounts of technological resources held by a firm's partners should distort the firm's leverage and, in turn, its innovative benefits.

Second, resource-rich firms are attractive partners and therefore have more potential partnering alternatives than resource-poor firms. Their attractiveness thus increases their leverage. The focal firm is then constrained 
in its alliance-related innovative potential because it risks losing important, resource-rich partners to competitors if such partners suspect opportunistic, self-oriented behaviors on the part of the focal firm (Baum et al. 2000: 271272).

Lastly, the technological resources that partners possess reflect historical investments in their knowledge base. This knowledge base serves as a source of absorptive capacity, which enables a better understanding and easier assimilation of external and newly created technologies (Cohen \& Levinthal 1990). Hence, a larger technological knowledge base not only makes a firm more attractive as an alliance partner, it also increases such a firm's capacity to assimilate external knowledge, including that jointly created in R\&D alliances with other firms.

In short, there is a natural tension between the value potential of access to partners' technological resources and partners' concomitant abilities for securing private benefits. Generally, I expect that there is an increasing value potential associated with alliances with resource-rich partners. Yet, partners' ability to extract knowledge from, and at the expense of, the focal firm also rises. The net effect will be a positive effect on firm innovation, with decreasing marginal returns. Consequently:

Hypothesis 1. A firm's subsequent innovative performance first increases and then decreases with the amount of technological resources held by that firm's $R \mathcal{E D}$ alliance partners.

\subsubsection{Partners' structural holes and firm innovation}

Whereas the above arguments concern the influence on firm innovation of the technological resources of a firm's R\&D alliance partners, firm innovation may also depend on the network structure, in terms of structural holes, of partners' R\&D alliance portfolios. Again, although this structure is largely a by-product of firms' search for technological resources, I probe its importance as an additional source of partner influence. Despite many results that identify the firm-level importance of bridging structural holes, there is little research that investigates how partners' structural holes influence a firm. Given the abundance of studies showing that a variety of alliance partner characteristics such as their status (Stuart, Hoang, \& Hybels 1999), their reputation (Saxton 1997), and their resources (Lavie 2006, 2007; Stuart 2000) have a significant impact on a firm, there seems little reason to believe that effects of partners' structural holes will not affect the focal firm. The main question, however, is what the direction of the influence is. For example, it can be positive if partners transfer the benefits of timely information and novel ideas to the focal firm. Or it can be negative if partners use their autonomy to primarily serve their own interests.

The $R \& D$ alliance literature provides little guidance here, although there are a few precedents outside this literature on which to base my expecta- 
tions. First, Burt (2007) argues that structural holes as bridged by a person's contacts provide the person with indirect access to the benefits of contacts' structural holes. Thus, to the extent contacts bridge structural holes, the focal person should catch some of the related advantages, even though they may be smaller than the benefits of that person's own structural holes. Burt finds that the benefits of structural holes are surprisingly local, so that contacts' structural holes have no significant effects on the focal person's performance. In a more recent effort, however, Burt (2008) revisits his earlier predictions and tests them at the industry level. He finds evidence that net of the advantages that an industry experiences from bridging the structural holes among its suppliers and customers, a significant and positive effect on industry performance is associated with the structural holes surrounding those suppliers and customers. In sum, these results indicate that contacts' advantage is partly the focal actor's, so that contacts' structural holes correlate positively with the performance of the focal actor.

Jensen (2008) provides a second precedent. He finds that incumbent firms in investment banking will favor cooperation with entrant firms that are constrained in their networks of partnerships, i.e. they bridge few, if any, structural holes. Entrants enjoy autonomy and power if they bridge structural holes in their own networks, which may at some point in time work against the incumbent that initiated the partnership. If entrants do not bridge structural holes, their extant partners work together in a dense group in which social norms and expectations curb the entrants' potential for selfinterested actions (Ahuja 2000a; cf. Coleman 1988). In sum, Jensen's results indicate that contacts' advantage of structural holes likely correlates negatively with the performance of the focal actor when opportunism is a major concern. ${ }^{9}$

What I take from Burt's $(2007,2008)$ results is that advantages of partners' structural holes may have positive spillover effects to the focal firm for the same reason that partners' reputation or technological endowments may: they may provide the focal firm with legitimacy in the market and partners' timing and information benefits can be enjoyed through cooperation in R\&D alliances. What I take from Jensen's (2008) result is that the lack of social norms surrounding partners that bridge structural holes potentially leads to self-interested behaviors, especially when the risk of opportunism is a concern.

Figure 3.1 shows the two alternative structures that firm A may face. I focus on B and E's portfolio structure among their respective contacts other

9. Results by Silverman and Baum (2002) back this indication. Their results show that the odds of survival of Canadian biotech firms fall significantly when their partners bridge many structural holes. However, partners' amount of structural holes is a control variable in their models and their theory does not speak to the reasons behind this finding. 
than $A$, as B and E's respective tie to $A$ is irrelevant for explaining the difference between the two situations. ${ }^{10} \mathrm{~B}$ bridges a structural hole between $\mathrm{C}$ and $D$, whereas E's partners $F$ and $G$ are directly connected. B has timing and information advantages by virtue of its structural holes; E does not. As Burt $(2007,2008)$ would argue, B has advantages, part of which A may benefit from through its alliance with B. As Jensen (2008) would argue, B potentially exhibits self-serving behavior when it sees productive opportunities that its partners A, C, and D do not.

Figure 3.1 Structural holes of A's partners B and E

\begin{tabular}{l|l|l} 
Partners with structural & $\begin{array}{l}\text { Partners without structural } \\
\text { holes (e.g., E) }\end{array}$ \\
\hline Advantage & $\begin{array}{l}\text { B has timing and informa- } \\
\text { tion benefits, part of which } \\
\text { benefit A. }\end{array}$ & $\begin{array}{l}\text { E's opportunism toward A } \\
\text { is curbed through the moni- } \\
\text { toring of cooperative norms } \\
\text { enabled by F and G's con- } \\
\text { nection. }\end{array}$ \\
\hline Disadvantage & $\begin{array}{l}\text { B is structurally autonom- } \\
\text { ous and may serve its own } \\
\text { interests when confronted } \\
\text { with productive opportuni- } \\
\text { ties. }\end{array}$ & $\begin{array}{l}\text { E, F, and G may exploit } \\
\text { the expense of A. }\end{array}$ \\
\hline the expased advantages at
\end{tabular}

Alternatively, Burt's findings suggest that $\mathrm{E}$ is less beneficial to A than B is, because $\mathrm{E}$ has fewer timing and information benefits than $\mathrm{B}$. Fewer benefits to E means decreased transfer of benefits to A, all else being equal. Jensen's result suggests that, given concerns for opportunism, F and G curb E's selfserving behavior, so that A stands to benefit more from $E$ than from B. Importantly, however, the extent to which F and G curb E's opportunistic acts toward A hinges on the extent to which $F$ and $G^{\prime}$ s interests are similar to A's. If $F$ and $G^{\prime}$ s interests differ from $A^{\prime} s$ and - by virtue of their transitive relationship - are closer to E's, then E, F, and G may enjoy group-based advantages that inhibit A's innovative potential. E's opportunism may still hurt A

10. These two connections (B-A and E-A) are also part of firm A's network. In my analyses, I filter out this effect by controlling for the amount of structural holes in $\mathrm{A}^{\prime} \mathrm{s}$ portfolio. 
when E serves the interest of its group (E-F-G) rather than the interest it shares with A. The table in figure 3.1 summarizes these competing positions.

What does this mean in the context of an R\&D alliance network? In high tech industries, firms use R\&D alliances to scan their environment for the best novel ideas necessary to stay competitive (Hagedoorn 1993). It is true that such R\&D alliances are deliberate cooperative attempts to develop novel technologies. Nevertheless, the risk of opportunism is particularly acute (Khanna, Gulati, \& Nohria 1998; Sampson 2007), as each individual firm has accumulated its own individual knowledge base against which to estimate the potential of novel knowledge (Cohen \& Levinthal 1994).

At various stages of the cooperative effort, partners may see potential in newly developed knowledge that the focal firm does not recognize and, for that reason, does not care to develop. Such instances cannot fully be caught in contracts. ${ }^{11}$ The flexibility provided by the structural holes in partners' alliance portfolio may allow them to unilaterally undertake developmental activities without reputational consequences beyond that particular alliance with the focal firm. Hence, the cooperative value of the individual alliance (A-B) may vanish, but without direct consequences for partners' reputation among their other alliance partners (C and D).

Partners that lack access to structural holes may behave differently, even when they experience similar pressures to develop novel technologies. When a firm's partner cooperates with other firms that also cooperate among each other (E-F-G), it is more likely that its actions are observed beyond individual alliances (A-E). These indirect observations shape other firms' views of the particular partner, and amplify both positive and negative perceptions they have of it. Hence, self-serving behavior on the part of a firm's partner is more likely to have negative consequences for such a partner when it is surrounded by a relatively dense group of other cooperating firms. After all, the latter ( $\mathrm{F}$ and $\mathrm{G})$ will have a similar interest in curbing excessive opportunism by their partner (E) as the focal firm (A). For example, others may terminate their alliances with such an opportunistic partner or impose stronger contractual terms upon it. A partner will avoid such consequences and diminish opportunistic behaviors, particularly at increased levels of connections among other contacts in its alliance portfolio.

In short, the benefits of partners' structural holes may be partly transferred in R\&D alliances (cf. Burt 2007, 2008), yet the uncertain nature of technological developments can lead to divergent estimates of idea value among R\&D alliance partners. This may prompt a firm's partners to develop

11. Certainly, the governance structure of an $R \& D$ alliance will influence the extent of self-serving behaviors (Oxley 1997; Sampson 2007; Williamson 1991). Ceteris paribus, the higher the (equity) stake each partner has in an alliance, the lower this risk. I control for the governance structure (contractual agreement or joint venture) of alliances in my models. 
individual self-serving initiatives that remain unobserved outside the individual alliance when such partners have autonomy in their own alliance portfolios (cf. Jensen 2008). Ceteris paribus, when uncertainty in technological and market environments causes severe risks of opportunism, I expect that a firm benefits more from partners that maintain portfolios of connected others. Although such partners do not experience the full benefits associated with structural holes, they do have additional incentives to cooperate beyond those provided in dyadic contracts.

Hypothesis 2. The amount of structural holes of a firm's RED alliance partners is negatively related to the firm's subsequent innovative performance.

An empirical analysis juxtaposing these two hypotheses is of value for strategy, as it addresses the question of whether firms should consider partners' network structure beyond considering their technological endowments. After all, the structure of an R\&D alliance network strictly exists only by virtue of firms seeking access to each others' technologies, i.e. external technology strategy is concerned first and foremost with the sourcing of technological resources rather than with the design of network structure. Network structure is therefore much more the by-product, deliberate or inadvertent, than the goal of purposive technology search (cf. Burt 2005: 27-28; Coleman 1990: 312; Stuart \& Podolny 1996). Structure's epiphenomenal tinge in turn raises questions about its substantial relevance, both for theory and practice. If network structure is, in its consequences, no more than an immaterial byproduct of technology search, its effects should be insignificant in performance models controlling characteristics of firms' technology stocks and, by implication, irrelevant to alliance strategy. But if network structure is consequential, the models should show significant network structural effects, in turn raising implications for strategy. ${ }^{12}$

\subsection{Method}

\subsubsection{Data and sample}

To test my predictions, I used a database developed at Brandeis University and Maastricht University, containing information on technology partner-

12. Though network structure may be an inadvertent by-product of purposive strategy, it need neither have negative, nor insignificant consequences to connected firms. To the former, Merton (1936: 895) noted that "unforeseen consequences [of purposive social action] should not be identified with consequences which are necessarily undesirable (from the standpoint of the actor)." Related to the significance of byproducts, Davis, Yoo, and Baker (2003: 305) argued that, in the context of interlocking directorates, "board interlocks may be a fortuitous by-product of board preferences $(\ldots)$, with little strategic intent $(\ldots)$, yet the result is the creation of a network that is highly consequential for board decision-making." 
ships, their sponsoring firms, and patents and patent citations in the IT industry between 1975 and 1999 (see Gomes-Casseres et al. 2006). The database contained data from the CATI database on interfirm technology alliances (Hagedoorn 2002), the NBER patent data file (Hall, Jaffe, \& Trajtenberg 2002), and Standard \& Poor's COMPUSTAT database. I collected additional information from CATI, USPTO, Osiris, Datastream, the SEC/10K filings, the U.S. Census Bureau, Eurostat, firms' annual reports and numerous press releases.

The IT industry consists of firms active in computers, semiconductors, and communications, covering patent classes for Communications, Computer Hardware \& Software, Computer Peripherals, Information Storage and Semiconductor Devices (technological subcategories 21-24 and 46 in Hall et al. 2002: 452-453). Historically, IT firms have actively used alliances to perform joint R\&D, share technologies, and develop novel products and processes (Hagedoorn 1993, 2002), which motivated my choice to use IT as the empirical setting to test my predictions.

I used two rules to include firms in my estimation sample. First, a firm was included if it had at least one patent in patent classes for communications, computer hardware and software, computer peripherals, information storage and semiconductor devices in 1978-1999. Second, using alliance announcements in CATI, I included only those firms that had at least one R\&D partnership in information technology, devised to perform joint R\&D and/or joint technology development. Hence, I did not include isolates (cf. Ahuja 2000a; Gulati 1995a; Shipilov 2006). Together, these two rules ensured that I could (1) identify key constructs relating to firms' knowledge base and (2) relate them to their R\&D alliance activities. The resulting matched firmpatenting sample contained 1,275 firm-years.

Availability of complete data for all firm-, relation-, and partner-specific variables and my use of a lagged model specification reduced the sample considerably. I probed the potentially non-random nature of missing values by estimating a two-stage Heckman model (Allison 2001: 79-81; Heckman 1979; Hsiao 2003: 230, 236). In the first-stage, I estimated the probability of non-missing values using probit regression. In the second stage, I estimated the full model that accounted for the probability of non-missing values. All results were identical and the additional control was insignificant $(p>0.10)$, indicating that missing values did not bias the final results.

My sampling window (1978-1999) captured the alliance development in IT almost from its inception (Hagedoorn 2002). Hence, left censoring was a marginal issue. Moreover, I dealt with remaining left censoring concerns by including the few alliances formed between 1975 and 1977 in the 1978 matrix, and by adding a control for a firm's overall R\&D partnering history.

\subsubsection{Network definition}

I defined the evolving R\&D network based on interfirm linkages through either bilateral contracts or equity joint ventures, both of which were created to 
jointly perform R\&D or develop new products and processes. Reasons to focus on these alliance types include their longer durability, greater intensity and higher strategic significance compared to other types, such as unilateral licensing and second-sourcing agreements (cf. Stuart 2000). ${ }^{13}$

I based network and relational measures on annual adjacency matrices reflecting all R\&D alliances among the sample firms for a window of three years. For example, the 1993 matrix contained the alliances for 1991-1993, the 1994 matrix those for 1992-1994, and so on. Specifying an alliance window is crucial as for many alliances (approximately 90\%), termination dates cannot be traced. Also, ignoring alliance duration would significantly underestimate the inertia of network structures. I based the three-year window on the approximately $10 \%$ of alliances with traceable duration. I also estimated the results for networks that incorporated all previous alliances, using an expanding window from an alliance's moment of network entry to $t$. Results were identical, in line with findings by Bae and Gargiulo (2004) and Gulati (1999).

\subsubsection{Dependent variable}

I measured innovative performance in a given year $t+1$ as the firm-level count of IT patents granted, based on years of application (cf. Ahuja 2000a; Stuart 2000). A patent represented an externally validated and assigned property right in an invention that is regarded as a nontrivial and useful contribution to the previous state of knowledge. Thus, generally, it serves well as a measure of innovative output and technological novelty (Hagedoorn \& Cloodt 2003; Jaffe \& Trajtenberg 2002)..$^{14}$ Following Gomes-Casseres et al. (2006), I treated all patents classified in subcategories $21-24$ and 46 as IT patents, see

13. This approach is akin to studies of interpersonal networks that use data on individuals' perceived interaction frequencies (e.g., Burt 2007). For example, relations cited as being the subject of interactions 'often' are used to define the network, whereas those that are 'sometimes' or 'rarely' the subject of interaction are discarded for the purpose of network definition.

14. As I focus on IT only, I avoid interpretive problems resulting from heterogeneity in patenting propensities across industries, and heterogeneity more broadly (Carroll \& Hannan 2004: ch. 5). Still, within IT it seems that some firms patent more aggressively than others, for reasons other than solely securing the ownership of inventions (Hall 2005). In industry segments where rights to external technologies are widely distributed across legal entities, firms may build up stocks of patents ('patent fences') to avoid costly contracting and lawsuits (cf. Gallini 2002; Ziedonis 2004). This effect should be stronger after strengthened patent rights in the 1980s. I include firm and year fixed effects in my models to capture such heterogeneity in patenting propensities. Nevertheless, I tested if the potential occurrence of patent fencing strategies changed my results in models that allowed for industry segment fixed effects. In particular, I estimated a conditional fixed effects negative binomial model (Hausman et al. 1984) and a cross-sectional negative binomial model with yearly and pre-sample fixed effects (Blundell et al. 1995). Results were similar, although semiconductor firms (SIC 3674) indeed patented more intensely than others after 1985. 
Hall et al. (2002: 452-453). I used IT patents because the alliances I studied focused on IT-related R\&D. To avoid simultaneity bias and enable causal inference, I regressed innovative performance in $t+1$ on all independent variables and controls in $t$.

In line with earlier work (Ahuja 2000a; cf. Jaffe \& Trajtenberg 2002; Sampson 2007), I counted assigned patents based on their application dates. A patent assigned in 1991 yet filed in 1988 is thus counted in 1988. First, this ensured a close match to the 'real' invention dates on which firms created novel knowledge (Hall et al. 2002: 409). Second, the process involved in ruling upon applications and assigning patents typically spans one to several years, which causes patent-specific grant delays that add considerable noise to an analysis of patenting propensities. Thus, to ensure consistent treatment of patents across firms and over time, I used application dates. To limit right truncation, I used data on patents granted until 2005 to allow for delays in the processing of 1999 patent applications. Since the bulk of the patents are granted within three years from application, I believe this procedure effectively eliminated concerns of right truncation.

\subsubsection{Independent variables}

Partner technological resources. I measured partners' technological resources as their indegree in the IT patent citation network in a given year $t$, which is an annual count of the citations partners receive to their IT patents (Kalaignanam, Shankar, \& Varadarajan 2007; Stuart 2000). Such citations represent acts of deference to partners' knowledge bases and, as such, are a measure of technological status (Stuart 1998; Wasserman \& Faust 1994). High values on this measure indicated that the partners' technologies were major building blocks for others' inventions. As such, these firms were visible as technological stars in the industry. I calculated the measure partner technological resources as the mean value (across partners in a firm's alliance portfolio) of partners' citation counts in $t$. I used the mean value to enable the comparison of technological resources across R\&D alliance portfolios of varying size. To test Hypothesis 1, I included both the main effect and the squared term of this measure in my models.

Partner structural holes. As basis for measuring the amount of structural holes in partners' networks, I used the inverse of Burt's constraint measure (Burt 1992: 54-55). First, the proportion of firm $i$ 's networking efforts directly invested in partner $j$ in year $t$ equals $p_{i j t}=\left(1 / n_{i t}\right)^{*}\left(n_{i j t}\right)$, where $n_{i t}$ is firm $i^{\prime}$ s total number of R\&D alliances and $n_{i j t}$ its number of R\&D alliances with partner $j$, both in $t$. Second, using UCINET 6 (Borgatti, Everett, \& Freeman 2002), I calculated the network constraint experienced by firm $i$ in year $t$ as:

$$
c_{i t}=\sum_{j \neq i}\left(p_{i j t}+\sum_{q}^{Q} p_{i q t} p_{q j t}\right)^{2}
$$


where the bracketed, squared term is the constraint imposed on firm $i$ by a single partner $j$; the summated product term between brackets is the sum of $i$ 's relational investments in $q$ that lead to $j$ as well (Burt 1992: 54-55); and $q$ is unequal to $i$ and $j$. Third, I obtained firm structural holes $\left(f_{s} h_{i t}\right)$, firm $i$ 's access to structural holes in $t$, by calculating the inverse of constraint as follows: $\left(9 / 8-c_{i t}\right) .{ }^{15}$ A highly constrained ego network is devoid of structural holes and related benefits, whereas low constraint characterizes an ego network in which the focal firm bridges structural holes; hence my use of the inverse of constraint. A high value on the inversed constraint measure indicates that the focal firm bridges many structural holes, while a low value indicates that the firm is relatively well embedded through maintaining redundant connections. Lastly, I calculated the partner structural holes variable as the arithmetic mean of partners' amount of structural holes as:

$$
\sum_{j=1}^{A_{i t}} f s h_{j t} / A_{i t}
$$

where $f s h_{j t}$ is the amount of structural holes bridged by $i$ 's partner $j$ in $t$, and $A_{i t}$ is the number of $i$ 's alters in $t$ (see also Burt 2007: 125-126). Again, I used the mean value across partners to enable the comparison of partner structural holes across R\&D alliance portfolios of diverse size.

\subsubsection{Control variables}

In the analyses, I estimated the effects of partners' technological resources and structural holes on firm innovation net of controls for the focal firms' technology stock and structural holes, and a range of other potential confounds. Greve (2005) indicated that the transfer of knowledge between firms is a function of the characteristics of origin and destination firms, and their relationship. Similarly, Kalaignanam et al. (2007) argued that firm, alliance, and partner characteristics should be considered simultaneously when estimating the impact of alliances on firm performance. Thus, to provide a conservative test of the hypotheses, I incorporated a set of firm-level, relational, and partner-level controls. Also, in addition to the firm fixed effects, I included year dummies to capture unobserved temporal heterogeneity.

Firm controls. Firm size is the logarithm of a firm's total asset value in year $t$. Firm age is the logarithm of a firm's age since incorporation. Firm profitability was included as the yearly ratio of firms' operating income to sales. I included the measure firm RED intensity as the ratio of a firm's R\&D spending to its sales in $t$. To control for a firm's focus on IT, I included firm IT-focus as the ratio of its patent stock in IT to its overall patent stock in $t$. Finally, I included firm alliance experience, a count of the technology partnerships a firm had entered by $t$.

15. Buskens and van de Rijt (2008: 376, 398-399) show that $c_{i t}$ lies between 0 and 9/8. 
Relational controls. To control for the effects of partner firms' common knowledge base on firm innovation (Sampson 2007), I included Jaffe's (1986) measure of technological proximity to capture common knowledge. First, firm $i^{\prime}$ s position in technology space in year $t$ is a vector $\boldsymbol{F}_{i t}=\left(F_{i 1 t} \ldots F_{i K t}\right)$, where $F_{i k t}$ is the fraction of firm i's patents in patent class $k$ in year $t$. Second, the technological proximity of two firms $i$ and $j$ is the angular separation of the firms' technological positions, or $P_{i j t}=\boldsymbol{F}_{i t} \boldsymbol{F}_{j t^{\prime}} /\left[\left(\boldsymbol{F}_{i t} \boldsymbol{F}_{i t^{\prime}}\right)\left(\boldsymbol{F}_{j t} \boldsymbol{F}_{j t^{\prime}}\right)\right]^{1 / 2}$, which is bounded by 0 and 1 , and values closer to 1 indicate a larger overlap of the firms' knowledge bases. Finally, to obtain the variable common knowledge, I calculated the arithmetic mean of all dyadic proximities as:

$$
P_{i t}=\sum_{j=1}^{A_{i t}} P_{i j t} / A_{i t}
$$

where $A_{i t}$ is the number of $i$ 's alters in $t$.

To capture effects of alliance governance on firm innovation rates (Mowery et al. 1996; Pisano 1989; Sampson 2007), I included joint venture as the proportion of a firm's R\&D alliances that were joint ventures in $t$. Finally, to capture geographic effects on firm innovation, I calculated international RED partners as the share of a firm's R\&D alliances with firms outside its home region (headquarter location) in year $t$.

Partner controls. To rule out that my measures of partners' technological resources and network positions captured other partner attributes, I controlled four of them. Partner size was the average of the logged total asset value of a firm's direct partners in $t$. Partner age was the average of the logged age since incorporation of a firm's direct partners in $t$. To control for partner IT-focus, I included the mean value of partners' IT-to-overall patent stock ratio in $t$. Lastly, I controlled partner non-IT technological resources as the averaged count of citations to partners' non-IT patents in $t$.

\subsubsection{Statistical analysis}

I modeled firm innovation for firm $i$ in year $t+1, \mathrm{P}_{\mathrm{it}+1}$, as:

$$
E\left(P_{i t+1} \mid X_{i t}, C_{i t}, \alpha_{t}, \delta_{i}\right) \propto \exp \left(\beta_{X} X_{i t}+\beta_{C} C_{i t}+\beta_{a} \alpha_{t}+\delta_{i}\right),
$$

where $X_{\mathrm{it}}$ is a time-varying vector of resource and network variables characterizing firm $i ; \mathrm{C}_{\mathrm{it}}$ is a time-varying vector of control variables characterizing firm $i ; a_{\mathrm{t}}$ is a vector of year dummies; and $\delta_{\mathrm{i}}$ indexes unobserved timeinvariant firm effects. I used an unconditional fixed effects negative binomial specification to estimate this model (Allison \& Waterman 2002). ${ }^{16}$

16. A Hausman (1978) specification test rejected the null hypothesis of uncorrelated unobserved and observed firm effects. Sorting on unobservables was thus a justified concern and using random effects would have generated inconsistent estimates. 
Two issues complicated the empirical separation of resource and network effects. First, unobserved (or unobservable) firm characteristics may both underlie favorable network structures as well as superior technological resources and performance (Durlauf 2002; cf. Munshi 2003). Thus, sorting on unobservable firm characteristics might generate resource and network effects that are inseparable from firms' unobserved abilities, severely limiting the exchangeability of empirical findings across heterogeneous firms (Durlauf 2002: F463-F464). To address this issue, I included firm fixed effects (i.e. $\delta_{i}$ ) in the performance regressions (Allison \& Waterman 2002; Greene 2003: 285), assuming that firms' unobserved abilities are stable over time. Inclusion of firm fixed effects meant that the models incorporated a within-firm correlation structure, precluding the identification of time-invariant covariates (e.g., firms' headquarter location).

Second, network structure may be endogenous to firm innovation (Manski 1993; Mouw 2006), the latter being the generator of firms' technology stocks. For example, technological resources expand a firm's cognitive skills to handle disparate knowledge - that of partners separated in social structure - which may spark further investments in alliances with dissimilar, otherwise disconnected partners. Alternatively, high-performers transmit a signal of quality, increasing their attractiveness to a broader range of potential partners. The resulting econometric concern was that given endogenous structure, effects of structural holes may in part or fully be indirect technology effects, leading to flawed theoretical conclusions (namely, the misattribution of technology effects to network structural attributes).

With feedback from innovation to network structure, the cause of endogeneity would in fact be an omitted variable bias stemming from uncontrolled variables capturing firms' history of technological activities. Both at the firm- and the partner-level, I therefore included two endogenous state dependency variables (Heckman \& Borjas 1980; Jacobson 1990), one capturing firms' stock of patents up to seven years old (i.e. assigned in $t-6$ to $t$ ), and one capturing those older than seven years (i.e. assigned before $t-6) .{ }^{17}$ Essentially, with these lagged innovation controls and the one-year lag structure, I can more confidently interpret the effects of the other covariates as causally affecting subsequent firm innovation over and above the effects of prior innovation (before $t-6$ and between $t-6$ and $t$ ) on firm innovation in $t+1$ (Granger 1969; Jacobson 1990). Further, to the extent that a firm's innovations were endogenous with respect to observed and unobserved factors, any dispositional differences across firms should be manifest in prior innovations and,

17. I defined the variables based on this temporal breakdown because Jaffe and Trajtenberg (1996; see also Jaffe \& Trajtenberg 2002) indicated that most patents get cited when they are up to 6 years old, and less when they are older. This in turn suggests that younger patents are attended to more intensely. Arguably, they are thus of larger importance in shaping alliance strategy and, by implication, network structure. 
thus, in firms' technology stocks. Inclusion of the state dependency terms thus additionally addressed the confounding effects of time-varying unobserved heterogeneity. Note that given their multifaceted purpose, the occurrence dependence variables cannot be interpreted unambiguously.

\subsection{Results}

Table 3.1 shows the descriptive statistics and bivariate correlations. Though some correlations are rather high $(>0.7)$, additional robustness tests revealed that the results on the hypothesized effects remained unaffected. Regarding table 3.1, I wish to emphasize one set of figures. The correlations between the joint venture measure and the measures of partner and firm structural holes are $r=0.16$ and $r=0.34$, respectively. Firms thus tend to use less hierarchical governance forms when cooperating in structurally closed portfolios (cf. Rowley et al., 2000), or when the portfolios of their partners are closed (cf. hypothesis 2), which is consistent with my expectation that structural closure (the lack of structural holes) partially curbs individual firms' opportunism.

\subsubsection{Control variable results}

Table 3.2 shows the statistical models of firm innovative performance. The subsequent models improve significantly (beyond $p<0.05$ ) on the baseline model and the results are stable across the five specifications, both in terms of the direction and significance of the estimates. As for the control variables, firm innovative performance increases with firm size, firm age, firm R\&D intensity, and its amount of structural holes. It also increases with its stock of patents, but it decreases with an increase in the stock of old patents. Firm alliance experience is also (marginally) significant. Common knowledge generally has positive effects on firm patenting. The share of joint ventures and the share of international partners both spark firm innovation rates. The latter is surprising, especially since firms in IT have largely favored local (U.S.) partnering (Hagedoorn 2002). According to Lavie and Miller (2008), however, international cooperation may be endogenous to expected outcomes so that firms that do have international partners potentially benefit more from such foreign partners, for reasons unrevealed yet absorbed by the international partners variable. Further, Peri (2005) shows that knowledge in especially the computer sector flows significantly further than in a number of other sectors. Larger partners impede firm innovation, possibly due to bargaining advantages that come with size. Partners' IT-focus sparks firm innovation and their non-IT technological resources reduce firm innovation. Recent partner patents also increase firm innovation. 


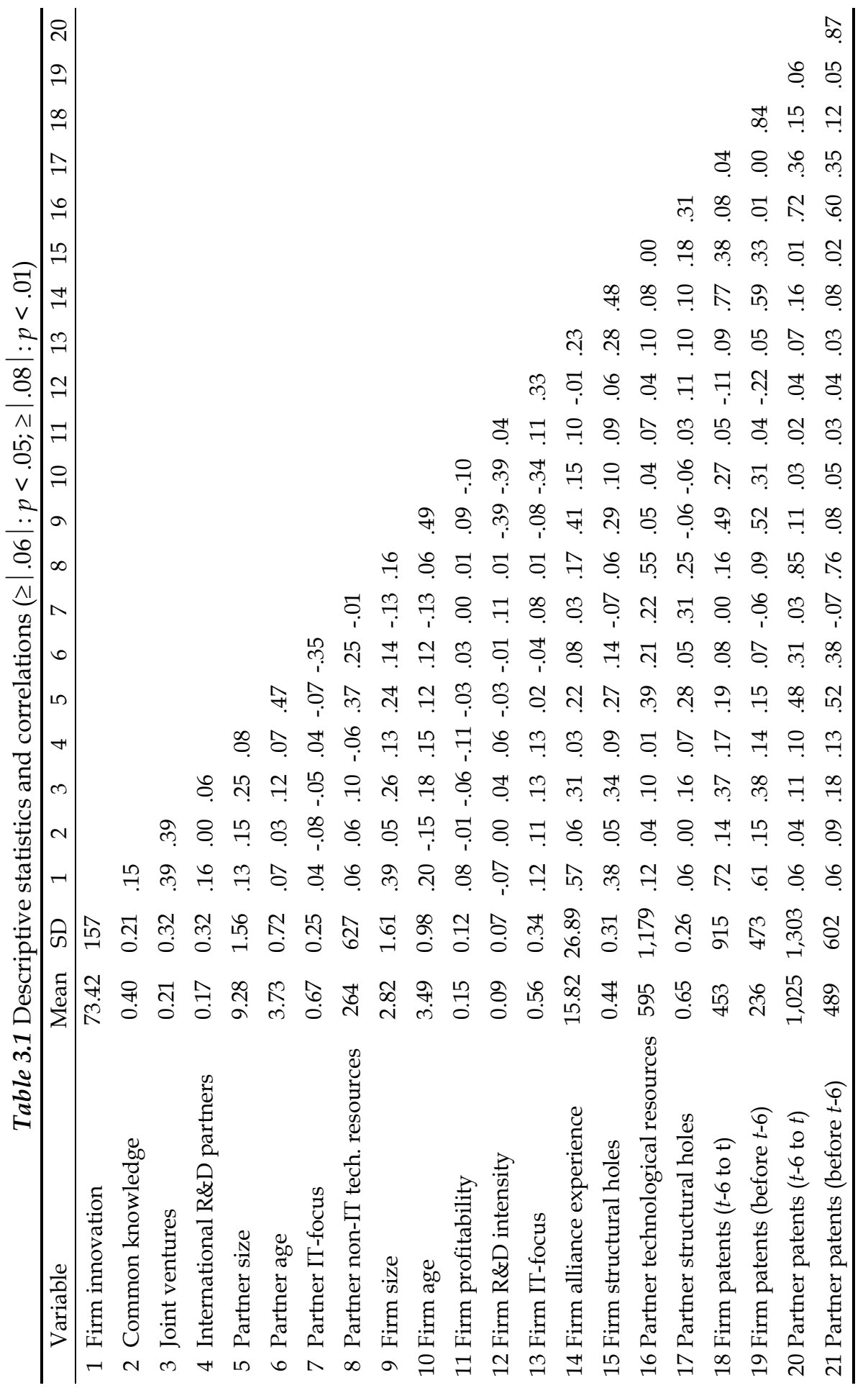


Table 3.2 Unconditional FE negative binomial estimates of firm innovation

\begin{tabular}{|c|c|c|c|c|c|}
\hline Variable & $(1)$ & $(2)$ & (3) & $(4)$ & $(5)$ \\
\hline Constant & $\begin{array}{l}-4.10^{* * *} \\
(.855)\end{array}$ & $\begin{array}{c}-4.11^{* * *} \\
(.799)\end{array}$ & $\begin{array}{c}-4.44^{* * *} \\
(.795)\end{array}$ & $\begin{array}{l}-4.24^{* * *} \\
(.799)\end{array}$ & $\begin{array}{c}-4.37^{* * *} \\
(.874)\end{array}$ \\
\hline Common knowledge & $\begin{array}{l}.615^{* *} \\
(.220)\end{array}$ & $\begin{array}{l}.574^{* *} \\
(.220)\end{array}$ & $\begin{array}{l}.656^{* *} \\
(.221)\end{array}$ & $\begin{array}{l}.614^{* *} \\
(.221)\end{array}$ & $\begin{array}{l}.628^{* *} \\
(.220)\end{array}$ \\
\hline Joint ventures & $\begin{array}{l}.600^{* * *} \\
(.129)\end{array}$ & $\begin{array}{l}.602^{* * *} \\
(.128)\end{array}$ & $\begin{array}{l}.630^{* * *} \\
(.130)\end{array}$ & $\begin{array}{l}.632^{* * *} \\
(.129)\end{array}$ & $\begin{array}{l}.632^{* * *} \\
(.128)\end{array}$ \\
\hline International R\&D partners & $\begin{array}{l}.674^{* * *} \\
(.134)\end{array}$ & $\begin{array}{c}.653^{* * *} \\
(.134)\end{array}$ & $\begin{array}{l}.682^{* * *} \\
(.134)\end{array}$ & $\begin{array}{c}.661^{* * *} \\
(.134)\end{array}$ & $\begin{array}{l}.675^{* * *} \\
(.134)\end{array}$ \\
\hline Partner size & $\begin{array}{l}-.081^{* *} \\
(.027)\end{array}$ & $\begin{array}{l}-.085^{* *} \\
(.027)\end{array}$ & $\begin{array}{l}-.078^{* *} \\
(.027)\end{array}$ & $\begin{array}{l}-.082^{* *} \\
(.027)\end{array}$ & $\begin{array}{l}-.076^{* *} \\
(.027)\end{array}$ \\
\hline Partner age & $\begin{array}{l}-.037 \\
(.052)\end{array}$ & $\begin{array}{l}-.045 \\
(.052)\end{array}$ & $\begin{array}{l}-.020 \\
(.053)\end{array}$ & $\begin{array}{l}-.028 \\
(.053)\end{array}$ & $\begin{array}{l}-.021 \\
(.053)\end{array}$ \\
\hline Partner IT-focus & $\begin{array}{l}.380^{* *} \\
(.134)\end{array}$ & $\begin{array}{l}.330^{*} \\
(.138)\end{array}$ & $\begin{array}{l}.442^{* *} \\
(.139)\end{array}$ & $\begin{array}{l}.394^{* *} \\
(.143)\end{array}$ & $\begin{array}{l}.403^{* *} \\
(.142)\end{array}$ \\
\hline Partner non-IT tech. resources $(\times 10)$ & $\begin{array}{l}-.002^{* *} \\
(.001)\end{array}$ & $\begin{array}{l}-.002^{* *} \\
(.001)\end{array}$ & $\begin{array}{l}-.002^{* *} \\
(.001)\end{array}$ & $\begin{array}{l}-.002^{* *} \\
(.001)\end{array}$ & $\begin{array}{l}-.003^{* *} \\
(.001)\end{array}$ \\
\hline Firm size & $\begin{array}{l}.787^{* * *} \\
(.108)\end{array}$ & $\begin{array}{l}.789^{* * *} \\
(.107)\end{array}$ & $\begin{array}{l}.768^{* * *} \\
(.108)\end{array}$ & $\begin{array}{l}.771^{* * *} \\
(.107)\end{array}$ & $\begin{array}{l}.792^{* * *} \\
(.107)\end{array}$ \\
\hline Firm age & $\begin{array}{c}1.070^{* * *} \\
(.158)\end{array}$ & $\begin{array}{c}1.048^{* * *} \\
(.158)\end{array}$ & $\begin{array}{c}1.084^{* * *} \\
(.157)\end{array}$ & $\begin{array}{c}1.061^{* * *} \\
(.157)\end{array}$ & $\begin{array}{c}1.012^{* * *} \\
(.159)\end{array}$ \\
\hline Firm profitability & $\begin{array}{l}-.032 \\
(.371)\end{array}$ & $\begin{array}{c}.005 \\
(.370)\end{array}$ & $\begin{array}{l}-.038 \\
(.369)\end{array}$ & $\begin{array}{c}.000 \\
(.368)\end{array}$ & $\begin{array}{c}.027 \\
(.367)\end{array}$ \\
\hline Firm R\&D intensity & $\begin{array}{c}2.202^{* *} \\
(.796)\end{array}$ & $\begin{array}{c}2.292^{* *} \\
(.795)\end{array}$ & $\begin{array}{c}2.195^{* *} \\
(.796)\end{array}$ & $\begin{array}{c}2.282^{* *} \\
(.794)\end{array}$ & $\begin{array}{c}2.309^{* *} \\
(.785)\end{array}$ \\
\hline Firm IT-focus & $\begin{array}{l}-.305 \\
(.191)\end{array}$ & $\begin{array}{l}-.331 \dagger \\
(.191)\end{array}$ & $\begin{array}{l}-.329 \dagger \\
(.191)\end{array}$ & $\begin{array}{l}-.353 \dagger \\
(.191)\end{array}$ & $\begin{array}{l}-.335 \dagger \\
(.191)\end{array}$ \\
\hline Firm alliance experience & $\begin{array}{l}.003 \dagger \\
(.002)\end{array}$ & $\begin{array}{l}.003 \dagger \\
(.002)\end{array}$ & $\begin{array}{l}.004^{*} \\
(.002)\end{array}$ & $\begin{array}{l}.004^{*} \\
(.002)\end{array}$ & $\begin{array}{l}.004^{*} \\
(.002)\end{array}$ \\
\hline Firm structural holes & $\begin{array}{l}.386^{* * *} \\
(.102)\end{array}$ & $\begin{array}{l}.368^{* * *} \\
(.102)\end{array}$ & $\begin{array}{l}.402^{* * *} \\
(.102)\end{array}$ & $\begin{array}{l}.384^{* * *} \\
(.102)\end{array}$ & $\begin{array}{l}.388^{* * *} \\
(.101)\end{array}$ \\
\hline Partner tech. resources $\left(\times 10^{2}\right)$ & & $\begin{array}{l}.011 \dagger \\
(.006)\end{array}$ & & $\begin{array}{l}.011 \dagger \\
(.006)\end{array}$ & $\begin{array}{l}.011 \dagger \\
(.006)\end{array}$ \\
\hline Partner tech. resources ${ }^{2}\left(\times 10^{6}\right)$ & & $\begin{array}{l}-.014^{*} \\
(.006)\end{array}$ & & $\begin{array}{l}-.014^{*} \\
(.006)\end{array}$ & $\begin{array}{l}-.013^{*} \\
(.006)\end{array}$ \\
\hline Partner structural holes & & & $\begin{array}{l}-.232^{*} \\
(.111)\end{array}$ & $\begin{array}{l}-.229^{*} \\
(.110)\end{array}$ & \\
\hline Partners with few structural holes & & & & & $\begin{array}{l}.273^{* *} \\
(.096)\end{array}$ \\
\hline Partners with many structural holes & & & & & $\begin{array}{c}.068 \\
(.090)\end{array}$ \\
\hline Firm patents $(t-6$ to $t)(\times 10)$ & $\begin{array}{l}.002^{* * *} \\
(.001)\end{array}$ & $\begin{array}{l}.002^{* * *} \\
(.001)\end{array}$ & $\begin{array}{l}.002^{* * *} \\
(.001)\end{array}$ & $\begin{array}{l}.002^{* * *} \\
(.001)\end{array}$ & $\begin{array}{l}.002^{* * *} \\
(.001)\end{array}$ \\
\hline Firm patents (before $t-6)(\times 10)$ & $\begin{array}{l}-.005^{* *} \\
(.002)\end{array}$ & $\begin{array}{c}-.006^{* * *} \\
(.002)\end{array}$ & $\begin{array}{l}-.005^{* *} \\
(.002)\end{array}$ & $\begin{array}{l}-.005^{* *} \\
(.002)\end{array}$ & $\begin{array}{c}-.006^{* *} \\
(.002)\end{array}$ \\
\hline Partner patents $(t-6$ to $t)(\times 10)$ & $\begin{array}{l}.002^{* * *} \\
(.001)\end{array}$ & $\begin{array}{l}.002^{* * *} \\
(.001)\end{array}$ & $\begin{array}{l}.002^{* * *} \\
(.001)\end{array}$ & $\begin{array}{l}.002^{* * *} \\
(.001)\end{array}$ & $\begin{array}{l}.002^{* * *} \\
(.001)\end{array}$ \\
\hline
\end{tabular}


Table 3.2 Continued

\begin{tabular}{lccccc}
\hline Variable & $(1)$ & $(2)$ & $(3)$ & $(4)$ & $(5)$ \\
\hline Partner patents (before $t-6)(\times 10)$ & -.001 & -.002 & -.001 & -.002 & -.002 \\
& $(.001)$ & $(.001)$ & $(.001)$ & $(.001)$ & $(.001)$ \\
\hline Log likelihood & -2849.76 & -2845.96 & -2847.39 & -2843.61 & -2842.94 \\
\hline
\end{tabular}

Note: $† p<.10{ }^{*} p<.05 ;{ }^{* *} p<.01 ;{ }^{* * *} p<.001$; year fixed effects included

\subsubsection{Hypotheses}

Partner technological resources has both a significant, positive linear and negative squared effect on firm innovation, suggesting decreasing marginal returns to associations with well-endowed partners. Partner structural holes, unlike a firm's own structural holes, has a significant negative effect on firm innovation. Hence, both hypotheses 1 and 2 receive support in the data.

Figure 3.2 shows the effect of partners' technological resources on firm innovation, based on estimates from model 4 . Though the inflection point of the resource effect lies well beyond one standard deviation from the sample mean, there is a clear penalty to $R \& D$ alliances with extremely resource-rich firms, even eventually to the detriment of firm innovation. Figure 3.3 shows the joint effects of a firm's structural holes and partners' structural holes on firm innovation. Clearly, a firm benefits significantly from bridging structural holes among its direct alliance partners. Yet, the figure shows that these benefits vanish if the focal firm's partners also bridge structural holes among their own partners. Ideally, therefore, a firm bridges structural holes among partners that do not. On the contrary, the largest penalty for firm innovation arises in situations where the focal firm does not bridge structural holes while its partners do.

Figure 3.2 Partners' technological resources and firm innovation

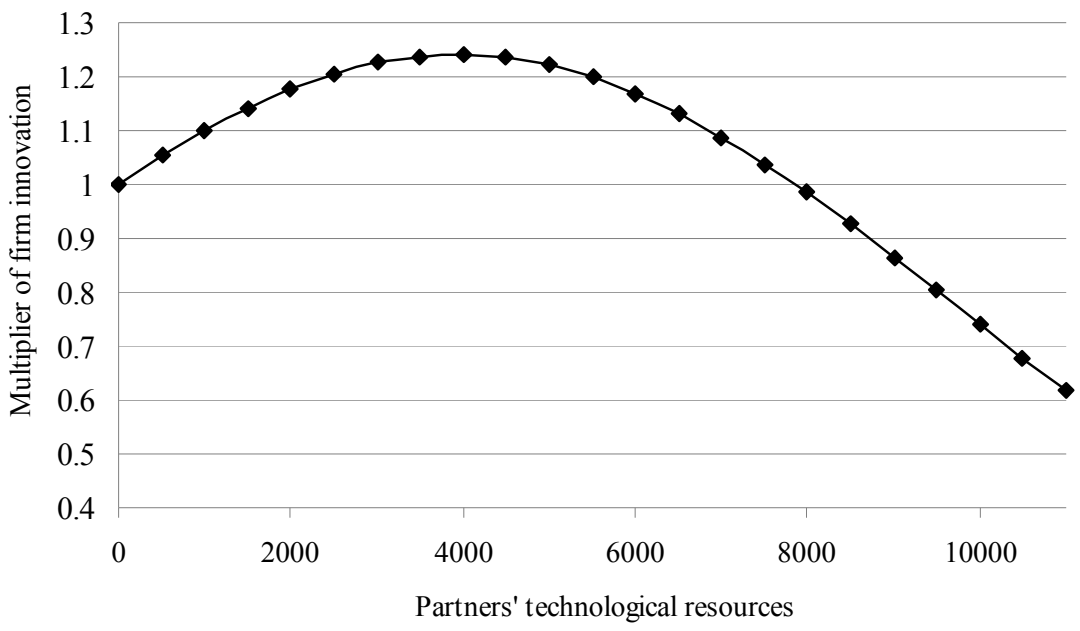


The finding concerning partner structural holes is striking for at least two reasons. First, it emerges in models with strict controls for unobserved heterogeneity and for firms' network positioning and history of technological achievements. Second, the effect turns up as negative, contrasting earlier findings by Burt (2008) showing that there would seem to be benefits of association with others that bridge structural holes as well. To get a firmer grip on the mechanism that might explain the negative effect, I estimate an additional model to tease apart the two explanations for a negative effect of partner structural holes on firm innovation as pictured in figure 3.1. Note that the finding is theoretically consistent with both the logic in the upper right and lower left quadrants of the figure. In other words, the negative coefficient might be due to benefits of association with embedded partners and/or due to self-serving behaviors of partners that bridge structural holes.

In the spirit of Burt (2008), I split partner structural holes into two variables that measure (1) the fraction of a firm's partners with few structural holes and (2) the fraction of a firm's partners with many structural holes. Operationally, I define the two variables as a firm's fraction of partners in the lower and upper quartile of the observed range of partner structural holes (i.e. $<0.25$ and $>0.76$ ) in $t$ (Burt 2008). This allows me to observe if either the positive effect of the absence of partner structural holes (an embeddedness effect) or the negative effect of their presence (a competition effect) has a disproportionate share in the overall negative effect in models 3 and 4 of table 3.2. Model 5 shows that the positive effect of partnerships with embedded partners (i.e. those in networks devoid of structural holes) disproportionally shapes the negative main effect of partner structural holes in models 3 and 4 .

Figure 3.3 Firm and partner structural holes, and firm innovation

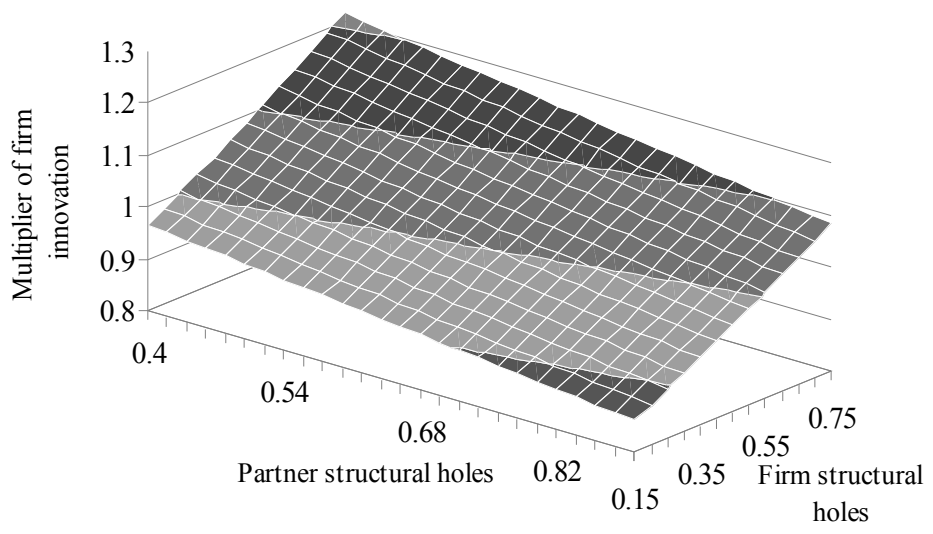


The implication of this supplemental result is this: although the negative main effect of partner structural holes (models 3 and 4) suggests that structurally autonomous partners impede firm innovation, a closer look reveals that it hides a strong positive influence of affiliations with embedded partners. Thus, in the context of this R\&D network, what is transferred between partners and the focal firm is mainly the embeddedness benefit rather than the competition effect. This foreshadows that embedded partners show a predisposition to portray cooperative behaviors more than that autonomous partners are competitors.

Although I predicted independent effects of partners' technological resources and their structural position on firm innovation, I also tested for their potential interaction. In particular, a firm may benefit more from a partner with many technological resources to the extent the latter is embedded. Also, I tested whether the influence of partners' structural position is better modeled as a nonlinear effect. I found no evidence for any of these alternatives.

\subsection{Discussion and conclusion}

My goal has been to examine how firm innovation varies with two attributes of the partners in its R\&D alliance portfolio. I examined how a firm's innovative output changes with the extent to which (1) it is affiliated with partners that hold a large stock of technological resources and (2) it is affiliated with partners that bridge structural holes among their direct alliance partners. In so doing, I respond to recent calls for a more extensive inquiry of partner attributes as salient scope conditions for the influence of alliance portfolios on firm performance (e.g., Gulati 2007; Lavie 2006, 2007).

At its essence, this chapter is an attempt to answer a question concerning the role of networks in selecting exchange partners for conducting joint R\&D. As network structure is mostly the by-product of substantive technology search efforts, it would seem that it might not matter for outcomes. If indeed it did not, firms could focus on technological resources in selecting alliance partners. Yet, the current findings indicate that networks, particularly the degree to which partners span structural holes, might be highly consequential for firm performance. This is true net of a strong baseline specification that remedies the concerns for unobserved heterogeneity and endogeneity as expressed by Halaby (2004), Mouw (2006), and Munshi (2003), among others.

The evidence regarding partners' technological resources extends previous findings on the linear, positive effect of partners' endowments on firm performance (e.g., Lavie 2007; Stuart 2000) by pointing to decreasing marginal returns of this relation. Partners with excessive amounts of technological resources deteriorate firm innovation. The evidence on the network effects extends previous work by Burt $(2007,2008)$ by showing that firm innovation benefits most from affiliations with well-embedded partners. Al- 
though partners that bridge structural holes may experience information and control benefits, my results indicate that these are unlikely to spill over to the focal firm. Rather, what spills over is the positive effect of partners' embeddedness among their respective direct partners. The occurrence of spillovers is similar to Burt (2008) and Jensen (2008), who both also find evidence that the effects of structural position spill over between adjacent contact portfolios. The results differ from Burt's (2008), however, who shows that the benefits of structural holes tend to spill over, rather than the benefits of embeddedness. Possibly, this is due to the highly uncertain and dynamic nature of the IT industry, in which alliances carry severe risks of opportunism that are best bounded. To the extent a partner firm bridges structural holes, it has the autonomy to act upon its ideas, which in turn deteriorates information spillovers to the focal firm. However, when the partner is embedded, it portrays cooperative behavior, as evidenced by a significant increase in firm patenting rates.

The strong positive impact on firm innovation of partners' embeddedness in their respective portfolios deserves some more attention. Some prior work has found that the trust and establishment of cooperative norms that result from a firm's embeddedness (its lack of structural holes) in its alliance portfolio may have positive effects on firm performance (e.g., Ahuja 2000a; Rowley et al. 2000). What has not been established, however, is that this cooperative spirit can spill over to the portfolio of partners. In the current setting, cooperative attitudes do have positive externalities to surrounding firms. The cooperative habits that emerge in partners' alliance portfolios thus carry further than their immediate surroundings (cf. Adler \& Kwon 2002: 29-30), which also means that a firm's performance depends on more than just its direct partners. Rather, it depends to a nontrivial extent on the partners of its partners.

All in all, the broad implication to be drawn from this study is that partners' advantage can be firm disadvantage. In particular, the interesting tension in the findings is this: despite positive contributions of a firm's technological resources and structural holes to its innovative performance, the technological resources and structural holes of the partners in its R\&D alliance portfolio may decrease it. This empirically corroborates the notion that, as each firm individually experiences pressures to make "unique adaptations to local conditions" (Aldrich \& Ruef 2006: 26), its strategic choices do not necessarily benefit its partners (Hamel 1991; Khanna et al. 1998).

Several directions for further research come to mind that may help us shed further light on the intricate geography of interfirm alliance portfolios. They may also address some of the limitations of this work. First, the structural effect captures a mix of information and control benefits. Delving deeper into the relative importance of these benefits will provide a better handle to identify the micro-processes that underlie the spillover of structural effects. 
Second, I considered the performance impact of resource access and network positioning in one specific setting, the information technology industry. The environmental conditions experienced by IT firms may be similar to firms in an industry like pharmaceuticals, but they are vastly different from medium- and low-tech industries (e.g., Rowley et al. 2000). Also, accessing technological resources may be viewed as especially vital in high tech sectors. Future research should thus explore the implications of my findings for different industries.

Lastly, I considered performance effects in terms of a firm's annual innovative performance. Evidently, network actors "typically pursue multiple purposes simultaneously in intersecting social formations" (Granovetter 2002: 38). Moreover, innovative performance is not always considered an exclusive end in itself (Lavie 2007) and often it is especially related to competitive success in high tech environments (Stuart 2000: 793). Additional work should therefore investigate how resource access and network positions facilitate the realization of a variety of firm-level outcomes, in both horizontal as well as vertical alliance networks.

Apart from the theoretical contributions, this study also speaks to the practice of alliance management. Notwithstanding the dominant importance of a focus on partners' technological endowments, the far-reaching implication arising from the results here is that a firm will benefit from a careful assessment of the R\&D alliance portfolios of its (potential) partners. Although the structure of others' $R \& D$ alliance portfolios is largely a by-product of technology search, it can have important consequences for the focal firm. It is this message that can add an important dimension to the increasingly strategic nature of alliance management. A proactive partner evaluation enables a firm to judge ex ante their general exchange credibility, which increases the prospects for satisfactory alliance performance.

In conclusion, the overall message is that firms face a tension between own interests and those of their alliance partners. The view emerges that the extent to which firms leverage their alliance portfolio should be regarded increasingly as a consequential aspect in sparking innovative performance and, more generally, in generating firm-specific competitive benefits. 



\title{
FOUR
}

\section{Technological Dynamism and the Performance of R\&D Alliances ${ }^{18}$}

\begin{abstract}
Prevailing research claims that equity joint ventures contribute more to interfirm knowledge flows and firm innovative performance than nonequity contractual agreements. This chapter investigates how technological dynamism at the industry level moderates these relationships. I propose that though, on the average, joint ventures outperform contractual agreements, their performance versus contractual agreements declines during periods of rapid and unpredictable technological change. Results of dyadic and firmcentered analyses linking R\&D alliance governance and technological dynamism to interfirm knowledge flows and firm innovative performance support these predictions. Also, supplementary results at the firm level suggest that, over and above affecting innovation rates, maladapted R\&D alliance governance may be consequential commercially, by affecting new product launch.
\end{abstract}

\subsection{Introduction}

R\&D alliances affect interfirm knowledge flows (Gomes-Casseres, Hagedoorn, \& Jaffe 2006; Mowery, Oxley, \& Silverman 1996; Oxley \& Wada 2009) and firms' innovative performance (Baum, Calabrese, \& Silverman 2000; Powell, Koput, Smith-Doerr, \& Owen-Smith 1999; Stuart 2000), reflecting that they provide an important context in which firms' innovative efforts transpire. One part of this work has focused on the performance consequences of the structural governance of R\&D alliances. Specifically, research has found that equity joint ventures frequently outperform nonequity contractual agreements because their administrative and physical structure is more appropriate to bound opportunism (Oxley 1997; Pisano 1989; Pisano, Russo, \& Teece 1988), spark informal coordination among the employees of the partner firms (Kogut 1988b; Teece 1992), and limit the unintended leakage of knowledge unrelated to the venture (Oxley \& Wada 2009).

18. I appreciate the insights and suggestions of John Hagedoorn, Wilko Letterie, J. Muir Macpherson, Marc van Ekert, and Diederik van Liere. Dries Faems and Paul Vlaar provided specific comments and Martin Carree, Bronwyn Hall, and Gerard Pfann shared their econometric expertise. This chapter also benefited from comments at the 2009 Academy of Management Meeting (Chicago, IL) and seminars at Maastricht and RSM Erasmus Universities. 
Though these findings suggest that firms best govern their joint R\&D activities through joint ventures (e.g., Gulati \& Singh 1998; Pisano 1989), other work shows that firms in dynamic environments instead favor contractual agreements to govern their external R\&D (Auster 1992; Hagedoorn, Cloodt, \& van Kranenburg 2005; Kale \& Puranam 2004; Santoro \& McGill 2005; van de Vrande, Vanhaverbeke, \& Duysters 2009). This alternative finding perhaps reflects that firms in dynamic environments experience pressures to remain flexible in order to achieve consistent, reliable performance over time (cf. Haveman 1994: 153). But to date, the performance implications of $R \& D$ alliance governance in dynamic environments have received little attention. Consequently, it remains unresolved if and how industry dynamism alters the performance contribution of joint ventures versus contractual agreements.

In this chapter, I aim to bridge the gap between the nature of R\&D alliance governance in dynamic environments and its empirical performance consequences, both in terms of interfirm knowledge flows and firm innovation. Specifically, I conceptualize firms and their R\&D alliance activities as situated within an industry-level technological environment that changes longitudinally. Using this conception, I exploit performance changes that allied firms experience as they move through periods of increasing and decreasing technological dynamism. Theory suggests that, all else equal, firms focusing on joint ventures outperform those focusing on contractual agreements. Yet, per flexibility arguments, increases in technological dynamism should reduce the strength and perhaps reverse the form of this average effect because joint ventures have stronger inertial, maladaptive features than contractual agreements and would therefore inhibit firms' ability to change. I test these ideas with data on the innovative activities of a sample of firms engaged in IT-related R\&D alliances between 1978 and 1999.

\subsection{R\&D alliances, structural governance, and performance}

The ability to produce innovations is important for firms' prosperity (Chaney, Devinney, \& Winer 1991; Hall, Jaffe, \& Trajtenberg 2005; Pakes 1985) and innovation is therefore endogenous to the organizational choices of any firm looking to stay competitive. Here, I focus on the innovative consequences of firms' organizational choices in the area of R\&D alliancesinterfirm alliances aimed at joint research and development relating to new technologies, products and processes (Hagedoorn 1993). Because they are key conduits for the interfirm transfer of complex technological knowledge (Almeida, Song, \& Grant 2002; Gomes-Casseres et al. 2006; Mowery et al. 1996; Oxley \& Wada 2009; Rosenkopf \& Almeida 2003; Stuart \& Podolny 1999), R\&D alliances should generate significant increases in the innovative performance of partner firms (Baum et al. 2000; Hagedoorn \& Schakenraad 1994; Powell et al. 1999; Stuart 2000). But not all R\&D alliances are equally effective. It is a central tenet of alliance research that variation in the gover- 
nance structure of R\&D alliances greatly affects the magnitude of interfirm knowledge flows and partner firms' innovative performance (GomesCasseres et al. 2006; Mowery et al. 1996; Oxley \& Wada 2009; Pisano et al. 1988).

R\&D alliances are hybrid organizational arrangements variably situated between markets and hierarchies (Oxley 1997), and they can be governed either through nonequity contractual agreements (hereafter: contractual agreements) or, alternatively, through equity joint ventures (hereafter: joint ventures), the latter resembling the governance attributes of internal organization. ${ }^{19}$ Contractual agreements are project- or program-based agreements between independent firms but in joint ventures, the partner firms "share ownership of the assets and derived revenues and, thus, share monitoring and control rights" (Kogut 1988a: 175). The dominant position in the literature is that joint ventures are much more effective toward sparking interfirm knowledge flows and firm innovation than are more arms-length contractual agreements (Mowery et al. 1996; Oxley \& Wada 2009). This is due to at least three interrelated mechanisms. First, as emphasized in transaction cost economics theory, the parent firms owning a joint venture share equity. This economic commitment creates incentives to forego opportunistic behaviors and share technological knowledge (Oxley 1997; Pisano 1989; Williamson 1991).

Second, from a knowledge-based view, the creation of a separate physical entity following the formation of a joint venture leads to the collocation of personnel representing the parent firms, which in turn enables the transfer of fine-grained tacit technological knowledge (Kogut 1988b). This is unlike most contractual agreements, even though joint research pacts sometimes take the form of a temporary research lab where the research personnel of sponsoring firms meets and interacts. As much of the knowledge underlying technological innovations is tacit and context-specific, informal communication channels facilitated by collocation are crucial for the effective transfer of knowledge. Joint ventures provide the organizational context for such informal coordination between the personnel of parent firms (Teece 1992).

Third, the separate legal and physical entities created for a joint venture provide clear boundaries between parent firms and their joint venture (Harrigan 2003 [1985]). This clear boundary and the presence of a joint management board in turn allow for a range of mechanisms geared toward controlling employee conduct, responsibilities, mobility (and, hence, knowledge leakage), and the sharing of administrative and auditing responsibilities (Harrigan 2003 [1985]; Kogut 1988a; Pisano et al. 1988). For example, Oxley

19. I focus on bilateral contractual agreements and equity joint ventures. As "an alliance by definition can never have one side receiving only cash" (Teece 1992: 20), unilateral contracts are beyond the scope of my theory and empirics. 
and Wada (2009) show that a joint venture sparks interfirm knowledge flows related to the venture's operations precisely because its administrative structure curbs leakage of unrelated knowledge.

These arguments have at least two refutable implications. First, from a dyadic perspective, two firms that are connected through one or more joint ventures should generate more dyad-specific knowledge flows than two otherwise identical firms connected through contractual agreements. Second, from a firm perspective, a firm with a higher share of joint ventures in its portfolio of R\&D alliances should experience higher innovation rates than an otherwise identical firm focusing on contractual agreements. Consequently:

Hypothesis 1a: All else equal, dyad-specific knowledge flows increase with the share of joint ventures in an RED alliance dyad. ${ }^{20}$

Hypothesis 1b: All else equal, firm innovative performance increases with the share of joint ventures in a firm's RED alliance portfolio.

These presumptions follow directly from prior literature. Yet, I spell them out as baseline hypotheses because they hide a vital contextual contingency that I aim to address. Note that the hypotheses are silent concerning the industry situatedness of R\&D alliances and the firms maintaining them. However, a number of studies have stressed that coalignment between firm organization and the competitive environment is crucial for firm performance (e.g., Aldrich 2008; Venkatraman \& Prescott 1990), i.e. organizational forms are not equally adapted to all environments. Thus, the effect of organization on performance likely differs over time due to longitudinal changes in firms' industry environment. One industry dimension of particular relevance for understanding the performance effects of $R \& D$ alliance governance-an element of interfirm organization - is an industry's technological dynamism.

\subsection{Technological dynamism, flexibility, and performance}

Firms and their R\&D alliance activities are embedded in a technological environment, defined here as a flow of technological opportunities at the industry level (Aldrich 2008: 122-125; Davis, Eisenhardt, \& Bingham 2009). Technological dynamism represents longitudinal change in such a technological environment. In the spirit of influential work on environmental variability, I conceptualize change as varying simultaneously in both its rate and unpredictability (Cameron, Kim, \& Whetten 1987; Dess \& Beard 1984; Jurko-

20. I pitch my prediction concerning knowledge flows at the level of dyads rather than individual R\&D alliances because I cannot meaningfully attribute knowledge flows (as indexed by patent citations) to individual alliances in case of multiple alliances in a firm-partner dyad. In the empirical analysis, I control for the number of R\&D alliances in a dyad. 
vich 1974; Miles, Snow, \& Pfeffer 1974: 248-249). First, the rate of technological change represents the magnitude of changes in technological opportunity flow, a higher rate indicating a higher pace at which technological knowledge is released in the industry (cf. Eisenhardt 1989). Second, unpredictability of technological change is the extent to which current and prior flows of technological opportunities are dissimilar (Cameron et al. 1987: 230-231; Davis et al. 2009; Dess \& Beard 1984: 56). Higher unpredictability thus makes prior opportunities a poor source of knowledge concerning current ones. Combining these two aspects, technological environments can be anything from slowly changing and highly predictable to rapidly changing and notoriously unpredictable (Jurkovich 1974: 386-391).

Both aspects of technological dynamism are important antecedents of firms' exogenous technological uncertainty (Cameron et al. 1987; Milliken 1987; Pfeffer \& Salancik 1978; Tushman \& Anderson 1986). First, rapid technological change reflects that a technological environment augments quickly, which speeds extant technologies to obsolescence (Hannan \& Freeman 1989: 166) and disproportionally enlarges the opportunity space that firms face (Eisenhardt 1989; Henderson \& Stern 2004), both in terms of technological and partnering opportunities. Second, in an environment with unpredictable technological change, shifts in the nature of technological opportunities are unforeseeable. Then, any current activity necessarily has uncertain future relevance. In broad terms, exogenous technological uncertainty due to rapid and unpredictable change may therefore surface as the increased potential for misfits between firms' commitments to technologies and partnerships on the one hand, and a relentlessly shifting window of opportunities on the other (Bourgeois \& Eisenhardt 1988; Dagnino \& Mariani 2004; Eisenhardt 1989; Ghemawat 1991).

Technological dynamism, altering the opportunity flow in both its magnitude and direction, thus limits the extent to which the substance of firms' cooperative $R \& D$ activities is to remain stable over time. Specifically, if the environment changes, firms that can adapt to the changing flow of technological opportunities should obtain a performance premium vis-à-vis those that are maladaptive (Haveman 1994: 153). The literature undergirding this idea has a broad and diverse lineage (cf. Carlsson 1989; Davis et al. 2009), including structural contingency theory (Burns \& Stalker 1961; Lawrence \& Lorsch 1967), models of product and process flexibility (Athey \& Schmutzler 1995; Thomke 1997), texts on competitive strategy and hypercompetition (d'Aveni 1994; Ghemawat 1991), and real options theory (Folta 1998). A central idea across these works is that having optimized their ability to adapt, firms should have a higher probability of achieving consistent, reliable performance in dynamic environments (Aldrich 2008; Shimizu \& Hitt 2004). On the part of firms situated in such environments, this requires strategic flexibility, forcing them to (1) forego excessive, irreversible commitments that 
would lead to lock-in into suboptimal courses of action and (2) avoid undue administrative and decision-making burdens of hierarchical organization.

\subsubsection{Organizational commitment and technological dynamism}

Depending on the level of technological dynamism in an industry, there may be significant opportunity costs to firms' R\&D alliance investments in money, effort, and time. During periods of slow and predictable change, opportunity costs are low as new opportunities present themselves in a piecewise fashion and in ways that can broadly be foreseen. But during periods of rapid and unpredictable change, opportunity costs are significant. With significant longitudinal shifts in the window of technological opportunities, any investment has uncertain returns as the opportunities toward which commitments have been made may quickly become obsolete and replaced by new ones. In such situations, higher investments therefore undeniably imply larger opportunity costs and, conversely, lower investments imply opportunity benefits (Kale \& Puranam 2004). In short, with severe technological dynamism, firms should commit to their R\&D alliance partners more sparingly as any investments have uncertain future relevance. Here, beyond the question of whether firms make decisions in line with this normative implication, the assertion is that those that do will outperform those that do not.

Contractual agreements and joint ventures differ tremendously in the extent of commitments and concomitant investments in money, effort, and time. Specifically, the literature recognizes that joint ventures demand much higher commitments than contractual agreements (Auster 1992; Hagedoorn 1993; Harrigan 2003 [1985]; Pisano 1989; Pisano et al. 1988). Setting up a joint venture entails the creation of a new, separate firm and, thus, a new legal entity. The legal dimension formalizes the expectations of the partners, how partners' assets are protected, unexpected contingencies are addressed, disputes are settled, and so on. These issues are often highly technical and require that lawyers become involved. Though this is often also true for contractual agreements, joint ventures additionally require that the ownership structure is formalized, and that rights to monitor and control and disclosure arrangements are negotiated (Kogut 1988a). Beyond investments in money, all these negotiation steps take significant effort and time (Pisano et al. 1988). Parallel to shaping the legal dimension of a joint venture, the partner firms also have to build or acquire physical space to house the venture, again demanding significant investments.

Some studies also indicate that joint ventures are often broader in scope than contractual agreements (Hagedoorn 1993; Oxley 1997; Oxley \& Sampson 2004). Whereas contractual R\&D agreements are typically dedicated to R\&D only, joint ventures frequently also entail manufacturing and/or marketing. Apart from taking time to implement an infrastructure facilitating them, these additional functions also signal that joint ventures are likely to have more ambitious agendas than contractual agreements. As such, they 
tend to be a variable amount less focused toward the piecewise development of cutting-edge technologies and more toward the introduction of integrated and marketable solutions. For example, Kaleida, an R\&D joint venture between IBM and Apple formed in October 1991, aimed at creating a standard enabling both PCs and interactive television systems to display multimedia content (Hagedoorn, Carayannis, \& Alexander 2001). Yet, it took Kaleida more than three years to ship the first full version of its new software package and, in the meantime, it was surpassed by competitors that had focused their efforts. ${ }^{21}$ Thus, joint ventures, in their commitment to integral solutions, may distract from the focus necessary in highly dynamic environments (Hagedoorn 1993, 2002; Harrigan 1988: 147-148; Harrigan 2003 [1985]: ch. 10).

Compared to contractual agreements, joint ventures thus take more time to negotiate due to issues regarding shared ownership, monitoring and control, but also due to their scope of operations. Moreover, firms have to invest significantly more money into realizing a joint venture versus a contractual agreement. Clearly, most of these issues are ex ante commitments made by the alliance partners that might carry into the operation of the alliance. The key is that all such pre-alliance processes condition the extent of persistence with an R\&D alliance set up to address a window of opportunities that, due to technological dynamism, may be shutting more quickly than projected at the outset of the negotiations.

Significant investments in money, effort, and time impose formidable constraints on rational decisions concerning the continuance or discontinuance of a joint venture when, close to its commencement, opportunities intended to be seized by the partner firms vanish (Inkpen \& Ross 2001). No rational decision maker would continue a project when exogenous forces rendered it outdated or too risky regarding future payoffs. Nevertheless, investments into $R \& D$ alliance relationships are mostly relation specific and, hence, irrecoverable once the joint project terminates prematurely. An extensive literature on the social-psychological and behavioral aspects of project continuation decisions indicates that such sunk costs-irreversible investments in money, effort, and time-may increase decision makers' commitment to a suboptimal course of action (Arkes \& Blumer 1985; Garland 1990; Parayre 1995; Staw 1981), especially when a significant share of the projected setup costs has already been sunk (Garland \& Conlon 1998; Moon 2001) and when the cause of suboptimalities appears exogenous to the project at hand (Staw \& Ross 1978).

Sunk costs are prone to enter into decisions concerning the future of a given R\&D alliance while, from a rational view, only incremental costs and benefits should (de Bondt \& Makhija 1988). Prior relational commitments

21. Ironically, Apple itself managed to outcompete Kaleida through an earlier launch of QuickTime (Hagedoorn et al. 2001: 845), putting IBM at a severe disadvantage. 
therefore impose large inertial pressures on decision makers (cf. Ghemawat 1991; Hannan \& Freeman 1977: 931; Staw 1981). Staw and Ross (1987) indicate that the tendency for decision makers to consider sunk costs in deciding on the continuance of previously instigated projects results from a range of factors, including project-related, social-psychological, and organizational factors. For example, decision makers may feel that, with little extra investment, poor prospects might be turned into promising ones. Given the highly uncertain nature of $R \& D$, decision makers also need not know about eventual payoffs, providing an incentive to stick to prior commitments. Further, extensive time and effort expended in alliance negotiations creates a psychological contract between the parties, imposing social pressures on decision makers to resist withdrawal (Ring \& van de Ven 1994). Also, premature withdrawal from highly visible initiatives such as joint ventures puts senior managers at risk of losing significant personal political capital and credibility (Harrigan 2003 [1985]; Inkpen \& Ross 2001).

The bottom line is that joint ventures commencing during a period of significant technological dynamism are more likely than contractual agreements the ones that rationally should not have been formed in the first place or, at least, concern R\&D on issues that are past their prime. Because firms invest far less money, effort, and time in agreeing on the terms of a contractual agreement, the goals of any functioning contractual agreement should be far closer aligned with the latest window of technological opportunities. The processes related to commitment thus imply that contractual agreements should be (relatively) more productive than joint ventures during periods of technological dynamism, i.e. they should generate a more intense knowledge exchange between the alliance partners and, ultimately, contribute increasingly to firms producing novel bits of technology.

\subsubsection{Hierarchical organization and technological dynamism}

Not only do contractual agreements and joint ventures differ in terms of commitments by the partner firms, they also differ in terms of their ex post administrative intensity and decision-making patterns. Contractual agreements are agreements between independent firms that often take effect through project teams. They are essentially lateral deals with decentralized management. But joint ventures are quasi-hierarchical entities with a centralized authority, and with the parent firms overlooking their operations and management (Sampson 2004). Hence, joint ventures have a number of bureaucratic features such as vertical communication patterns, loose coupling, reliance on documented rules, and centralized decision making, all of which bring about political constraints inhibiting rapid adaptive action (Ouchi 1979; Williamson 1991).

Further, joint ventures might draw heavy involvement from senior management to the point where important decisions become slow and bureaucratic processes sensitive to corporate politics, even to those in the par- 
ent firms. This is not typically a problem in a stable environment, as the dayto-day operations of a joint venture are in practice the sole responsibility of the venture's management board. With the main goals set and the technological environment stable, the joint venture can autonomously work toward innovations and new products in an efficient way. ${ }^{22}$ But in a dynamic environment where major and rapid adaptations are necessary, the parent firms' management and that of the venture have to coordinate extensively to consider the interests of both partners as well as the joint management board. Despite fostering coordination and control, such triangular communication between parents and their joint venture child brings about bureaucratic costs, most evidently in terms of slowing any major adaptation processes. Consequently, in a technologically dynamic environment, a tension arises between a joint venture's need for autonomy to respond rapidly to a changing knowledge infrastructure on the one hand, and the need for triangular coordination to agree on strategic adaptations on the other (Harrigan 2003 [1985]: 93-94, 254-255, 330-331).

In the presence of technological dynamism, the ex post differences between contractual agreements and joint ventures affect interfirm knowledge flows and firm innovation in one of two ways. First, they complement any effects of firms' prior commitments on adaptation. That is, the administrative inertia in a joint venture will aggravate any misfit between, on the one hand, the venture's goals at commencement and, on the other hand, the technological environment. Second, even if the technological environment in which a joint venture was formed was stable and the venture's goals aligned with the opportunities, technological dynamism during the venture's operations may require adaptations nevertheless. Hence, the need to adapt may surface only after the venture's commencement, generating an increasing burden on joint ventures' effectiveness.

The organizational features of joint ventures are well suited for the efficient execution of R\&D activities toward new technologies, products, and processes of which the key features are known and foreseeable. With relatively clear goals, the internal efficiency of a joint venture's hierarchical organization should work well. Yet, the same organizational features stifle a joint venture's dynamic efficiency necessary to seize new technological opportunities. In short, even though on the average, joint ventures should be more suitable than contractual agreements for governing R\&D alliances, this effect will decline in a dynamic environment. At increasing levels of technological dynamism, an undue emphasis on joint ventures may therefore be more costly than allowing for an arbitrary amount of flexibility to adapt to changes in technological foci, even despite concomitant coordination prob-

22. Even in a stable environment with little exogenous technological uncertainty, R\&D may be difficult due to endogenous technological uncertainty. Here, I assume that the latter is randomly dispersed across firms. 
lems and risks of opportunism (Folta 1998; Sampson 2004). Consequently, I expect that increased technological dynamism leads to a systematic shift in the collaborative determinants of interfirm knowledge flows and firm innovative performance:

Hypothesis 2a. As technological dynamism increases, the positive effect of joint venture governance on dyad-specific knowledge flows declines.

Hypothesis $2 b$. As technological dynamism increases, the positive effect of joint venture governance on firm innovative performance declines.

\subsection{Method}

\subsubsection{Data and sample}

I use data on R\&D alliances, patents and patent citations of firms engaged in IT-related R\&D alliances during 1978-1999. IT includes industry segments for communications, computer hardware and software, computer peripherals, information storage, and semiconductors (patent class subcategories 21-24 and 46 in Hall, Jaffe, \& Trajtenberg 2002). Firms active in the IT industry have both actively patented their innovations (Griliches 1990; Hall et al. 2002) and widely formed R\&D alliances (Hagedoorn 2002), making them suitable subjects for the current analysis. I focus on a single industry to weed out much of the industry heterogeneity, leading to more precise estimates of the hypothesized relations (cf. Carroll \& Hannan 2004: ch. 5).

An important part of the data was matched by researchers from Brandeis and Maastricht Universities for analyses reported in Gomes-Casseres et al. (2006). The alliance data come from CATI (Hagedoorn 2002), the patent data come from the NBER patent data file (Hall et al. 2002), and several control variables come from COMPUSTAT. For this study, data were added from CATI, containing detailed information about R\&D alliances formed since 1960, including partner identities and governance structures; from USPTO, Osiris, Datastream, the SEC and 10K filings, the U.S. Census Bureau, Eurostat, firms' annual reports and numerous press releases.

Two rules combined to determine firms' inclusion in the estimation sample. First, firms needed at least one patent in the IT patent classes in 19781999. Second, firms needed at least one R\&D partnership in IT in 1978-1999. Together, these rules ensured that I could (1) identify key constructs relating to firm innovation and (2) link them to firms' R\&D alliance activities. All results should therefore be interpreted as conditional on firms being engaged in R\&D alliances and IT patenting (as is common if often implicit, see Ahuja 2000a; Stuart 2000). I generated two separate datasets: a dyad-year panel to test my predictions concerning dyad knowledge flows and a firm-year panel to test my predictions concerning firm innovative performance. Of the 3,545 dyad-year records and the 1,275 firm-year records in the sample, I had com- 
plete data for 2,635 dyad-years and 904 firm-years, which formed the basis for the statistical analyses. Both panels were unbalanced, reflecting that firms' proclivity to enter into R\&D alliances increased considerably during 1978-1999.

All dyad and portfolio measures were based on annual adjacency matrices reflecting the $R \& D$ alliances among the sampled firms within a threeyear window. For example, the 1993 matrix contained the alliances for 19911993, the 1994 matrix those for 1992-1994, and so on. Specifying an alliance window is crucial as for many alliances (roughly 90\%), termination dates cannot be traced. Further, including alliances only in the formation year would severely underestimate their impact on the partner firms. The threeyear window was based on the approximately $10 \%$ of alliances with traceable duration, as documented in CATI. Left censoring may be a concern for sample firms that were already in business prior to the sampling window. I therefore included the R\&D alliances formed by the sample firms between 1975 and 1978 in the 1978 adjacency matrix. R\&D alliance activity in IT was negligible before 1975 .

\subsubsection{Dependent variables}

As patent-based measures are currently the most consistent indicators of firms' innovative activities over time (Griliches 1990; Jaffe \& Trajtenberg 2002), I used patent citation data to construct my dependent variables. First, patent citations indicate that existing patents, representing 'prior art', were relevant for a new patent. Hence, they possibly represent the knowledge flows between the citing and cited parties. Survey research indeed indicates that the flow of technological knowledge between actors is significantly larger when they cite each other's patents (Duguet \& MacGarvie 2005; Jaffe, Trajtenberg, \& Fogarty 2000). Jaffe et al. (2000) thus concluded that aggregated citation counts could proxy for the intensity of knowledge flow.

Second, closely related, patent citations represent acts of deference. If a firm's patent portfolio receives many citations, it is thought to be of technological importance (Albert, Avery, Narin, \& McAllister 1991) and valued by others (Dutta \& Weiss 1997; Kalaignanam, Shankar, \& Varadarajan 2007; Stuart 2000). Moreover, citations signal both firms' growth potential (Podolny, Stuart, \& Hannan 1996) as well as the commercial potential of their technological knowledge base, as reflected in their market valuation (Hall et al. 2005).

Nevertheless, at least two criticisms befall the role of patent data as proxy measures. First, patents embody codified knowledge, while much of the technological knowledge in the innovation process is tacit. Clearly, tracing tacit knowledge empirically is difficult, especially in a longitudinal research design. I therefore align with Almeida et al. (2002: 152), Mowery et al. (1996: 83), and Patel and Pavitt (1997: 143) in arguing that codified and tacit knowledge is closely related and complementary. According to this logic, pa- 
tents are valid, if somewhat noisy indicators of unpatented, tacit knowledge. If anything, as the signal-to-noise ratio decreases, associations with the patent-based variables should be biased toward insignificance.

Second, recent work challenges the use of patent citations to proxy flows of technological knowledge (Alcácer \& Gittelman 2006). Part of the citations on a patent may be included to avoid litigation and, more notably, patent examiners might add citations that the inventors were unaware of themselves. But only since 2001 do U.S. patents contain a separate listing of inventor- and examiner-inserted citations. Hence, my sampling period precludes the use of more fine-grained measures excluding examiner-inserted citations. Nonetheless, extant work reveals no reasons to expect that patent examiners pattern their interventions on characteristics of applicants' R\&D alliance activities. Thus, examiner-inserted citations should only add noise to the citation data, without systematically (dis-)favoring particular firms. Again, excessive noise should work against me by deteriorating empirical associations with the governance and dynamism variables.

I counted the number of patent cross-citations in a given dyad $i j$ in year $t+1$ to capture dyad knowledge flows in the dyad models. Though knowledge flows are directional, possibly leading to asymmetries, I am interested only in the effects of two firms' symmetric R\&D tie and its governance on total dyad knowledge flows. In the firm models, I used the count of citations a firm received to its stock of IT patents in year $t+1$ to measure firm innovative performance (cf. Jaffe \& Trajtenberg 2002).

\subsubsection{Governance and dynamism variables}

$R \mathcal{E D}$ alliance governance. I constructed the governance variables using the alliance classification data available in CATI to distinguish two categories: bilateral contractual agreements (CATI categories: Joint Research Pacts and Joint Development Agreements) and equity joint ventures (CATI categories: Joint Ventures and Research Corporations). After labeling each alliance, the variable dyad JV-share represented a dyad's share of joint ventures. At the firm level, the variable portfolio JV-share is the share of joint ventures in a firm's R\&D alliance portfolio. Higher values on these variables indicate higher shares of joint ventures.

Technological dynamism. I constructed time-varying measures of the rate and unpredictability of technological change at the industry level (Cameron, Kim, \& Whetten 1987: 230-231; Dess \& Beard 1984: 56; Jurkovich 1974: 388; Miles, Snow, \& Pfeffer 1974: 248-249). The basis for the measures was formed by data on all assigned patents in the 39 IT patent classes during 1975-1999 (all classes in patent class subcategories 21-24 and 46 in Hall et al. 2002: 452-453), drawn from the Pat63_99 sheet of the NBER patent data file. As is by now widely accepted in the literature, patent data are well suited to proxy aggregate properties of technological change across entities and over longer periods of time (Jaffe \& Trajtenberg 2002). 
Rate of technological change is the difference between the change in the count of assigned patents from $t-1$ to $t$ and the average change between $t-3$ and $t-1$ (Delacroix \& Swaminathan 1991: 646). Algebraically, let $\Delta P(t-i)=P_{t-i}-$ $P_{t-i-1}$, where $P_{t-i}$ denotes the total number of patents assigned in period $t-i$. Then, the rate of technological change is given by:

$$
\Delta P(t)-\left[\frac{\sum_{i=1}^{3} \Delta P(t-i)}{3}\right] .
$$

Positive (negative) values indicate that the current rate of change is larger (smaller) than the average rate of change in the prior three years. Hence, the measure assumes that in any given year, firms perceive and interpret the technological activities in an industry with reference to those in the recent past, rather than as stand-alone givens.

Unpredictability of technological change is the degree to which counts of patents assigned to individual IT patent classes between $t-3$ and $t-1$ were poor predictors of counts in $t$. First, I compiled a dataset with the 39 patent classes as rows and the annual counts of patents assigned in these classes as columns. Second, I regressed the within-class patent volume in $t$ on the within-class average patent volume between $t-3$ and $t-1$. Finally, by analogy with Cameron et al. (1987: 231), I used the yearly adjusted $R^{2}$-values to calculate the coefficient of alienation for year $t$ as $\sqrt{ }\left(1-R_{t}^{2}\right)$. This measure indexed the unpredictability of technological change - the difficulty of predicting subsequent technological opportunities at the industry level with information about the recent past. Figure 4.1 shows the two technological dynamism variables. I tested hypotheses $2 a$ and $2 b$ by interacting the $R \& D$ alliance governance and technological dynamism variables.

Figure 4.1 Rate and unpredictability of technological change in IT, 1978-1999

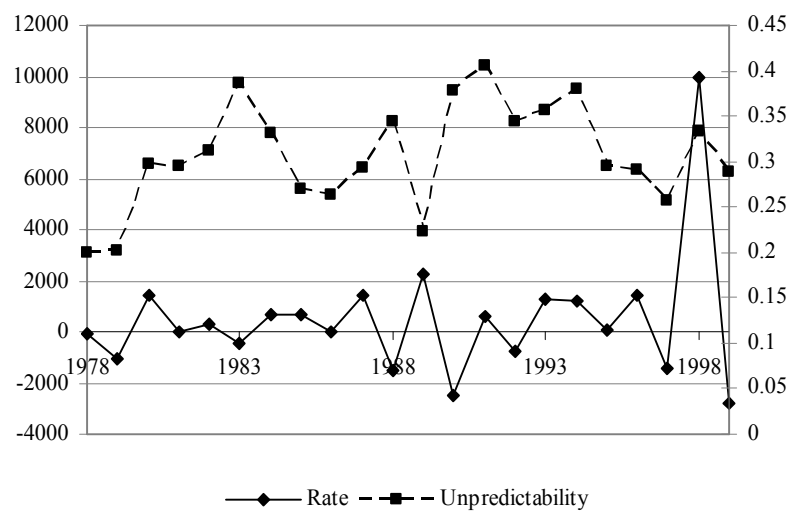




\subsubsection{Control variables}

Dyad models. Dyad RED alliance count is the number of concurrent R\&D alliances in a dyad, included in monotonic and squared form to model nonlinear effects of intense bilateral cooperation. Dyad tenure is the logarithm of partner firms' alliance association in years, included to capture relational evolution (Ring \& van de Ven 1994).

Firm attributes may influence dyad knowledge flows in two distinct ways. First, they index firms' dispositional tendencies potentially affecting any dyad that firms are part of, regardless of who is the alliance partner. Second, partner firms' attributes may combine to determine knowledge flows, engendering interaction effects that are dyad specific. I drew on Lincoln (1984: 49-52) to specify controls for this dual effect. To capture dispositional effects, I included the sum of two firms' scores on the respective controls and to capture the interaction effects, I included the product of two firms' scores. ${ }^{23}$ They are reported as Total [variable name] $(i+j)$ and [Variable name] product (ij), respectively. Variables were included for citable patent stock, measured as the count of patents assigned to the firm to date; age as the log of firms' age in years since incorporation; R\&D portfolio size as the count of R\&D alliances currently maintained; innovative performance as defined above; size as the log of firms' sales, and profitability as the yearly ratio of firms' operating income to sales.

Firm models. Firms manage rapid and uncertain technological change by building portfolios of simultaneous alliances (Powell et al. 1996; Schilling \& Steensma 2001). While extant work controlling portfolio size often includes its linear form only, the logic of carrying capacity would predict that though small portfolios might increasingly come to consist of joint ventures, bounds on management capacity weaken and possibly reverse this association in larger portfolios. ${ }^{24}$ Thus, I included monotonic and squared terms for R\&D portfolio size. To capture a repeat-partnering strategy that firms might use as a stabilizing response to environmental dynamism (Beckman, Haunschild, \& Phillips 2004; Podolny 1994), I included the variable repeat alliances, capturing a firm's share of current partners that it had already cooperated with before the current three-year window.

23. Summing individual firms' main effects is more efficient than including both firms' main effects separately. Results using individual main effects are similar. For parsimony, I therefore present the results based on sum scores.

24. Indeed, at the firm level, partial correlations of portfolio JV-share with the respective monotonic and squared portfolio size terms were $0.31(p<0.001)$ and $-0.21(p<$ $0.001)$. The pooled data indicated that in portfolios containing up to three concurrent R\&D alliances, the association between portfolio size and JV-share was positive and significant, while beyond three concurrent alliances, the association turned to negative significance. Thus, absent a squared portfolio size term, the portfolio JV-share variable of central interest would systematically pick up portfolio size effects. 
Firm age as defined above was included as both a monotonic and squared term (Sørensen \& Stuart 2000). Firm size and profitability were included as defined above. A firm's patent intensity was measured as patents granted divided by sales in a given year. To account for the regional concentration of firms' R\&D alliance activities, I calculated a regional concentration measure as the proportion of a firm's partners in its home region, using firms' headquarters to pinpoint their location. Finally, I controlled for a number of time-varying partner attributes. I created arithmetic means of four indicators to capture the effects of partner characteristics on firm innovation: partners' innovative performance, their logged age, their logged size, and their patent intensity.

\subsubsection{Statistical analysis}

Both dependent variables were overdispersed integers. To estimate the dyad and firm models, I therefore used a Poisson quasi-maximum likelihood estimator with conditional dyad and firm fixed effects, respectively (Wooldridge 1999). ${ }^{25,26}$ This estimator allows for autocorrelated disturbances, and for distributional and conditional heteroskedasticity. ${ }^{27}$

Unobserved heterogeneity. Though panel data models are widely used in the alliance literature to model performance at the firm level (e.g., Powell et al. 1999; Stuart 2000), at the dyad level they are mostly bound to studies of alliance formation. Yet, scholars have long acknowledged relational heterogeneity due to interpersonal synergies (Mohr \& Spekman 1994), tacitness and complexity of a knowledge exchange (Simonin 1999), bilateral interdependencies (Gulati \& Singh 1998), relative absorptive capacity (Lane \& Lubatkin 1998), tendencies toward divergent development (Mowery et al. 1996), and so on. I capture these factors through a dyadic panel analysis, in which fixed effects capture permanent residual dyad heterogeneity, over and above the relational, firm, and period controls..$^{28}$

25. See http://people.bu.edu/tsimcoe/data.html for the STATA code.

26. Both in the dyad and firm models, a Hausman (1978) specification test revealed significant differences between the fixed effects estimates presented here and random effects and pooled estimates (i.e. without unit effects). These differences were due to correlations between unobserved unit effects and the covariate matrices, providing prima facie evidence for persistent unobserved heterogeneity across dyads and firms. I therefore estimated fixed effects models, which generate conservative estimates representing only within-unit variation over time (Greene 2003: 285).

27. Distributional heteroskedasticity in the disturbances is due to overdispersion. Though the conditional negative binomial estimator as specified by Hausman, Hall, and Griliches (1984) is widely used to generate estimates on overdispersed count data, Wooldridge's conditional fixed effects Poisson estimator generates consistent estimates even if the dispersion is mis-specified. It is thus preferable, as it is consistent under weaker assumptions.

28. Per Walker (2008: 5-6), any comparison of inter-actor ties should be predicated on removing "any suggestion that the analysis is confounded by tie heterogeneity." 
Temporal heterogeneity. In all models, period fixed effects controlled supra-unit temporal influences not captured by the technological dynamism variables. Yearly fixed effects would preclude the identification of the dynamism variables, all two of which varied by year but not across units. I therefore used a dummy per two years (10 dummies for 22 years, excluding the 11th one as default two-year period).

Dyad autocorrelation. In the dyad models, multiple dyads have firms in common if firms have alliances with more than one partner simultaneously. This causes dyad autocorrelation, perhaps leading to systematically underestimated standard errors for firm attributes that are constant across multiple dyads of the same firm. As suggested by Lincoln (1984: 56-61), I therefore included a time-varying measure representing the mean of the dependent variable (dyad knowledge flows) for all dyads the partner firms maintained, but excluding the focal dyad. As this variable controls partner firms' baseline proclivities to generate knowledge flows across their dyads, it also captures otherwise uncontrolled firm heterogeneity.

Endogeneity. A final complication across dyad and firm models concerned the possible endogeneity of alliance governance, stemming from decision makers deliberately comparing and choosing governance structures (Hamilton \& Nickerson 2003; Shaver 1998). In the main-effects specifications, a generalized Durbin-Wu-Hausman $\chi^{2}$-test (Davidson \& MacKinnon 1993: 237-240) rejected the null hypothesis that estimates of dyad JV-share were consistent and, by implication, unaffected by endogeneity $\left(\chi^{2}=10.75 ; p<\right.$ $0.005 ; 1$ d.f.), whereas I found no such evidence at the firm level $\left(\chi^{2}=0.31 ; p\right.$ $>0.5 ; 1$ d.f.). ${ }^{29}$ This conclusion held across the contingency specifications. Consequently, I applied a two-stage selectivity model (Heckman 1979) at the dyad level, with governance choice as the first stage and knowledge flows as the second. ${ }^{30}$ To absorb any effects on dyad knowledge flows that would otherwise be spurious treatment effects of dyad governance, I added the inverse Mills ratio constructed from the first-stage binary probit estimates to control for a selection hazard in the second-stage knowledge flow models.

29. See pp. 71-72 for a description of the instruments.

30. I modeled a binary choice in the first stage (i.e. 1 if a dyad contained at least one joint venture, 0 otherwise), even though about $20 \%$ of the dyads contained more than one alliance. Thus, implicit in my modeling approach was the assumption that most of the endogeneity came from the decision of whether to use joint ventures at all. This follows prior work by, among others, Tong, Reuer, and Peng (2008: 1022, footnote 3) and Lavie and Miller (2008: 635), the latter in the context of alliance portfolio internationalization. Ideally, one would estimate the performance model in log-linear form using a GMM estimator with dyad JV-share endogenized (e.g., Crepon \& Duguet 1997). Unfortunately, dyad JV-share is close to binary and therefore ill-behaved in a linear selection equation. However, I did perform the two-stage estimation on the dyads containing only one alliance, revealing identical results. 
Apart from some variables also included in the second-stage knowledge flow models, the probit models included two instruments for dyad governance structure. To be valid, these should be uncorrelated with the secondstage residuals and have a nonzero partial correlation with dyad governance structure (cf. Greene 2003: 75; Heckman 1979; Murray 2006: 112).

First, firms may generally prefer joint ventures over contractual agreements - e.g. due to perceptions of competence in managing them (Levinthal \& March 1993) or due to managerial preferences more broadly (Lewin \& Stephens 1994). Hence, the baseline preferences of the partner firms impose constraints on dyad governance structure - in particular, partner firms' preference for joint ventures across their other R\&D alliances should correlate positively with the focal dyad containing one or more joint ventures. Second, per institutional theory, firms tend to conform to externally constructed conceptions of legitimate organization (DiMaggio \& Powell 1983). With an eye to assuring legitimacy, they are therefore more likely to adopt joint ventures if others in the industry also prefer joint ventures over contractual agreements. By implication, the aggregate industry-level preference for joint ventures should correlate positively with the focal dyad containing one or more joint ventures.

In both cases, there is little conceptual reason to believe that dyad knowledge flows are affected directly. In fact, prevailing research argues that normative organizing principles and conformity pressures affect firms' rate of adopting a certain formal structure or practice, while the adoption itself is the more proximate source of any performance consequences (e.g., Amburgey \& Miner 1992; DiMaggio \& Powell 1983; Hannan \& Freeman 1977; Westphal, Gulati, \& Shortell 1997). Theoretically, therefore, it is plausible that joint venture preferences in partner firms' R\&D alliance portfolios and in the industry will be related to dyad knowledge flows only through their impact on dyad governance structure, making the exclusion of portfolio- and industry-level joint venture activity from the knowledge flow equation valid.

Since the number of instruments (two) exceeds the number required for exact identification (one), I examined the empirical validity of these theoretical suppositions using a generalized Sargan (1958) $X^{2}$-test of over-identifying restrictions. This test probes the null hypothesis that one of two instruments has a zero coefficient (i.e. is exogenous) when the second-stage disturbances are regressed against both instruments, conditional on the validity of the other instrument necessary for exact identification. Below, I report the relevant $X^{2}$ test statistic for the dyad knowledge flow models that include the endogenous governance term.

The first instrument, joint venture preference, represents the mean of the dependent variable (dyad governance structure) for all dyads the partner firms maintained in a given year, but excluding the focal dyad. The second instrument, industry joint ventures, represents the percentage of joint ven- 
tures in all R\&D alliances formed in a given year. ${ }^{31}$

\subsection{Results}

Tables 4.1 and 4.2 present descriptive statistics and correlations for the variables in the dyad and firm analyses. Some correlations are high but sensitivity analyses indicated that none of them affected my central results.

\subsubsection{Dyad models}

First-stage: dyad governance structure. Table 4.3 shows the first-stage robust probit estimates of dyad governance structure. The model shows that the likelihood of at least one joint venture in a dyad increases when two firms have been together for a longer period of time, and when both partner firms are large and innovative, while total firm size decreases the likelihood of joint venture governance.

Interestingly, the dynamism variables have opposite effects. In line with evidence on firms' preference for flexible alliance governance in dynamic environments (e.g., Kale \& Puranam 2004; Santoro \& McGill 2005), the rate of technological change decreases the probability of joint venture governance. However, the effect of the unpredictability of technological change on the probability of joint venture governance is positive. To the extent technological unpredictability increases managerial perceptions of uncertainty (Duncan 1972; Milliken 1987: 136-137), this finding is consistent with transaction cost economics theory. The joint venture preference coefficient indicates that two firms' overall dispositions toward forming joint ventures spill over to the focal dyad. The percentage of joint ventures formed by firms in the industry relates positively to a dyad containing at least one joint venture, converging with the institutionalist notion of mimetism. Thus, the two instruments are significant correlates of dyad governance structure.

Second-stage: dyad knowledge flows. Table 4.4 shows the second-stage models of dyad knowledge flows. The one-year lag specification and the conditional estimation account for the difference in sample size with the first-stage probit models. Across the models, the tests for over-identifying restrictions fail to reject the null hypothesis of exogenous instruments. Coupled with their significance in the first stage, the instruments are thus sufficiently valid for the two-stage estimation I employ (Murray 2006: 112). ${ }^{32}$ Note that models 2-5 improve significantly (beyond $p<0.001$ ) on model 1 .

31. The first instrument takes the same form as the dyad autocorrelation measure in the second stage. Hence, it also addresses dyad autocorrelation in the first stage (Lincoln 1984: 56-61). Further, since it controls partner firms' baseline proclivities to favor joint ventures, it also captures otherwise uncontrolled firm heterogeneity.

32. Note that, beyond reducing omitted variable bias in the second stage, the dyad fixed effects and the relational, firm, and period controls also contributed to increasing the validity of the instruments - by evading the latter's spurious correlations with otherwise omitted variables and, by implication, the second-stage residuals. 
Technological Dynamism and R\&D Alliances

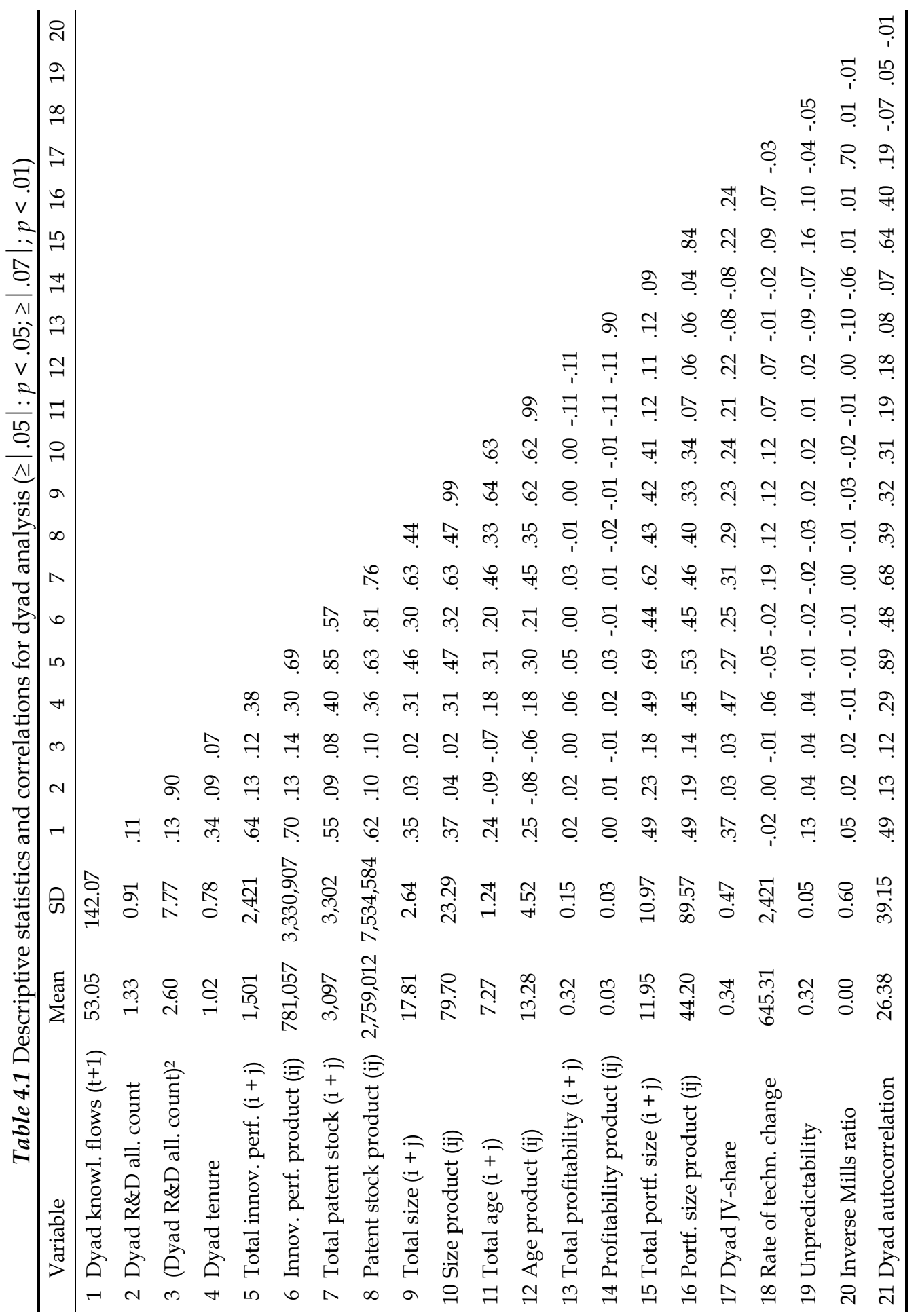




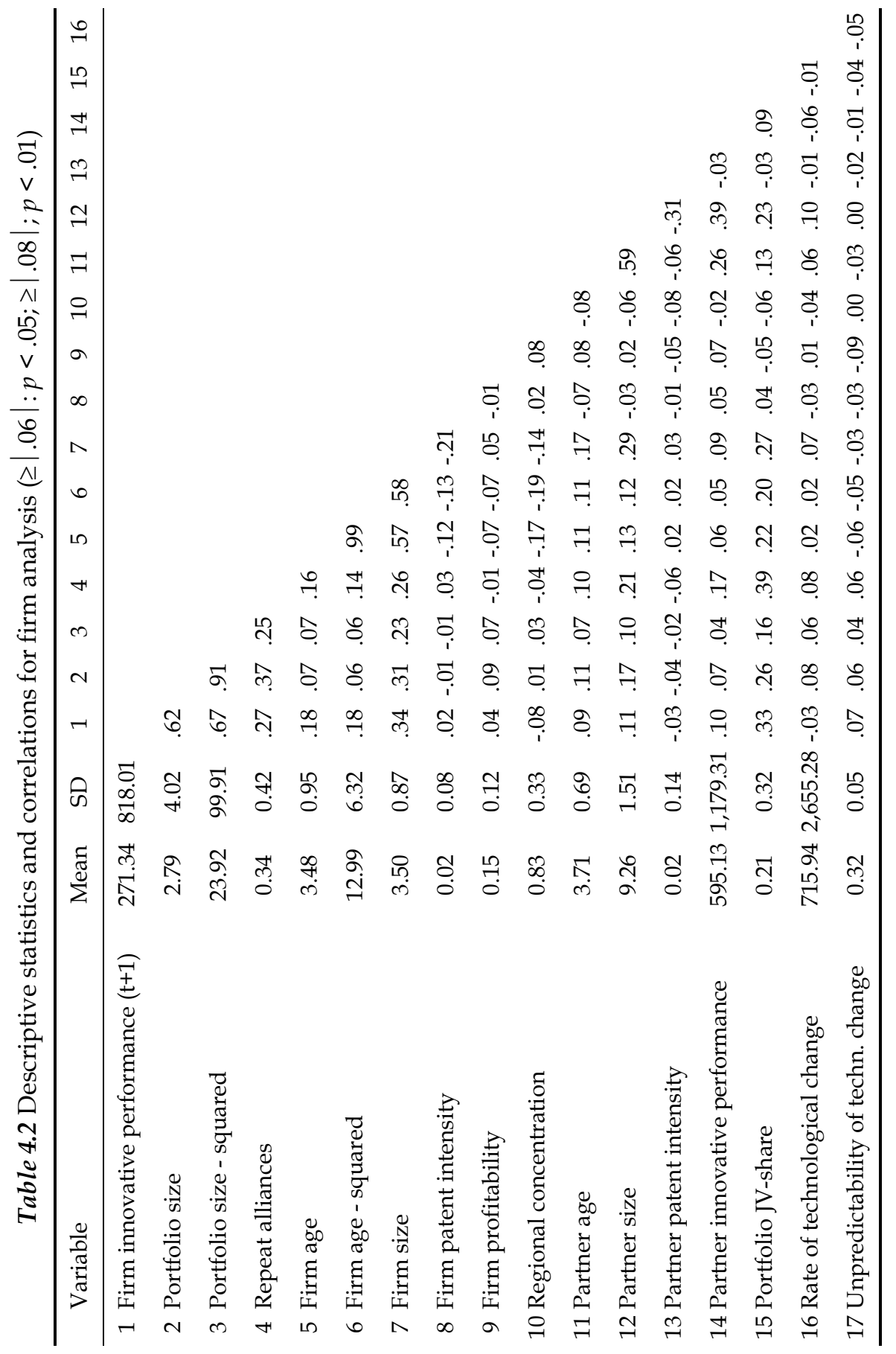


Table 4.3 Robust probit estimates of dyad governance structure ( $1=$ at least one joint venture; $0=$ only contractual agreements)

\begin{tabular}{lc}
\hline Variable & \\
\hline Constant & -1.348 \\
Dyad tenure & $(1.078)$ \\
& $1.049^{* * *}$ \\
Total size $(\mathrm{i}+\mathrm{j})$ & $(.053)$ \\
& $-.286^{* *}$ \\
Size product $(\mathrm{ij})$ & $(.108)$ \\
& $.041^{* *}$ \\
Total innovative performance $(\mathrm{i}+\mathrm{j})\left(\times 10^{3}\right)$ & $(.012)$ \\
& -.009 \\
Innovative performance product $(\mathrm{ij})\left(\times 10^{4}\right)$ & $(.026)$ \\
& $.004^{* * *}$ \\
Rate of technological change $(\times 10)$ & $(.000)$ \\
& $-.001^{* * *}$ \\
Unpredictability of technological change & $(.000)$ \\
Joint venture preference & $3.641^{* *}$ \\
& $(1.289)$ \\
Industry joint ventures & $1.329^{* * *}$ \\
& $(.171)$ \\
\hline Log pseudolikelihood & $3.940^{*}$ \\
Pseudo R-squared & $(1.787)$ \\
\hline
\end{tabular}

Note: ${ }^{*} p<.05 ;{ }^{* *} p<.01 ;{ }^{* * *} p<.001$; period fixed effects included

Based on model 2, higher shares of joint ventures in a dyad increase dyad knowledge flows, supporting hypothesis 1a. Yet, in line with hypothesis 2a, model 5 shows that this effect weakens when technological change is rapid $(\beta=-0.00006, p<0.05)$ and unpredictable $(\beta=-1.661, p<0.05)$. Figures 4.2 and 4.3 show these interaction effects. The plots show that both dimensions of technological dynamism moderate the strength, but not the form, of the relationship between joint venture governance and dyad knowledge flows. Hence, even though joint ventures at the dyad level seem better adapted to technological dynamism, contractual agreements become a feasible alternative when dynamism increases.

\subsubsection{Firm models}

Table 4.5 shows the models of firm innovative performance. Models 2-5 improve significantly (beyond $p<0.001$ ) on model 1 . Based on models $2-5$ and in support of hypothesis $1 \mathrm{~b}$, higher shares of joint ventures in a portfolio increase firm innovative performance. Yet, in line with hypothesis $2 b$, this effect weakens when technological change is rapid $(\beta=-0.0002, p<0.05)$ and unpredictable $(\beta=-3.049, p<0.05)$. Figures 4.4 and 4.5 show these effects. 
Table 4.4 Poisson QML conditional FE panel estimates of dyad knowledge flows

\begin{tabular}{|c|c|c|c|c|c|}
\hline Variable & (1) & (2) & (3) & (4) & (5) \\
\hline \multirow[t]{2}{*}{ Dyad R\&D alliance count } & $-.060 \dagger$ & $\begin{array}{l}.050 \\
\end{array}$ & $-.046^{*}$ & $-.047^{*}$ & $-.046^{*}$ \\
\hline & $(.036)$ & $(.032)$ & $(.021)$ & $(.020)$ & $(.021)$ \\
\hline \multirow[t]{2}{*}{ (Dyad R\&D alliance count) ${ }^{2}$} & .004 & .004 & $.003 \dagger$ & $.003 \dagger$ & $.003 \dagger$ \\
\hline & $(.003)$ & $(.003)$ & $(.002)$ & $(.002)$ & $(.002)$ \\
\hline \multirow[t]{2}{*}{ Dyad tenure } & $-.153^{*}$ & $-.352^{* * *}$ & $-.358^{* * *}$ & $-.345^{* * *}$ & $-.343^{* * *}$ \\
\hline & $(.063)$ & $(.074)$ & $(.075)$ & $(.076)$ & $(.075)$ \\
\hline \multirow[t]{2}{*}{ Total innovative performance $(i+j)$} & $.002 *$ & $.001^{* *}$ & $.002^{* * *}$ & $.002^{* * *}$ & $.002^{* * *}$ \\
\hline & $(.001)$ & $(.001)$ & $(.000)$ & $(.000)$ & $(.000)$ \\
\hline \multirow[t]{2}{*}{ Innovative perf. product $(\mathrm{ij})\left(\times 10^{5}\right)$} & -.002 & -.001 & $-.001^{*}$ & $-.001^{*}$ & $-.001^{*}$ \\
\hline & $(.001)$ & $(.001)$ & $(.001)$ & $(.001)$ & $(.001)$ \\
\hline \multirow[t]{2}{*}{ Total patent stock $(\mathrm{i}+\mathrm{j})(\times 10)$} & $-.004^{* * *}$ & $-.004^{* * *}$ & $-.004^{* * *}$ & $-.004^{* * *}$ & $-.004^{* * *}$ \\
\hline & $(.001)$ & $(.001)$ & $(.001)$ & $(.001)$ & $(.001)$ \\
\hline \multirow[t]{2}{*}{ Patent stock product $(\mathrm{ij})\left(\times 10^{5}\right)$} & .001 & $.002 *$ & $.002^{* *}$ & $.002^{* *}$ & $.002^{* *}$ \\
\hline & $(.001)$ & $(.001)$ & $(.001)$ & $(.001)$ & $(.001)$ \\
\hline \multirow[t]{2}{*}{ Total size $(i+j)$} & -.031 & .012 & -.343 & -.408 & -.397 \\
\hline & $(.529)$ & $(.525)$ & $(.404)$ & (.410) & $(.413)$ \\
\hline \multirow[t]{2}{*}{ Size product (ij) } & .071 & .058 & $.096^{*}$ & $.102 *$ & $.102^{*}$ \\
\hline & $(.054)$ & $(.053)$ & $(.040)$ & $(.041)$ & $(.041)$ \\
\hline \multirow[t]{2}{*}{ Total age $(\mathrm{i}+\mathrm{j})$} & 2.032 & 1.959 & $3.078 \dagger$ & $3.218 \dagger$ & $3.190 \dagger$ \\
\hline & $(2.056)$ & $(1.910)$ & (1.653) & $(1.733)$ & $(1.726)$ \\
\hline \multirow[t]{2}{*}{ Age product (ij) } & -.238 & -.265 & -.421 & -.472 & -.457 \\
\hline & $(.537)$ & $(.470)$ & (.412) & $(.434)$ & $(.430)$ \\
\hline \multirow[t]{2}{*}{ Total profitability $(\mathrm{i}+\mathrm{j})$} & -.972 & -.768 & -.462 & -.480 & -.477 \\
\hline & $(.656)$ & $(.628)$ & $(.498)$ & $(.490)$ & $(.492)$ \\
\hline \multirow[t]{2}{*}{ Profitability product (ij) } & -1.101 & -.040 & -.934 & -.653 & -.758 \\
\hline & $(2.757)$ & $(2.679)$ & $(2.294)$ & $(2.247)$ & $(2.249)$ \\
\hline \multirow[t]{2}{*}{ Total portfolio size $(i+j)$} & $.012^{* *}$ & $.020^{* * *}$ & $-.014^{* *}$ & $-.012^{* *}$ & $-.012^{* *}$ \\
\hline & $(.004)$ & $(.004)$ & $(.004)$ & $(.004)$ & $(.004)$ \\
\hline \multirow[t]{2}{*}{ Portfolio size product $(\mathrm{ij})(\times 10)$} & .000 & $-.004^{*}$ & $.006^{* * *}$ & $.006^{* * *}$ & $.005^{* * *}$ \\
\hline & $(.002)$ & $(.002)$ & $(.002)$ & $(.002)$ & $(.002)$ \\
\hline \multirow[t]{2}{*}{ Dyad JV-share } & & $1.223^{* * *}$ & $1.315^{* * *}$ & $1.858^{* * *}$ & $1.907^{* * *}$ \\
\hline & & $(.190)$ & $(.197)$ & $(.343)$ & $(.340)$ \\
\hline \multirow[t]{2}{*}{ Rate of technological change $(\times 10)$} & & & $.002^{* * *}$ & $.001^{* * *}$ & $.001^{\star * *}$ \\
\hline & & & $(.000)$ & $(.000)$ & $(.000)$ \\
\hline \multirow[t]{2}{*}{ Unpredictability of techn. change } & & & $3.653^{* * *}$ & $4.978^{\star * *}$ & $5.016^{* * *}$ \\
\hline & & & $(.384)$ & $(.852)$ & $(.826)$ \\
\hline \multirow{2}{*}{$\begin{array}{l}\text { Dyad JV-share } \times \\
\text { rate of technological change }\left(\times 10^{2}\right)\end{array}$} & & & $-.006^{*}$ & & $-.006^{*}$ \\
\hline & & & $(.003)$ & & $(.003)$ \\
\hline \multirow[t]{2}{*}{$\begin{array}{l}\text { Dyad JV-share } \times \\
\text { unpredictability of techn. change }\end{array}$} & & & & $-1.631 \dagger$ & $-1.661^{*}$ \\
\hline & & & & $(.860)$ & $(.836)$ \\
\hline \multirow[t]{2}{*}{ Inverse Mills ratio } & & $-.705^{* * *}$ & $-.602^{* * *}$ & $-.608^{* * *}$ & $-.596^{* * *}$ \\
\hline & & $(.095)$ & $(.093)$ & $(.093)$ & $(.092)$ \\
\hline
\end{tabular}


Table 4.4 Continued

\begin{tabular}{lccccc}
\hline Variable & $(1)$ & $(2)$ & $(3)$ & $(4)$ & $(5)$ \\
\hline Dyad autocorrelation & $.004^{*}$ & $.003 \dagger$ & $.004^{* * *}$ & $.004^{* * *}$ & $.004^{* * *}$ \\
& $(.002)$ & $(.001)$ & $(.001)$ & $(.001)$ & $(.001)$ \\
\hline Log likelihood & $-8,839.05$ & $-8,414.50$ & $-6,812.05$ & $-6,812.56$ & $-6,792.33$ \\
$\chi^{2}$-test for over-identifying restric- & n.a. & 1.40 (n.s.) & 1.30 (n.s.) & 1.38 (n.s.) & 1.38 (n.s.) \\
tions (1 d.f.) & & &
\end{tabular}

Note: $\uparrow p<.1 ;{ }^{*} p<.05 ;{ }^{* *} p<.01 ;{ }^{* * *} p<.001$; period fixed effects included

Figure 4.2 Rate of technological change, dyad JV-share, and dyad knowledge flows

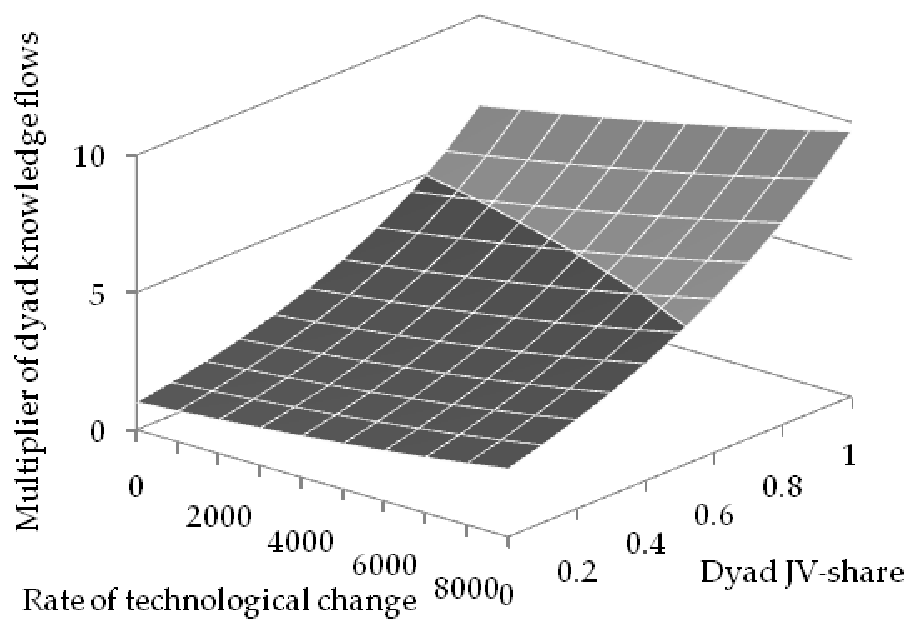

Figure 4.3 Unpredictability of technological change, dyad JV-share, and dyad knowledge flows

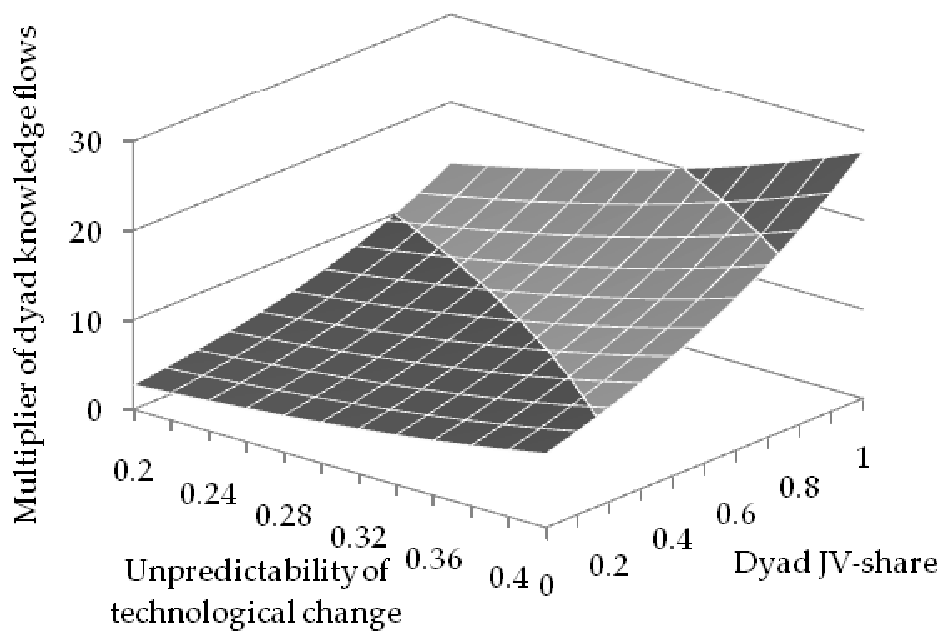


Table 4.5 Poisson QML conditional FE panel estimates of firm innovative performance

\begin{tabular}{|c|c|c|c|c|c|}
\hline Variable & $(1)$ & $(2)$ & (3) & $(4)$ & $(5)$ \\
\hline \multirow[t]{2}{*}{ Portfolio size } & .018 & .019 & .022 & $.029 \dagger$ & .026 \\
\hline & $(.018)$ & $(.019)$ & $(.018)$ & $(.017)$ & $(.018)$ \\
\hline \multirow[t]{2}{*}{$(\text { Portfolio size })^{2}\left(\times 10^{2}\right)$} & -.005 & -.008 & -.021 & -.037 & -.026 \\
\hline & $(.038)$ & $(.040)$ & $(.040)$ & $(.036)$ & $(.038)$ \\
\hline \multirow[t]{2}{*}{ Repeat alliances } & .143 & .064 & .037 & .016 & .045 \\
\hline & $(.119)$ & $(.116)$ & $(.104)$ & $(.112)$ & $(.108)$ \\
\hline \multirow[t]{2}{*}{ Firm age } & .630 & .686 & .713 & .665 & .605 \\
\hline & $(.496)$ & $(.507)$ & $(.468)$ & (.509) & $(.437)$ \\
\hline \multirow[t]{2}{*}{$(\text { Firm age })^{2}$} & -.004 & -.026 & -.039 & -.018 & -.003 \\
\hline & $(.186)$ & $(.186)$ & $(.188)$ & $(.194)$ & $(.177)$ \\
\hline \multirow[t]{2}{*}{ Firm size } & $1.476^{* * *}$ & $1.403^{* * *}$ & $1.404^{* * *}$ & $1.375^{* * *}$ & $1.430^{* * *}$ \\
\hline & $(.207)$ & $(.208)$ & $(.222)$ & $(.226)$ & $(.229)$ \\
\hline \multirow[t]{2}{*}{ Firm patent intensity } & 3.133 & 3.076 & 3.332 & 3.400 & 3.161 \\
\hline & $(2.083)$ & $(2.000)$ & $(2.286)$ & $(2.321)$ & $(1.942)$ \\
\hline \multirow[t]{2}{*}{ Firm profitability } & $-1.245^{*}$ & $-1.116^{*}$ & -.753 & -.754 & -.785 \\
\hline & $(.558)$ & $(.538)$ & $(.704)$ & $(.731)$ & $(.685)$ \\
\hline \multirow[t]{2}{*}{ Regional concentration } & $-.660^{* *}$ & $-.817^{* *}$ & $-.853^{* *}$ & $-.884^{* *}$ & $-.865^{* *}$ \\
\hline & $(.252)$ & $(.248)$ & $(.259)$ & $(.266)$ & $(.261)$ \\
\hline \multirow[t]{2}{*}{ Partner age } & $.120 \dagger$ & $.118 \dagger$ & $.130 \dagger$ & $.135+$ & .112 \\
\hline & $(.070)$ & $(.071)$ & $(.073)$ & $(.076)$ & $(.075)$ \\
\hline \multirow[t]{2}{*}{ Partner size } & -.043 & -.072 & -.079 & -.070 & -.066 \\
\hline & $(.045)$ & $(.054)$ & $(.049)$ & $(.051)$ & $(.049)$ \\
\hline \multirow[t]{2}{*}{ Partner patent intensity } & $-.501 \dagger$ & $-.575^{*}$ & $-.567^{*}$ & $-.532^{*}$ & $-.524^{*}$ \\
\hline & $(.257)$ & $(.271)$ & $(.273)$ & $(.266)$ & $(.266)$ \\
\hline \multirow[t]{2}{*}{ Partner innovative performance $\left(\times 10^{2}\right)$} & .006 & .004 & .004 & .004 & .004 \\
\hline & $(.005)$ & $(.005)$ & $(.004)$ & $(.004)$ & $(.005)$ \\
\hline \multirow[t]{2}{*}{ Portfolio JV-share } & & $.366 \dagger$ & $.460^{*}$ & $1.092^{* *}$ & $1.416^{* *}$ \\
\hline & & $(.198)$ & $(.194)$ & $(.367)$ & $(.470)$ \\
\hline \multirow[t]{2}{*}{ Rate of technological change $(\times 10)$} & & & $.002^{* * *}$ & $.002^{* * *}$ & $.002^{* * *}$ \\
\hline & & & $(.000)$ & $(.000)$ & $(.000)$ \\
\hline \multirow[t]{2}{*}{ Unpredictability of techn. change } & & & $1.600^{* * *}$ & $2.893^{* * *}$ & $3.262^{* * *}$ \\
\hline & & & $(.431)$ & $(.677)$ & $(.820)$ \\
\hline \multirow{2}{*}{$\begin{array}{l}\text { Portfolio JV-share } \times \\
\text { rate of technological change }(\times 10)\end{array}$} & & & $-.001^{*}$ & & $-.002^{*}$ \\
\hline & & & $(.001)$ & & $(.001)$ \\
\hline \multirow[t]{2}{*}{$\begin{array}{l}\text { Portfolio JV-share } \times \\
\text { unpredictability of techn. change }\end{array}$} & & & & $-2.218^{*}$ & $-3.049^{*}$ \\
\hline & & & & $(.997)$ & $(1.309)$ \\
\hline Log likelihood & $-22,867$ & $-22,594$ & $-17,976$ & $-18,103$ & $-17,783$ \\
\hline
\end{tabular}

Note: $\dagger p<.1 ;{ }^{*} p<.05 ;{ }^{* *} p<.01 ;{ }^{* * *} p<.001$; period fixed effects included

Figure 4.4 shows that the rate of technological change moderates both the strength and the form of the relationship between joint venture governance and firm innovative performance. All else equal, at the highest rate of tech- 
nological change observed in the data, a portfolio without joint ventures contributes more than twice as much to a firm's innovative performance than one with only joint ventures. Figure 4.5 shows that the unpredictability of technological change moderates the strength of the relationship between joint venture governance and firm innovative performance, and it is close to moderating its basic form as well.

Figure 4.4 Rate of technological change, portfolio JV-share, and firm innovation

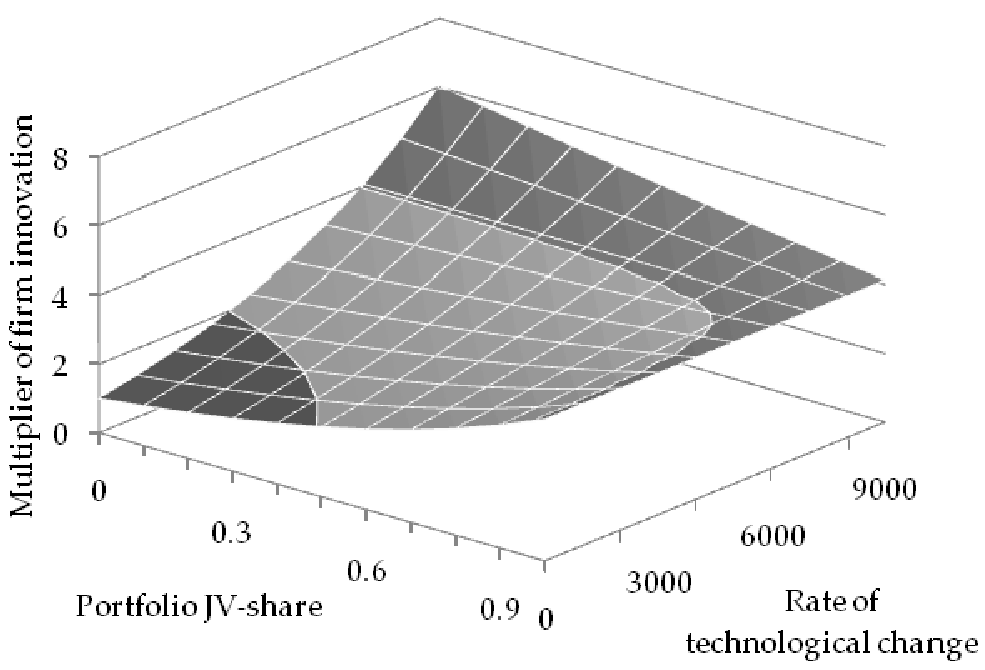

Figure 4.5 Unpredictability of technological change, portfolio JV-share, and firm innovation

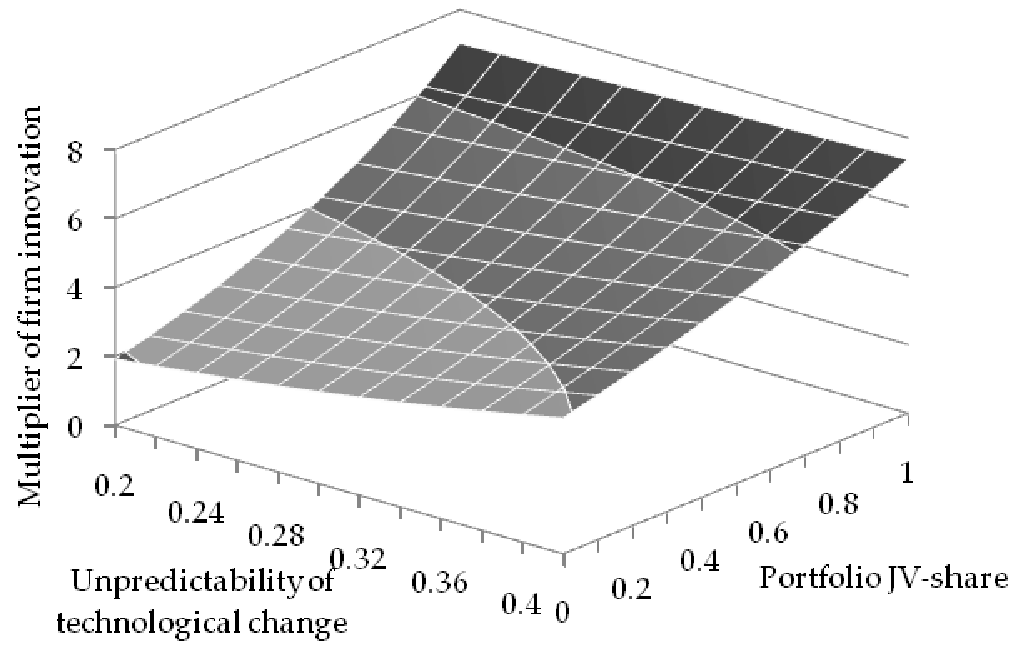




\subsubsection{Supplementary analysis}

The preceding firm-level analysis concerned firms' innovative performance, indexed by the prestige of their inventions. But "as long as they are not carried into practice, inventions are economically irrelevant" (Schumpeter 1934: 88 ). Even though some work does show that inventions might have economic relevance as signals of downstream commercial activity (Hall et al. 2005; Pakes 1985), their commercialization is both more proximate and relevant to firms' market performance (Bayus, Erickson, \& Jacobson 2003; Chaney et al. 1991). Moreover, at the firm level, inventions do not always lead to the launch of new products (Devinney 1993) and, conversely, a lack of inventions need not dampen product launch initiatives (Katila \& Shane 2005). Consequently, if firms can re-adjust downstream product development activities to counterbalance imperfections in the invention process, their commercial prosperity need not drop. This raises a question concerning the downstream significance of more upstream governance decisions. Specifically, beyond affecting technological inventions, does R\&D alliance governance directly impact the rate at which firms subsequently launch new products?

To generate some tentative evidence concerning this question, I used data on new product announcements in computers, networks, office, semiconductors, and telecom during 1997-2000. These were drawn from Dialog's New Product Announcements/Plus (NPA/Plus) online database containing full-text press releases issued directly by firms and their marketing representatives. During 1997-2000, the sampled segments saw 90,769 press releases, of which 19,378 concerned the firms analyzed here. After removing duplicate announcements, simultaneous announcements by multiple firms, and announcements not concerning new products, I matched 8,368 press releases to the sample firms. ${ }^{33}$

I used the aggregate counts to calculate a firm-level measure of the number of new products announced annually during 1997-2000. I regressed this measure on all covariates presented in table 4.5, plus contemporaneous firm innovative performance. Controlling the latter - as index for (more) upstream inventive activity - allowed me to interpret significant effects of the governance-dynamism interactions as suggestive evidence concerning the effect on downstream commercialization rates of maladapted R\&D alliance governance.

Table 4.6 shows negative binomial models for the number of new products a firm launched one, two, and three years down the line. ${ }^{34}$ Though the results for the 1-year lag specifications are insignificant, the results for

33. I dropped press releases concerning new services, product development projects, product modifications and discontinuations, market trends, interfirm collaborative agreements, and firms' strategic intentions, investment plans, and legal actions.

34. Hausman (1978) specification tests revealed no significant differences between negative binomial models and Poisson quasi-maximum likelihood estimates with conditional firm fixed effects. 
Table 4.6 Negative binomial estimates of firms' new product announcements

\begin{tabular}{|c|c|c|c|c|c|c|}
\hline Variable & $(1 ; t+1)$ & $(2 ; t+2)$ & $(3 ; t+3)$ & $(4 ; t+1)$ & $(5 ; t+2)$ & $(6 ; t+3)$ \\
\hline Constant & $\begin{array}{c}16.219^{* *} \\
(5.944)\end{array}$ & $\begin{array}{l}9.393^{*} \\
(3.873)\end{array}$ & $\begin{array}{l}7.085^{*} \\
(3.018)\end{array}$ & $\begin{array}{c}16.966^{* *} \\
(5.932)\end{array}$ & $\begin{array}{l}7.276 \dagger \\
(4.025)\end{array}$ & $\begin{array}{l}8.555^{* \star} \\
(3.232)\end{array}$ \\
\hline Portfolio size & $\begin{array}{l}.288^{* * *} \\
(.062)\end{array}$ & $\begin{array}{l}.200^{* * *} \\
(.051)\end{array}$ & $\begin{array}{l}.170^{* *} \\
(.051)\end{array}$ & $\begin{array}{l}.284^{* * *} \\
(.062)\end{array}$ & $\begin{array}{l}.206^{* * *} \\
(.051)\end{array}$ & $\begin{array}{l}.178^{* *} \\
(.054)\end{array}$ \\
\hline$(\text { Portfolio size })^{2}\left(\times 10^{2}\right)$ & $\begin{array}{l}-.009^{* *} \\
(.003)\end{array}$ & $\begin{array}{l}-.005^{* *} \\
(.002)\end{array}$ & $\begin{array}{l}-.004^{*} \\
(.002)\end{array}$ & $\begin{array}{l}-.009^{* *} \\
(.003)\end{array}$ & $\begin{array}{l}-.006^{* *} \\
(.002)\end{array}$ & $\begin{array}{c}-.005^{* *} \\
(.002)\end{array}$ \\
\hline Repeat alliances & $\begin{array}{l}-.145 \\
(.357)\end{array}$ & $\begin{array}{c}.001 \\
(.383)\end{array}$ & $\begin{array}{l}-.034 \\
(.457)\end{array}$ & $\begin{array}{l}-.148 \\
(.357)\end{array}$ & $\begin{array}{l}.022 \\
(.389)\end{array}$ & $\begin{array}{l}.337 \\
(.472)\end{array}$ \\
\hline Firm age & $\begin{array}{l}-1.020 \\
(1.493)\end{array}$ & $\begin{array}{l}-2.364 \\
(1.475)\end{array}$ & $\begin{array}{l}-1.668 \\
(1.551)\end{array}$ & $\begin{array}{l}-1.027 \\
(1.493)\end{array}$ & $\begin{array}{l}-2.380 \\
(1.503)\end{array}$ & $\begin{array}{l}-1.669 \\
(1.620)\end{array}$ \\
\hline$(\text { Firm age })^{2}$ & $\begin{array}{l}.060 \\
(.208)\end{array}$ & $\begin{array}{l}.216 \\
(.206)\end{array}$ & $\begin{array}{l}.124 \\
(.217)\end{array}$ & $\begin{array}{l}.060 \\
(.208)\end{array}$ & $\begin{array}{c}.223 \\
(.210)\end{array}$ & $\begin{array}{c}.145 \\
(.227)\end{array}$ \\
\hline Firm size & $\begin{array}{l}.707^{* *} \\
(.204)\end{array}$ & $\begin{array}{l}.816^{* * *} \\
(.222)\end{array}$ & $\begin{array}{c}.345 \\
(.246)\end{array}$ & $\begin{array}{l}.712^{* *} \\
(.205)\end{array}$ & $\begin{array}{l}.803^{* * *} \\
(.224)\end{array}$ & $\begin{array}{l}.090 \\
(.254)\end{array}$ \\
\hline Firm patent intensity & $\begin{array}{c}.774 \\
(.655)\end{array}$ & $\begin{array}{c}.750 \\
(.563)\end{array}$ & $\begin{array}{l}-.161 \\
(.561)\end{array}$ & $\begin{array}{l}.755 \\
(.654)\end{array}$ & $\begin{array}{c}.755 \\
(.566)\end{array}$ & $\begin{array}{l}-.286 \\
(.569)\end{array}$ \\
\hline Firm profitability & $\begin{array}{c}2.801^{* * *} \\
(.709)\end{array}$ & $\begin{array}{c}2.197^{* *} \\
(.823)\end{array}$ & $\begin{array}{l}1.965^{*} \\
(.993)\end{array}$ & $\begin{array}{c}2.806^{* * *} \\
(.711)\end{array}$ & $\begin{array}{c}2.114^{* *} \\
(.821)\end{array}$ & $\begin{array}{l}1.619 \\
(.991)\end{array}$ \\
\hline Regional concentration & $\begin{array}{c}-1.236^{* * *} \\
(.310)\end{array}$ & $\begin{array}{l}-.888^{* *} \\
(.305)\end{array}$ & $\begin{array}{l}-.622 \dagger \\
(.362)\end{array}$ & $\begin{array}{c}-1.23^{* * *} \\
(.309)\end{array}$ & $\begin{array}{l}-.948^{* *} \\
(.309)\end{array}$ & $\begin{array}{l}-.701 \dagger \\
(.392)\end{array}$ \\
\hline Partner age & $\begin{array}{c}.238 \\
(.199)\end{array}$ & $\begin{array}{c}.236 \\
(.207)\end{array}$ & $\begin{array}{l}.130 \\
(.262)\end{array}$ & $\begin{array}{c}.237 \\
(.200)\end{array}$ & $\begin{array}{c}.283 \\
(.210)\end{array}$ & $\begin{array}{l}.226 \\
(.274)\end{array}$ \\
\hline Partner size & $\begin{array}{l}-.393^{* *} \\
(.139)\end{array}$ & $\begin{array}{c}-.504^{* * *} \\
(.134)\end{array}$ & $\begin{array}{l}-.216 \\
(.157)\end{array}$ & $\begin{array}{l}-.396^{* *} \\
(.139)\end{array}$ & $\begin{array}{c}-.525^{\star * *} \\
(.136)\end{array}$ & $\begin{array}{l}-.227 \\
(.159)\end{array}$ \\
\hline Partner patent intensity & $\begin{array}{l}-3.537 \\
(3.984)\end{array}$ & $\begin{array}{l}-4.257 \dagger \\
(2.535)\end{array}$ & $\begin{array}{l}-1.248 \\
(1.555)\end{array}$ & $\begin{array}{l}-3.471 \\
(3.986)\end{array}$ & $\begin{array}{l}-4.954 \dagger \\
(2.547)\end{array}$ & $\begin{array}{l}-1.450 \\
(1.601)\end{array}$ \\
\hline Partner innovative perf. $\left(\times 10^{2}\right)$ & $\begin{array}{l}.004^{* * *} \\
(.001)\end{array}$ & $\begin{array}{l}.003^{* * *} \\
(.001)\end{array}$ & $\begin{array}{l}.000 \\
(.000)\end{array}$ & $\begin{array}{l}.004^{* * *} \\
(.001)\end{array}$ & $\begin{array}{c}.000^{* * *} \\
(.000)\end{array}$ & $\begin{array}{l}.001 \\
(.001)\end{array}$ \\
\hline Portfolio JV-share & $\begin{array}{l}1.098 \dagger \\
(.654)\end{array}$ & $\begin{array}{l}.990^{*} \\
(.883)\end{array}$ & $\begin{array}{l}.398 \\
(.657)\end{array}$ & $\begin{array}{l}-1.391 \\
(3.603)\end{array}$ & $\begin{array}{c}12.971^{* *} \\
(4.462)\end{array}$ & $\begin{array}{l}7.155^{*} \\
(2.897)\end{array}$ \\
\hline Rate of techn. change $(\times 10)$ & $\begin{array}{l}.002^{*} \\
(.000)\end{array}$ & $\begin{array}{l}.000 \\
(.001)\end{array}$ & $\begin{array}{l}.003^{*} \\
(.001)\end{array}$ & $\begin{array}{l}.003^{* *} \\
(.001)\end{array}$ & $\begin{array}{l}-.000 \\
(.001)\end{array}$ & $\begin{array}{l}.0001 \\
(.001)\end{array}$ \\
\hline Unpred. of techn. change & $\begin{array}{l}-32.834^{*} \\
(13.904)\end{array}$ & $\begin{array}{l}-4.694 \\
(8.992)\end{array}$ & $\begin{array}{l}-1.591 \\
(3.058)\end{array}$ & $\begin{array}{l}-34.029^{*} \\
(13.956)\end{array}$ & $\begin{array}{c}2.138 \\
(9.394)\end{array}$ & $\begin{array}{c}4.801 \\
(3.740)\end{array}$ \\
\hline $\begin{array}{l}\text { Portfolio JV-share } \times \\
\text { rate of techn. change }\left(\times 10^{2}\right)\end{array}$ & $\begin{array}{l}.007 \\
(.008)\end{array}$ & $\begin{array}{l}-.003^{* *} \\
(.000)\end{array}$ & $\begin{array}{c}-.016^{* * *} \\
(.004)\end{array}$ & & & \\
\hline $\begin{array}{l}\text { Portfolio JV-share } \times \\
\text { unpred. of techn. change }\end{array}$ & & & & $\begin{array}{c}9.341 \\
(12.033)\end{array}$ & $\begin{array}{l}-43.29^{* *} \\
(14.965)\end{array}$ & $\begin{array}{l}-23.02^{*} \\
(9.263)\end{array}$ \\
\hline Firm innovative perf. $(\times 10)$ & $\begin{array}{l}.002^{*} \\
(.001)\end{array}$ & $\begin{array}{l}.002^{*} \\
(.001)\end{array}$ & $\begin{array}{l}.002^{*} \\
(.001)\end{array}$ & $\begin{array}{l}.002^{*} \\
(.001)\end{array}$ & $\begin{array}{l}.003^{*} \\
(.001)\end{array}$ & $\begin{array}{l}.003^{*} \\
(.001)\end{array}$ \\
\hline $\begin{array}{l}\text { Log likelihood } \\
\text { Pseudo R2 } \\
n \text { (firm-years) }\end{array}$ & $\begin{array}{c}-610.52 \\
0.12 \\
162\end{array}$ & $\begin{array}{c}-727.57 \\
0.12 \\
193\end{array}$ & $\begin{array}{c}-740.46 \\
0.07 \\
184\end{array}$ & $\begin{array}{c}-610.61 \\
0.12 \\
162\end{array}$ & $\begin{array}{c}-729.58 \\
0.12 \\
193\end{array}$ & $\begin{array}{c}-746.63 \\
0.07 \\
184\end{array}$ \\
\hline
\end{tabular}

Note: $\uparrow p<.1 ;{ }^{*} p<.05 ;{ }^{* *} p<.01 ;{ }^{* * *} p<.001$; firm-clustered SE's in parentheses 
the 2-year and 3-year lag specifications are fully consistent with my theoretical arguments. The models show that, beyond affecting firms' inventive abilities, inflexible R\&D alliance governance in a technologically dynamic environment has lasting effects on firms' downstream commercial activities.

Figure 4.6 Rate of technological change, portfolio JV-share, and new product launch

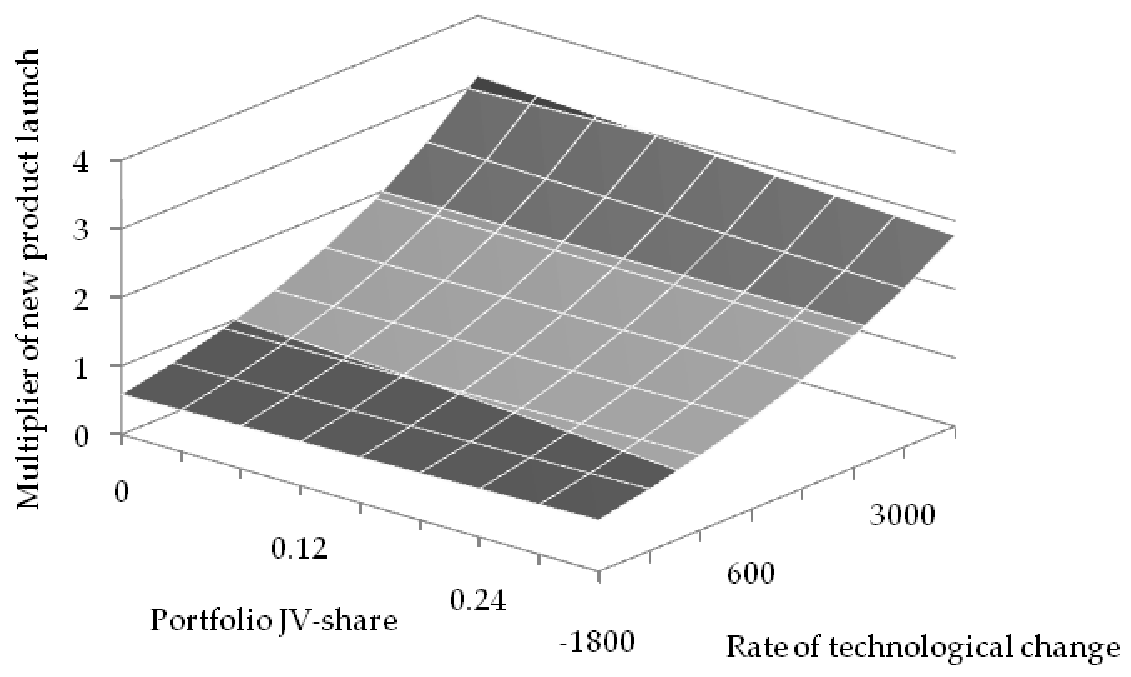

Figure 4.7 Unpredictability of technological change, portfolio JV-share, and new product launch

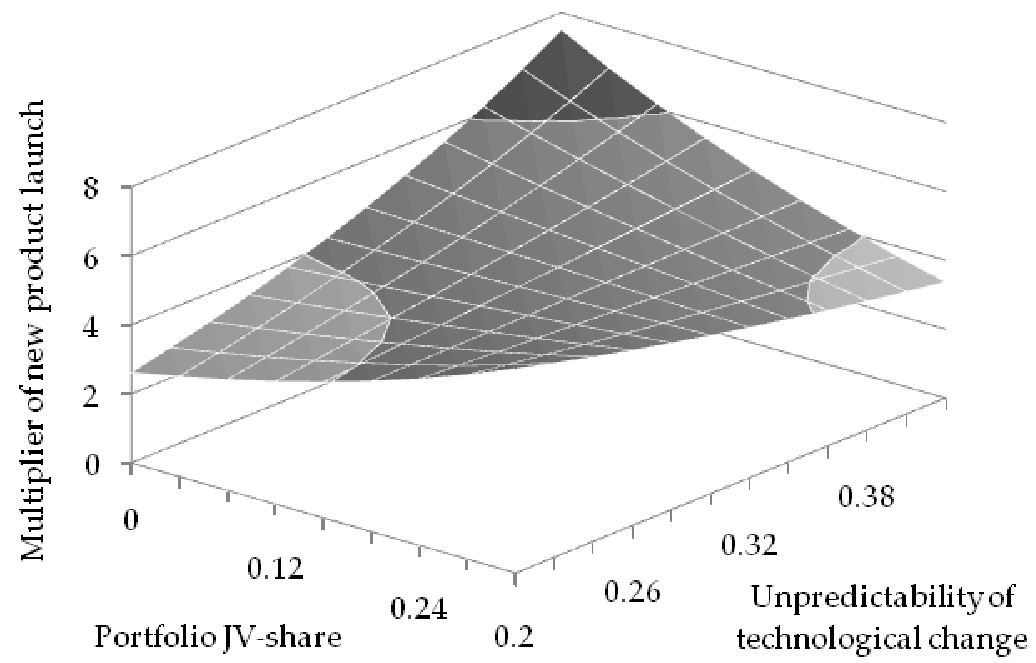


Figures 4.6 and 4.7 show the surface plots implied by the estimates in models 3 and 6 (those of models 2 and 5 are broadly similar). Generally, whereas joint ventures seem better adapted to slow and predictable technological change, contractual agreements commercially outperform joint ventures during regimes of rapid and unpredictable technological change. This is evidenced by the slope reversals of the portfolio governance effects at higher levels of technological dynamism.

I present these results as a footnote to the main analyses for three reasons. First, owing to the limited sample, the period dummies disappear from the models due to collinearity. Other time-varying macro factors might thus confound the dynamism variables. Second, unlike patents, new product announcements in the sampled segments are not externally validated. Third, I have no data concerning mediating processes connecting R\&D alliance governance to future new product announcement rates. For example, upstream decisions may influence managerial risk preferences concerning new product strategy (cf. Greve 2003). Nevertheless, even with these qualifications, I believe the findings illustrate the potential impact of early structural decisions on more nearly commercial innovation activities.

\subsection{Discussion and conclusion}

In this chapter, I hypothesized that technological dynamism in an industry would reduce the supremacy of joint ventures over contractual agreements as drivers of both interfirm knowledge flows as well as partner firms' innovative performance. Dyadic and firm-centered analyses of the innovative activities of firms engaged in IT-related R\&D alliances between 1978 and 1999 provided evidence in support of these predictions. At the dyad level, joint ventures generated more interfirm knowledge flows than contractual agreements, but decreasingly so as the rate and unpredictability of technological change in the industry increased. Similarly, technological dynamism decreased the contribution of joint ventures versus contractual agreements to firm innovative performance. Yet, this firm-centered result differed in one salient respect from the dyadic result. Whereas technological dynamism moderated the strength of the association between dyad governance and knowledge flows, it moderated both the strength and the form of the relation between portfolio governance and firm innovation. Thus, intriguingly, especially in periods of rapid technological change, contractual agreements contributed more to firm innovation than joint ventures.

From a methodological perspective, with controls for characteristics of the firms and their R\&D alliances, for endogenous alliance governance, dyadic autocorrelation, and for unobserved temporal, dyad, and firm heterogeneity, the statistical models would appear to represent conservative tests of the contingent effects of R\&D alliance governance. For example, as portfolio size and firms' emphasis on joint ventures might coincide systematically (see footnote 24), I believe that the inclusion of appropriate portfolio controls 
makes the evidence concerning structural alliance governance all the more credible. Further, by considering only variation within (rather than between) dyads and firms over time, the analyses evade spurious conclusions that would capitalize on unobserved heterogeneity.

Exploratory firm-centered evidence concerning the contingent effect of R\&D alliance governance on new product launch foreshadows that R\&D alliance governance also has downstream implications. Beyond having an instantaneous effect on firms' technologies, maladapted R\&D alliance governance carries deeply into their future product launch activities, in turn affecting firms' commercial prosperity. This finding is consistent with studies that point to path dependencies arising from firms' investment decisions in general (Ghemawat 1991; Hannan \& Freeman 1977) and technology development decisions in particular (Cohen \& Levinthal 1990; Teece, Pisano, \& Shuen 1997). A firm's decisions concerning external R\&D thus determine its current knowledge assets but, at the same time, also constrain its future market-directed behavior. This finding raises questions concerning the intermediate mechanisms leading to firms' apparent lock-in into R\&D trajectories. For example, it is well possible that sunk cost effects also play a role in decision makers' downstream persistence with ill-performing R\&D alliances. More fine-grained process studies are necessary to shed light on the causal mechanisms connecting decisions concerning upstream structural governance to product launch.

Taken together, the findings clearly support the view that more flexible, less institutionalized interfirm arrangements are increasingly beneficial to firms when technological dynamism in the industry increases. At a broad level, this study therefore extends previous findings on how environmental dynamism moderates the relation between organizational flexibility and performance. In a sense, the present findings serve as a replication of important prior findings in adjacent literatures, albeit in a different setting and across different performance measures. For example, the current findings mirror a seemingly disparate study by Sørensen (2002), showing that though strong-culture firms exhibit considerable static efficiencies in stable environments, they lack the dynamic efficiency to cope with major adaptations in the face of environmental volatility. Joint ventures are no different than strong cultures in their emphasis on internal efficiencies at the expense of dynamic efficiencies that would probe the external relevance of internal activities. I believe this example suggests that there is a good deal of room for generalizing specific results on the contingent effects of structure on performance to inform wider organizational literatures. Davis et al. (2009) provide an excellent example of such a bold approach.

Previous studies have shown that firms form interfirm alliances in the face of environmental dynamism (Hagedoorn 2002; Powell et al. 1996; Schilling \& Steensma 2001). Beyond firms forming R\&D alliances, the theory and evidence presented here contribute toward understanding the contingent 
value of realized dyads or portfolios of $R \& D$ alliances. In particular, being connected to other firms need not as such be optimal for firms' performance, as the findings suggest that relational aspects of interfirm connections are crucial for evaluating the efficacy of interorganizational strategy. This chapter thus joins the small but growing literature aimed at understanding causal relations between interfirm governance and performance outcomes (e.g., Leiblein, Reuer, \& Dalsace 2002; Sampson 2004), adding theory and evidence concerning a salient contextual moderator of these relations.

In analyzing both the dyadic and firm-centered sensitivity of R\&D alliance structuring to technological dynamism, I seized the recent suggestion by Mizruchi and Marquis (2006) to choose carefully the level of interorganizational analysis in light of the nature of the dependent variable(s). As knowledge flows are inherently dyadic and innovative output mostly firmcentered, I therefore analyzed panels at both the dyad and firm level. ${ }^{35}$ Substantially, this dual approach allows me to spell out some implications connecting the dyadic and portfolio levels of action. Consider that the dyadic results for knowledge flows are markedly less pronounced than those for innovation at the firm level. This result provides some reassurance for decision makers. After all, though an overall dedication to rigid interorganizational forms such as joint ventures might be highly disadvantageous when the rate of technological change is high and its direction unknown, no one commitment alone needs damage a firm's innovative prospects. Consequently, the reassurance is that there appears to be a margin for mistakes concerning the organizational governance of individual alliances.

Nevertheless, there is an important scope condition to this comforting note. For 'mistakes' concerning individual alliances not to be deleterious at the firm level, they need to be exogenous to a firm's aggregate preferences, deliberate or inadvertent. Unfortunately, this condition does not always hold, as firms do tend to portray systematic organizational predispositions. Consider two examples. First, per institutional theory, firms may mimic the actions of their industry competitors, anxious to diverge from the mainstream amidst uncertainty (DiMaggio \& Powell 1983). Table 4.3 indeed shows that the percentage of joint ventures formed in the industry correlates with any dyad's use of joint ventures. The implication is that, if competitors favor joint ventures over contractual agreements even though the latter are called for, firms might make decisions that are suboptimal. Second, firms may repeatedly engage in certain activities (e.g., joint ventures) due to normative or cognitive constraints on organizational design (Amburgey \& Miner 1992; Levinthal \& March 1993). Table 4.3 shows that firms' broader joint venture preference indeed affects individual dyads. Hence, even though the

35. Mizruchi and Marquis (2006) dealt with problems in which both the endogenous and the exogenous variables were relational and showed that dyadic analyses were most appropriate in such settings. 
context in which a new alliance relationship has to be formally structured might be different than the context of other alliances, earlier choices may be transferred to the focal alliance.

Together, these considerations suggest that there is no shortcut to informed decisions concerning R\&D alliance governance. Firm-level efforts at improving alliance decisions based on accurate information are therefore warranted, in order to make sure that any remaining errors turn out as strictly situational. Alliance departments are welcome vehicles in this context. For example, Kale, Dyer, and Singh (2002) reported evidence indicating that firms with a dedicated alliance function, aimed at strategically coordinating alliance activities, experienced significantly higher alliance success rates than those without one. More broadly, Heimeriks, Duysters, and Vanhaverbeke (2007) showed that there is a performance premium related to firms using alliance learning mechanisms toward integrating and institutionalizing experiences across disparate alliances. Future work could probe the extent to which alliance learning mechanisms contribute to randomizing residual interpretational problems going into alliance governance decisions.

A final subtlety is worth consideration. Both rapid and unpredictable technological change generate penalties on excessive commitment. The findings suggest that the penalty is strongest at the firm level when technological change is rapid (see figure 4.4). With rapid change, the direction of the effect of R\&D alliance governance actually reverses sharply. However, such strong moderation should not distract from the significance of the other results. One should not lose sight of the fact that setting up a joint venture requires much higher financial investments than setting up a contractual agreement. For a joint venture to be truly superior to a contractual agreement, any additional benefits achieved in a joint venture should offset this investment differential. It follows that if contractual agreements and joint ventures contribute roughly equally to a firm's innovative performance at a high level of technological dynamism (as is the case in figure 4.5), firms with contractual agreements will probably still do better financially. Hence, the findings are more in favor of contractual agreements than the plots of knowledge flows and innovation reveal, simply because innovation criteria are not the only ones at play.

These conclusions come with some caveats that perhaps spur further study beyond the earlier suggestions. First, I tested my arguments on interfirm $R \& D$ alliances in a high tech industry where innovation is at the core of firms' competitive prosperity. Even though my theoretical development did not rely on idiosyncrasies of IT-related interfirm partnering, the findings should be tested for their generalizability in different, perhaps lower tech settings. Such tests might also reveal if and how decisions makers attend to multiple performance criteria in deciding on $R \& D$ alliance governance. Second, measuring firm innovation and especially technological knowledge flows using patent citations has its shortcomings. Despite recent (2001 on- 
wards) changes enabling the isolation of examiner-added citations, some degree of noise to the information caught in patent citations will remain. Alternative measures with less noise are sparse, yet may be found outside the realm of patents. For science-based industries such as IT, a combination of patent citations and bibliometric research on joint publications and scientific citations could perhaps reveal additional insights into the technological knowledge flows between firms.

Finally, I worked from the assumption that macro-level technological dynamism occurred at the same rate for all firms. Yet, it is plausible that if firms develop heterogeneous capabilities over time, they should be affected stronger by dynamism concerning the technological domains they are engaged in. Though I believe that my basic approach should have generated conservative results, there is much room for additional research to examine the implications of firms' technological heterogeneity for the moderating effects of industry-wide versus niche-specific dynamism.

In sum, this chapter extends prior work by adding technological dynamism as a key moderator of the relations between R\&D alliance governance and interfirm knowledge flows and firms' innovative performance. Systematic evidence on these relations is important toward interpreting $R \& D$ alliance governance as an element of firms' adaptive repertoire, in turn causing performance heterogeneity in shifting industry environments. 



\section{FIVE}

\section{Conclusions}

\subsection{Introduction}

This dissertation has asked how R\&D alliances affect the interfirm flow of technological knowledge and firms' innovative performance. An answer to this broad question is relevant for spelling out the success factors of external R\&D strategy more fully, and for generating advice concerning the dimensions that firms should attend to in selecting their R\&D alliance partners.

Toward answering the overall research question, I developed three empirical studies answering sub research questions taking issue with a variety of dimensions of potential importance to the performance potential of R\&D alliances. In broad terms, the three studies reported here addressed R\&D alliance performance from three distinct yet interrelated perspectives: I invoked a portfolio view of $R \& D$ alliances in chapter 2 , a network view in chapter 3 , and a relational view in chapter 4 . As such, this dissertation mirrors recent contributions to the alliance and network literatures that point at the importance of multiple levels of analysis for understanding fully the effects of alliances on firm behavior and outcomes (e.g., Auster 1990; Hagedoorn 2006; Hagedoorn \& Frankort 2008; Mizruchi \& Marquis 2006; Simsek, Lubatkin, \& Floyd 2003). In particular, firms would seem to have to attend to relational, essentially dyadic aspects of their alliances, such as structural governance (chapter 4); to the portfolio of alliances (chapters 2, 3 and 4); and to the network of firms beyond firms' own alliance partners (chapter 3). Further, convergent with classic discussions in the literature on organizationenvironment linkages (e.g., Aldrich 2008; Miles et al. 1974), firms' embeddedness in a broader industry environment adds another layer to the range of factors of importance to decisions concerning external technology strategy (chapter 4).

Though the relational aspects of alliances have received a fair bit of attention in the literature, the portfolio and network views are relatively novel to the setting of $R \& D$ alliances. Indicative of this novelty may be that the core contributions used as building blocks in chapters 2 and 3 originate from the internal R\&D literature (e.g., Nelson 1961) and the broader, recent network literature (e.g., Burt 2007; 2008). Conversely, the relational aspects of R\&D alliances have received quite some attention (e.g., Gomes-Casseres et al. 2006; Mowery et al. 1996; Sampson 2007), which is probably due to the transaction cost economics heritage of the alliance field more broadly, in which the level of analysis is the transaction (i.e. the individual alliance).

The three studies share a common emphasis on R\&D alliances as access relationships that enable firms to extend their technological horizons beyond internal search. As such, R\&D alliances are viewed as conduits for the trans- 
fer of, at least (that is, with noise or among other things), technological knowledge related to the development of technological innovations. The validity of this conceptualization in turn hinges on identifying empirically such flows of technological knowledge and, eventually, effects on firm innovation. Therefore, all three chapters set out to identify such empirical associations. Chapter 2 focused on alliance effects on the inward flow of technological knowledge, chapter 3 focused on alliance effects on firm innovation, and chapter 4 addressed both, by studying both dyadic and portfolio effects of R\&D alliances.

In this concluding chapter, I first sum up the major findings of the three studies. Second, I spell out some implications of this dissertation for theory, method, and practice. Third, I devote some attention to the limitations of the analyses and I close with suggestions for further research.

\subsection{Major findings}

\subsubsection{Study 1}

The first sub research question is this:

How do compositional features of firms' $R \mathcal{E} D$ alliance portfolios influence the rate of technological knowledge flowing into these firms?

Chapter 2 developed theory to address this question. As a natural baseline, the chapter established that a portfolio of R\&D alliances might increasingly benefit firms if their portfolio grows larger. Although the analyses provide some support for this presumption, the findings illuminate that the focus of the portfolio, in terms of research or development, and the nature of the partners both are much more important for sparking inward flows of technological knowledge from alliance partners.

Convergent with claims made by Nelson (1961) in his classic account of parallel R\&D efforts, the results indicate that inward flows of technological knowledge are especially pronounced if firms engage in a portfolio of R\&D alliances that focus on early-stage basic and applied research rather than development. Arguably, endogenous uncertainty is highest during early-stage exploration (Roberts \& Weitzman 1981) and, therefore, most effectively countered during this stage through a number of parallel alliances. The results back this presumption, providing novel evidence on the hedging, information-gathering role of $\mathrm{R} \& \mathrm{D}$ alliances. To my knowledge, this research is the first to replicate portfolio suggestions by Nelson (1961) and Abernathy and Rosenbloom (1969) at the interfirm level of analysis.

Results further indicated that firms have to pay attention to the types of partners, in terms of novel or repeat ones, they collaborate with. Maintaining a portfolio full of repeat partners may benefit firms to some extent, as repeat interactions allow for information-sharing routines to develop (e.g., Dyer \& 
Singh 1998; Zollo et al. 2002). Yet, repeat partnerships are subject to decreasing marginal returns (cf. Gulati 1995a; Hagedoorn \& Frankort 2008), which means that possibilities for novel information flows dry up over time. Conversely, maintaining a portfolio full of novel partners may benefit firms as novel partners provide the focal firm with more novel information than repeat partners. Yet, novel partners represent the potential for large exchange hazards, most notably in terms of them behaving opportunistically. In short, I expected and found that a portfolio of R\&D alliances mixing recurrent and novel partners contributes most to inward flows of technological knowledge.

Broadly speaking, therefore, compositional features of $R \& D$ alliance portfolios influence the rate of technological knowledge flowing into firms (1) through the interaction of the number and research focus of these alliances and (2) through the balance of recurrent and novel partners in the portfolio.

\subsubsection{Study 2}

The second sub research question is this:

Does partners' position in the RED alliance network influence firm innovation net of the effects of partners' technological resources on firm innovation?

Chapter 3 addressed this question by juxtaposing the effect of partners' technological resources on firm innovation with that of partners' network positioning, in particular them bridging structural holes among their own alliance partners. In line with Stuart (2000), I start by observing that resource profiles are important indicators of firms' value potential as alliance partners. As such, resource-rich partners should benefit a firm, particularly by increasing its innovation rate. Extending this observation, I argue and find that this positive effect likely has decreasing marginal returns.

So far, absent from this line of reasoning is the consideration of the network of interfirm alliances spun as a by-product of firms' technology search initiatives. A fair body of work has addressed the effects of this network at the firm level, yet my substantive interest was in the network surrounding a firm's partners and its effect on firm innovation (e.g., Burt 2007, 2008; Jensen 2008). Since network structure is the by-product of technology search, a natural baseline prediction would be (1) that networks do not matter as such or (2) that networks do matter, yet merely as mediators between decisions and capabilities underlying firms' historical technological activities and outcomes. In the former case, the effect of the network surrounding alliance partners would be insignificant in a model of firm innovation. In the latter case, the network effect results from imperfectly controlled technology histories of the firm and its partners.

But strikingly, the results in chapter 3 revealed that, net of linear and squared terms for partners' technological resources, stringent occurrence 
dependence terms taking issue with both time-variant unobserved heterogeneity and network endogeneity, and firm and period fixed effects, partners' network positioning matters for firm innovation. In particular, though firms benefit from alliances with otherwise disconnected others, they innovate less if their partners also have alliances with otherwise disconnected others - if they also 'span structural holes' among their R\&D alliance partners.

In short, networks, in particular the structural holes surrounding a firm's alliance partners, do affect firm innovation beyond the substantive effects of technological resources that tend to spill over between allied firms.

\subsubsection{Study 3}

The third and last sub research question is this:

How does technological dynamism at the industry level moderate the relation between RED alliance governance and dimensions of firm innovation?

Chapter 4 developed theory to answer this question. First, I formulated a baseline expectation concerning the effect of the structural governance of R\&D alliances on interfirm knowledge flows and firm innovation. Drawing on extant work, I suggested that, on the average, joint ventures should outperform nonequity contractual agreements because their administrative and physical structure is more appropriate to bound opportunism (Oxley 1997; Pisano 1989; Pisano et al. 1988), spark informal coordination among the employees of the partner firms (Kogut 1988b; Teece 1992), and limit the unintended leakage of knowledge unrelated to the venture (Oxley \& Wada 2009). The results indeed indicated that, all else equal, firms focusing their alliance portfolios on joint ventures innovated more than those focusing their portfolios on contractual agreements. Similarly, at the dyadic level, two firms organizing their joint alliances as joint ventures shared significantly more technological knowledge than those organizing them as contractual agreements. Note that these results broadly converge with the ones as identified by Gomes-Casseres et al. (2006), Mowery et al. (1996), and Oxley and Wada (2009).

Yet, conceptualizing R\&D alliances as situated within an industry's technological environment adds nuance to this average effect. In particular, I argued that a technological environment represents a flow of technological opportunities that changes over time, both in its magnitude and direction. The larger the flow of opportunities and the higher the unpredictability of these opportunities, the more it should pay to refrain from making irreversible investments such as those in joint ventures. In short, with severe technological dynamism at the industry level, flexibility is called for. This in turn implies that more flexible contractual agreements should gain in importance for performance during periods of relentless technological dynamism. The 
results back this presumption. At the dyad level, knowledge flows in joint ventures drop during periods of rapid and unpredictable technological change, and so does firm innovation for firms focusing their R\&D alliance portfolios on joint ventures.

In broad terms, technological dynamism at the industry level therefore moderates the relation between R\&D alliance governance and dimensions of firm innovation by generating a penalty on irreversible investments in money, effort, and time necessary to initiate joint ventures, and on excessive rigidities characterizing the operations of joint ventures.

\subsection{Implications}

\subsubsection{Theoretical implications}

The studies in this dissertation address a number of issues that I believe are of theoretical importance to the literature. First, recent contributions by $\mathrm{Gu}$ lati $(2007)$ and Lavie $(2006,2007)$ have called for more extensive attention to the portfolio aspects of interfirm alliance networks. In chapter 2, I worked toward addressing this call, in particular in the context of knowledge flows in alliance portfolios. Though a number of studies have addressed the portfolio effects on firm innovation and others have addressed dyadic alliance effects on knowledge flows, there seems to be room for joining a portfolio view with the study of knowledge flows. Chapter 2 did exactly this. Alliances in a portfolio might be interdependent in such a way that the results of dyad-level analyses cannot be transferred (if at all they can be studied) easily to the portfolio level. The results I presented in chapter 2 indicated that, indeed, there would seem to be portfolio-level effects on alliancerelated knowledge flows.

Second, research on networks as applied in the strategy literature increasingly takes issue with questions of relevance, in particular the relevance of networks per se for explaining outcomes (e.g., Baum \& Rowley 2008; Borgatti \& Foster 2003; Salancik 1995; Stuart 2007) beyond other resources internal to firms. I add to the literature by taking issue with the relevance of network effects in the presence of substantial resource affects in the technological domain. In particular, I contribute empirical results juxtaposing the effects of technological resources with those of networks, showing that both have explanatory power in conservative models of firm innovation. The theory implication is this: if indeed networks have effects net of other resources, here technological resources, there is value in exploring more fully the mechanisms (other than the spillover of technological knowledge) explaining the additive significance of exogenous resource and network effects. Prior findings on the effects of network structure on outcomes at the firm level would thus indeed seem to present a valid, if perhaps somewhat overstated, base from which to theorize on the causal network mechanisms at work. 
Third, chapter 3 uncovered that there is value, in innovation terms, in associations with well-embedded partners. This result contrasts Burt (2007, 2008) who indicated that there may in fact be value in associations with others that span structural holes in their networks. The logic would be that the benefits accruing to actors spanning structural holes would in part spill over to adjacent others. I did not find such an effect. Rather, I found that there was a penalty connected to being allied with firms spanning structural holes in the R\&D alliance networks. In broad terms, these contrasting results are suggestive of contingency factors that determine the effects of 'secondhand' brokerage. For example, it may be that the extent of competition among the actors in the network has implications for the degree to which they are prepared to share some of their network-related benefits. I believe there is room for further research identifying and testing the contingent value of secondhand network connections.

Lastly, chapter 4 joined the classic interest in organizational environments with the efficacy of R\&D alliance strategy. In particular, there has been a curious tension between performance studies indicating that joint ventures are the most effective means of sharing knowledge and, by implication, increasing firm innovation (e.g., Gomes-Casseres et al. 2006; Mowery et al. 1996), and alliance formation studies showing that firms in dynamic environments have tended to form contractual agreements instead (e.g., Hagedoorn et al. 2005; van de Vrande et al. 2009). The implication of this tension would be that, apparently, there is a performance premium related to less hierarchical organization in environments that augment quickly and in unforeseeable ways. The results established just that. This result provides credibility for early suggestions by Harrigan (2003 [1985]) and Hagedoorn (1993) that, contrary to popular belief at the time, interfirm R\&D had actually been organized by contracts rather than joint ventures in the most dynamic sectors in industry.

\subsubsection{Methodological implications}

Beyond contributing to theory, the studies presented in this dissertation also have some methodological implications. First, chapter 2 introduced an empirical distinction between R\&D alliances focusing on early-stage basic and applied research on the one hand, and those focusing on development on the other. Apart from the distinction between preclinical-trial and later-stage alliances in the biopharmaceutical industry (e.g., Zhang et al. 2007), such a distinction has never been made in large-scale empirical work in sectors like IT, where the events separating research from development are less straightforward. Substantially, separating research- from developmentoriented R\&D alliances has helped me substantiate claims by Nelson (1961) and Abernathy and Rosenbloom (1969) that parallel investments (here: parallel alliances) have more informational value when these investments concern early-stage research rather than downstream development. Further ap- 
plications in different sectors would be necessary to investigate the universality of this finding in an alliance context. At any rate, the application here indicates that there is promise to looking deeper into the specific types of alliances that firms use, beyond how such alliances are governed.

Second, chapter 4 simultaneously studied the contingent value of joint ventures for knowledge flows at the dyad level and firm innovation at the firm level. The results indicated that the dyad findings were much weaker than the firm findings. Beyond the substantive meaning of this finding, the methodological implication is that there is value in multilevel approaches to the extent that they help a researcher establish a more nuanced look at the size of the causal effects at hand. In the application of chapter 4, for example, it turned out that misalignment of alliance governance with dimensions of the firm's technological environment was rather detrimental at the alliance portfolio level, while it was not at all such big of an issue at the dyad level. Suppose I had studied the dyad level only. I would have concluded that misalignment slightly affected interfirm knowledge flows but not a great deal and, hence, one need in fact not worry about it. I would simply not know that this is not true at the firm level. In short, a multilevel perspective has merit as it enriches the set of conclusions one can draw concerning causal relations and, more pressingly, their substantive effects (Shaver 2008).

Third, some researchers have recently expressed their hopes that more attention be paid to bolstering causal relationships when studying the consequences of organizational design choices such as those relating to network structure and alliances (e.g., Durlauf 2002; Halaby 2004; Mouw 2006; Reagans et al. 2007; Stuart 2007). Substantially, this broader call concerns two dimensions. One, we have to be careful in building on prior studies to generate credible baselines net of which we identify hypothesized relations. This should minimize concerns of uncontrolled or unobserved heterogeneity and, in more general terms, spuriousness.

Two, we have to address sufficiently the fact that many design decisions (e.g., the structural governance of $R \& D$ alliances) are part of an endogenous system of strategic decisions. In this dissertation, I took issue with these two broad categories of issues in a variety of ways. For example, in chapter 3, I modeled several endogenous occurrence dependence variables to filter out the indirect effects that firms' prior achievements might have on future ones, through affecting network structure (and, thus, boosting the effect size of network structure). As another example, I controlled for firms' tendency to engage in repeat partnerships when investigating the link between alliance governance and firm innovation in chapter 4. Gulati (1995) shows that repeat partnerships tend to be contractual agreements rather than joint ventures. By implication, absent a control variable for repeat partnerships, the governance variable might therefore capture the effects of repeat partnering to a certain extent. In short, the studies presented in this dissertation add to prior 
work by showing that, even with stricter models than typically applied in the literature, alliance and network effects still turn up significant.

\subsubsection{Managerial implications}

The performance effects of $R \& D$ alliances clearly depend on a number of dimensions at the relational, portfolio, and network levels of analysis. Managers thus require an understanding, or at a minimum awareness, of these levels in order to make decisions concerning the alliance partners to turn to and the alliance architecture to put into place. The results of the empirical analyses in this dissertation provide some guidance for managers, in terms of some relevant alliance dimensions to attend to in order to attract more technological knowledge and increase firm innovation.

First, firms stand to benefit a great deal if they perform their external research activities in portfolios of parallel partnerships (chapter 2). This finding indicates a key challenge for managers faced with the design of cooperative $R \& D$ strategies, because parts of the innovation inputs - here, joint research and concurrent, parallel alliances - have a strong contingent value regarding knowledge assimilation. It is important for such managers to develop an understanding of this counter-intuitive strategy aimed at improving prospects for future performance by investing in seemingly redundant information-gathering conduits in the present. Further, productive portfolios best mix recurrent partners with novel ones - the former which offer familiarity and the latter which provide novel perspectives in an inherently unstable environment like IT.

Beyond looking at R\&D alliances in the framework of an external portfolio investment strategy, the results suggest that managers would do well in considering the network embeddedness of their (potential) alliance partners, over and above considering their resource profiles. Chapter 3 reveals that firms benefit significantly if their alliance partners are well embedded, rather than structurally autonomous, in their own networks. Hence, establishing such embeddedness (i.e. are partners embedded?) would seem to be an important challenge for alliance management. Needless to say, alliance departments are welcome vehicles in this respect.

A final set of managerial implications concerns the alignment of alliance organization with the competitive environment. First, decision makers have to be aware of the rate and direction of technological developments in the industry in order to correctly design an alliance. If a technological environment alters quickly and in unforeseeable ways, firms best invest relatively little time, effort, and money into institutionalizing their alliances, as in such environments any investments have uncertain future relevance. Second, firms have to make sure that the first implication becomes engrained in their alliance management practices. The results in chapter 4 foreshadow that incidental governance mistakes need not be detrimental for firms' innovative prosperity but consistent misalignment leads a firm to an impaired innova- 
tion profile, both in terms of upstream technological productivity as well as downstream new product launch.

\subsection{Limitations and suggestions for further research}

A few obvious limitations cut across the three studies in this dissertation. First, I focused on IT-related R\&D alliances as a study setting. Even though IT-related R\&D has taken a pronounced share in all R\&D alliance activity in high tech sectors during the 1970s, 1980s, and 1990s, it is possible that some effects play out differently in other sectors such as biopharmaceuticals - due to a much longer new product development process necessitated by extensive trial processes. Replication of the current findings would serve the literature, by strengthening the empirical basis on which theory rests.

Second, patent-based measures of technological activity have shortcomings. Patent citations prior to 2001 are contaminated by citations that are not actually inserted by inventors but by patent examiners. Even despite recent (2001 onwards) changes enabling the isolation of examiner-added citations, some degree of noise to the information caught in patent citations will remain. Regardless, measures with less noise are sparse, yet might be found outside the realm of patents. For science-based industries such as IT, a combination of patent citations and bibliometric research on joint publications and scientific citations could perhaps reveal additional insights into the technological knowledge flows between firms.

Third, innovation is not usually an exclusive end for most manufacturing firms. Rather, new products leading to increased sales and profits are the ultimate aim of technology strategy. Therefore, there is ample room for research connecting upstream technology activity to downstream outcomes, much in the spirit of chapter 4 in this dissertation. Also, the mechanisms connecting R\&D strategy to knowledge flows, to innovations, and then to new products are interesting subjects for further research.

Over and above these limitations and the opportunities they generate, there is a broader teaser present in this dissertation. Though the managerial implications I draw are quite exclusively normative, I believe there is room for research investigating why firms would not optimize their alliances in line with these or any other normative implications drawn elsewhere in the literature. Remember that all empirical results are based on a distribution of firms and that I would not have been able to draw implications without firms not behaving and performing optimally. After all, I relied on longitudinal variation as an identification strategy. The sample firms thus did not systematically optimize their alliances, alliance portfolios, or alliance networks to benefit in terms of knowledge flows or innovative output.

The performance studies presented here have generated implications important for the emergence of alliances, alliance portfolios, and alliance networks. What we need now is research that endogenizes more fully the alliance dimensions of importance for firm performance. 



\section{Literature}

Abernathy, W. J. \& Rosenbloom, R. S. 1969. Parallel strategies in development projects. Management Science, 15: 486-504.

Adler, P. S. \& Kwon, S.-W. 2002. Social capital: Prospects for a new concept. Academy of Management Review, 27: 17-40.

Ahuja, G. 2000a. Collaboration networks, structural holes, and innovation: A longitudinal study. Administrative Science Quarterly, 45: 425-455.

Ahuja, G. 2000b. The duality of collaboration: Inducements and opportunities in the formation of interfirm linkages. Strategic Management Journal, 21: 317-343.

Albert, M. B., Avery, D., Narin, F., \& McAllister, P. 1991. Direct validation of citation counts as indicators of industrially important patents. Research Policy, 20: 251-259.

Alcácer, J. \& Gittelman, M. 2006. Patent citations as a measure of knowledge flows: The influence of examiner citations. Review of Economics and Statistics, 88: 774-779.

Aldrich, H. E. 2008. Organizations and environments. Stanford, CA: Stanford University Press.

Aldrich, H. E. \& Ruef, M. 2006. Organizations evolving. London, UK: SAGE Publications Ltd.

Allison, P. D. 2001. Missing data. Thousand Oaks, CA: SAGE.

Allison, P. D. \& Waterman, R. 2002. Fixed-effects negative binomial regression models. Sociological Methodology, 32: 247-265.

Almeida, P., Song, J., \& Grant, R. M. 2002. Are firms superior to alliances and markets? An empirical test of cross-border knowledge building. Organization Science, 13: 147-161.

Amburgey, T. L. \& Miner, A. S. 1992. Strategic momentum: The effects of repetitive, positional, and contextual momentum on merger activity. Strategic Management Journal, 13: 335-348.

Anand, B. N. \& Khanna, T. 2000. Do firms learn to create value? The case of alliances. Strategic Management Journal, 21: 295-315.

Appleyard, M. 1996. How does knowledge flow? Interfirm patterns in the semiconductor industry. Strategic Management Journal, 17: 137-154.

Argote, L., McEvily, B., \& Reagans, R. 2003. Managing knowledge in organizations: An integrative framework and review of emerging themes. Management Science, 49: 571-582.

Arkes, H. R. \& Blumer, C. 1985. The psychology of sunk cost. Organizational Behavior and Human Decision Processes, 35: 124-140.

Athey, S. \& Schmutzler, A. 1995. Product and process flexibility in an innovative environment. RAND Journal of Economics, 26: 557-574.

Auster, E. R. 1990. The interorganizational environment: Network theory, tools and applications. In F. Williams \& D. Gibson (Eds.), Technological Transfer: 63-89. Beverly Hills, CA: Sage Press.

Auster, E. R. 1992. The relationship of industry evolution to patterns of technological linkages, joint ventures, and direct investment between U.S. and Japan. Management Science, 38: 778792.

Autant-Bernard, C. 2001. The geography of knowledge spillovers and technological proximity. Economics of Innovation and New Technology, 10: 237-254.

Bae, J. \& Gargiulo, M. 2004. Partner substitutability, alliance network structure, and firm profitability in the telecommunications industry. Academy of Management Journal, 47: 843-859.

Bamford, J. \& Ernst, D. 2002. Managing an alliance portfolio. McKinsey Quarterly, 28: 29-39.

Bascle, G. 2008. Controlling for endogeneity with instrumental variables in strategic management research. Strategic Organization, 6: 285-327. 
Baum, J. A. C., Calabrese, T., \& Silverman, B. S. 2000. Don't go it alone: Alliance network composition and startups' performance in Canadian biotechnology. Strategic Management Journal, 21: 267-294.

Baum, J. A. C. \& Rowley, T. J. 2008. Network strategy - Advances in strategic management. Bingley, UK: JAI/Emerald.

Baum, J. A. C., Rowley, T. J., Shipilov, A. V., \& Chuang, Y.-T. 2005. Dancing with strangers: Aspiration performance and the search for underwriting syndicate partners. Administrative Science Quarterly, 50: 536-575.

Bayus, B. L., Erickson, G., \& Jacobson, R. 2003. The financial rewards of new product introductions in the personal computer industry. Management Science, 49: 197-210.

Beck, N., Brüderl, J., \& Woywode, M. 2008. Momentum or deceleration? Theoretical and methodological reflections on the analysis of organizational change. Academy of Management Journal, 51: 413-435.

Beckman, C. M., Haunschild, P. R., \& Phillips, D. J. 2004. Friends or strangers: Firm-specific uncertainty, market uncertainty, and network partner selection. Organization Science, 15: 259275.

Blundell, R., R. Griffith, \& Van Reenen, J. 1995. Dynamic count data models of technological innovation. Economic Journal, 105: 333-334.

Blundell, R., R. Griffith, \& Windmeijer, F. 2002. Individual effects and dynamics in count data models. Journal of Econometrics, 108: 113-131.

Borgatti, S. P., Everett, M. G., \& Freeman, L. C. 2002. Ucinet for Windows: Software for social network analysis. Harvard, MA: Analytic Technologies.

Borgatti, S. P. \& Foster, P. C. 2003. The network paradigm in organizational research: A review and typology. Journal of Management, 29: 991-1013.

Bourgeois, L. J., III, \& Eisenhardt, K. M. 1988. Strategic decision processes in high velocity environments: Four cases in the microcomputer industry. Management Science, 34: 816-835.

Burns, T. \& Stalker, G. M. 1961. The management of innovation. London, UK: Tavistock.

Burt, R. S. 1992. Structural holes: The social structure of competition. Cambridge, MA: Harvard University Press.

Burt, R. S. 2005. Brokerage \& closure: An introduction to social capital. Oxford, UK: Oxford University Press.

Burt, R. S. 2007. Secondhand brokerage: Evidence on the importance of local structure for managers, bankers, and analysts. Academy of Management Journal, 50: 119-148.

Burt, R. S. 2008. Industry performance and indirect access to structural holes. In J. A. C. Baum and T. J. Rowley (Eds.), Network Strategy - Advances in Strategic Management Vol. 25: 315360. Bingley, UK: JAI/Emerald Group.

Buskens, V. \& van de Rijt, A. 2008. Dynamics of networks if everyone strives for structural holes. American Journal of Sociology, 114: 371-407.

Cameron, K. S., Kim, M. U., \& Whetten, D. A. 1987. Organizational effects of decline and turbulence. Administrative Science Quarterly, 32: 222-240.

Carlsson, B. 1989. Flexibility and the theory of the firm. International Journal of Industrial Organization, 7: 179-203.

Carroll, G. R. \& Hannan, M. T. 2004. The demography of corporations and industries. Princeton, NJ: Princeton University Press.

Cassiman, B. \& Veugelers, R. 2002. R\&D cooperation and spillovers: Some empirical evidence from Belgium. American Economic Review, 92: 1169-1184.

Chaney, P. K., Devinney, T. M., \& Winer, R. S. 1991. The impact of new product introductions on the market value of firms. Journal of Business, 64: 573-610. 
Childs, P. D. \& Triantis, A. J. 1999. Dynamic R\&D investment policies. Management Science, 45: 1359-1377.

Cloodt, M., Hagedoorn, J., \& Roijakkers, N. 2006. Trends and patterns in inter-firm R\&D networks in the global computer industry: An analysis of major developments, 1970-1999. Business History Review, 80: 725-746.

Cohen, W. M. \& Levinthal, D. A. 1990. Absorptive capacity: A new perspective on learning and innovation. Administrative Science Quarterly, 35: 128-152.

Cohen, W. M. \& Levinthal, D. A. 1994. Fortune favors the prepared firm. Management Science, 40: 227-251.

Coleman, J. S. 1988. Social capital in the creation of human capital. American Journal of Sociology, 94: S95-S120.

Coleman, J. S. 1990. Foundations of social theory. Cambridge, MA: Harvard University Press.

Contractor, F. J. \& Lorange, P. 2002. The growth of alliances in the knowledge-based economy. International Business Review, 11: 485-502.

Crépon, B. \& Duguet, E. 1997. Estimating the innovation function from patent numbers: GMM on count panel data. Journal of Applied Econometrics, 12: 243-263.

Dagnino, G. B. \& Mariani, M. M. 2004. Dynamic gap bridging and realized gap set development: The strategic role of the firm in the coevolution of capability space and opportunity space. In U. Cantner \& F. Malerba (Eds.), Innovation, Industrial Dynamics and Structural Transformation - Schumpeterian Legacies: 321-341. Berlin: Springer.

D'Aveni, R. A. 1994. Hypercompetition: Managing the dynamics of strategic maneuvering. New York, NY: Free Press.

Davidson, R. \& MacKinnon, J. G. 1993. Estimation and inference in econometrics. New York, NY: Oxford University Press.

Davis, G. F., Yoo, M., \& Baker, W. E. 2003. The small world of the American corporate elite, 1982-2001. Strategic Organization, 1: 301-326.

Davis, J. P., Eisenhardt, K. M., \& Bingham, C. B. 2009. Optimal structure, market dynamism, and the strategy of simple rules. Administrative Science Quarterly, 54: 413-452.

de Bondt, W. F. M. \& Makhija, A. K. 1988. Throwing good money after bad? Nuclear power plant investment decisions and the relevance of sunk costs. Journal of Economic Behavior and Organization, 10: 173-199.

Deeds, D. L. \& Hill, C. W. L. 1996. Strategic alliances and the rate of new product development: An empirical study of entrepreneurial biotechnology firms. Journal of Business Venturing, 11: 41-55.

Delacroix, J. \& Swaminathan, A. 1991. Cosmetic, speculative, and adaptive change in the wine industry: A longitudinal study. Administrative Science Quarterly, 36: 631-661.

Dess, G. G. \& Beard, D. W. 1984. Dimensions of organizational task environments. Administrative Science Quarterly, 29: 52-73.

Devinney, T. M. 1993. How well do patents measure new product activity? Economics Letters, 41: 447-450.

DiMaggio, P. J. \& Powell, W. W. 1983. The iron cage revisited: Institutional isomorphism and collective rationality in organizational fields. American Sociological Review, 48: 147-160.

Duguet, E. \& MacGarvie, M. 2005. How well do patent citations measure flows of technology? Evidence from French innovation surveys. Economics of Innovation and New Technology, 14: 375-393.

Duncan, R. B. 1972. Characteristics of organizational environments and perceived environmental uncertainty. Administrative Science Quarterly, 17: 313-327.

Durlauf, S. N. 2002. On the empirics of social capital. Economic Journal, 112: F459-F479. 
Dutta, S. \& Weiss, A. M. 1997. The relationship between a firm's level of technological innovativeness and its pattern of partnership agreements. Management Science, 43: 343-356.

Dyer, J. H. \& Singh, H. 1998. The relational view: Cooperative strategy and sources of interorganizational competitive advantage. Academy of Management Review, 23: 660-679.

Economist, 1993. The coming clash of logic. Volume 328, July 3 issue: 21-23.

Edwards, J. R. \& Parry, M. E. 1993. On the use of polynomial regression equations as an alternative to difference scores in organizational research. Academy of Management Journal, 36: 1577-1613.

Eisenhardt, K. M. 1989. Making fast strategic decisions in high-velocity environments. Academy of Management Journal, 32: 543-576.

Faems, D., Janssens, M., \& Van Looy, B. 2007. The initiation and evolution of interfirm knowledge transfer in R\&D relationships. Organization Studies, 28: 1699-1728.

Faems, D., Van Looy, B., \& Debackere, K. 2005. Interorganizational collaboration and innovation: Toward a portfolio approach. Journal of Product Innovation Management, 22: 238-250.

Folta, T. B. 1998. Governance and uncertainty: The trade-off between administrative control and commitment. Strategic Management Journal, 19: 1007-1028.

Freeman, C. \& Soete, L. 1997. The economics of industrial innovation. London: Pinter.

Galaskiewicz, J. 1985. Interorganizational relations. Annual Review of Sociology, 11: 281-304.

Gallini, N. T. 2002. The economics of patents: Lessons from recent U.S. patent reform. Journal of Economic Perspectives, 16: 131-154.

Garland, H. 1990. Throwing good money after bad: The effect of sunk costs on the decision to escalate commitment to an ongoing project. Journal of Applied Psychology, 75: 728-731.

Garland, H. \& Conlon, D. E. 1998. Too close to quit: The role of project completion in maintaining commitment. Journal of Applied Social Psychology, 28: 2025-2048.

Gay, B. \& Dousset, B. 2005. Innovation and network structural dynamics: Study of the alliance network of a major sector of the biotechnology industry. Research Policy, 34: 1457-1475.

Ghemawat, P. 1991. Commitment: The dynamic of strategy. New York, NY: The Free Press.

Gnyawali, D. R. \& Madhavan, R. 2001. Cooperative networks and competitive dynamics: A structural embeddedness perspective. Academy of Management Review, 26: 431-445.

Gomes-Casseres, B. 2003. Competitive advantage in alliance constellations. Strategic Organization, 1: 327-335.

Gomes-Casseres, B., Hagedoorn, J., \& Jaffe, A. B. 2006. Do alliances promote knowledge flows? Journal of Financial Economics, 80: 5-33.

Granovetter, M. 2002. A theoretical agenda for economic sociology. In M. F. Guillén, R. Collins, P. England, \& M. Meyer (Eds.), The New Economic Sociology: Developments in an Emerging Field: 35-60. New York: Russell Sage Foundation.

Greene, W. H. 2003. Econometric analysis (5 $5^{\text {th }}$ edition). Upper Saddle River, NJ: Prentice Hall.

Greve, H. R. 2003. A behavioral theory of R\&D expenditures and innovations: Evidence from shipbuilding. Academy of Management Journal, 46: 685-702.

Greve, H. R. 2005. Interorganizational learning and heterogeneous social structure. Organization Studies, 26: 1025-1047.

Greve, H. R. \& Goldeng, E. 2004. Longitudinal analysis in strategic management. In D. J. Ketchen, Jr. \& D. D. Bergh (Eds.), Research Methodology in Strategy and Management Vol. 1: 135164. Bingley, UK: JAI Press.

Griliches, Z. 1990. Patent statistics as economic indicators: A survey. Journal of Economic Literature, 28: 1661-1707.

Gulati, R. 1995a. Social structure and alliance formation: A longitudinal analysis. Administrative Science Quarterly, 40: 619-652. 
Gulati, R. 1995b. Does familiarity breed trust? The implications of repeated ties for contractual choice in alliances. Academy of Management Journal, 38: 85-112.

Gulati, R. 1999. Network location and learning: The influence of network resources and firm capabilities on alliance formation. Strategic Management Journal, 20: 397-420.

Gulati, R. 2007. Managing network resources: Alliances, affiliations and other relational assets. Oxford, UK: Oxford University Press.

Gulati, R. \& Gargiulo, M. 1999. Where do interorganizational networks come from? American Journal of Sociology, 104: 1439-1493.

Gulati, R. \& Singh, H. 1998. The architecture of cooperation: Managing coordination costs and appropriation concerns in strategic alliances. Administrative Science Quarterly, 43: 781-814.

Hagedoorn, J. 1993. Understanding the rationale of strategic technology partnering: Interorganizational modes of cooperation and sectoral differences. Strategic Management Journal, 14: 371-385.

Hagedoorn, J. 2002. Interfirm R\&D partnerships: An overview of major trends and patterns since 1960. Research Policy, 31: 477-492.

Hagedoorn, J. 2006. Understanding the cross-level embeddedness of interfirm partnership formation. Academy of Management Review, 31: 670-680.

Hagedoorn, J., Carayannis, E., \& Alexander, J. 2001. Strange bedfellows in the personal computer industry: Technology alliances between IBM and Apple. Research Policy, 30: 837-849.

Hagedoorn, J., Cloodt, D., \& van Kranenburg, H. 2005. Intellectual property rights and the governance of international R\&D partnerships. Journal of International Business Studies, 36: 175-186.

Hagedoorn, J. \& Cloodt, M. 2003. Measuring innovative performance: Is there an advantage in using multiple indicators? Research Policy, 32: 1365-1379.

Hagedoorn, J. \& Frankort, H. T. W. 2008. The gloomy side of embeddedness: The effects of overembeddedness on inter-firm partnership formation. In J. A. C. Baum \& T. J. Rowley (Eds.), Network Strategy - Advances in Strategic Management Vol. 25: 503-530. Bingley, UK: JAI/Emerald Group.

Hagedoorn, J. \& Hesen, G. 2007. Contract law and the governance of inter-firm technology partnerships: An analysis of different modes of partnering and their contractual implications. Journal of Management Studies, 44: 342-366.

Hagedoorn, J. \& Narula, R. 1996. Choosing organizational modes of strategic technology partnering: International and sectoral differences. Journal of International Business Studies, 27: 265-284.

Hagedoorn, J. \& Schakenraad, J. 1994. The effect of strategic technology alliances on company performance. Strategic Management Journal, 15: 291-309.

Halaby, C. N. 2004. Panel models in sociological research: Theory into practice. Annual Review of Sociology, 30: 507-544.

Hall, B. H. 2005. Exploring the patent explosion. Journal of Technology Transfer, 30: 35-48.

Hall, B. H., Jaffe, A. B., \& Trajtenberg, M. 2002. The NBER patent-citations data file: Lessons, insights, and methodological tools. In A. B. Jaffe \& M. Trajtenberg (Eds.), Patents, Citations E Innovations: 403-459. Cambridge, MA: The MIT Press.

Hall, B. H., Jaffe, A. B., \& Trajtenberg, M. 2005. Market value and patent citations. RAND Journal of Economics, 36: 16-38.

Hamel, G. 1991. Competition for competence and inter-partner learning within international strategic alliances. Strategic Management Journal, 12: 83-103.

Hamilton, B. H. \& Nickerson, J. A. 2003. Correcting for endogeneity in strategic management research. Strategic Organization, 1: 51-78. 
Hannan, M. T. \& Freeman, J. 1977. The population ecology of organizations. American Journal of Sociology, 82: 929-964.

Harrigan, K. R. 1988. Joint ventures and competitive strategy. Strategic Management Journal, 9: 141-158.

Harrigan, K. R. 2003 [1985]. Joint ventures, alliances, and corporate strategy. Washington, D. C.: Beard Books.

Hausman, J. 1978. Specification tests in econometrics. Econometrica, 46: 1251-1271.

Hausman, J., Hall, B. H., \& Griliches, Z. 1984. Econometric models for count data with an application to the patents-R\&D relationship. Econometrica, 52: 909-938.

Haveman, H. A. 1994. The ecological dynamics of organizational change: Density and mass dependence in rates of entry into new markets. In J. A. C. Baum \& J. V. Singh (Eds.), Evolutionary Dynamics of Organizations: 152-166. New York, NY: Oxford University Press.

Heckman, J. 1979. Sample selection bias as a specification error. Econometrica, 47: 153-161.

Heckman, J. \& Borjas, G. 1980. Does unemployment cause future unemployment? Definitions, questions and answers from a continuous time model of heterogeneity and state dependence. Economica, 47: 247-283.

Heimeriks, K. H., Duysters, G., \& Vanhaverbeke, W. 2007. Learning mechanisms and differential performance in alliance portfolios. Strategic Organization, 5: 373-408.

Helper, S., MacDuffie, J. P., \& Sabel, C. 2000. Pragmatic collaborations: Advancing knowledge while controlling opportunism. Industrial and Corporate Change, 9: 443-488.

Henderson, A. D. \& Stern, I. 2004. Selection-based learning: The coevolution of internal and external selection in high-velocity environments. Administrative Science Quarterly, 49: 39-75.

Hennart, J. F. 1991. The transaction costs theory of joint ventures: An empirical study of Japanese subsidiaries in the United States. Management Science, 37: 483-497.

Hoffmann, W. 2007. Strategies for managing a portfolio of alliances. Strategic Management Journal, 28: 827-856.

Hsiao, Chen 2003. Analysis of panel data (2nd edition). New York, NY: Cambridge University Press.

Inkpen, A. C. \& Ross, J. 2001. Why do some strategic alliances persist beyond their useful life? California Management Review, 44: 132-148.

Iyer, B., Lee, C.-H., \& Venkatraman, N. 2006. Managing in a "small world ecosystem": Lessons from the software sector. California Management Review, 48: 28-47.

Jacobson, R. 1990. Unobservable effects and business performance. Marketing Science, 9: 74-85.

Jaffe, A. B. 1986. Technological opportunity and spillovers of R\&D: Evidence from firms' patents, profits, and market value. American Economic Review, 76: 984-1001.

Jaffe, A. B. \& Trajtenberg, M. 1996. Flows of knowledge from universities and federal laboratories: Modeling the flow of patent citations over time and across institutional and geographic boundaries. Proceedings of the National Academy of Sciences, 93: 12671-12677.

Jaffe, A. B. \& Trajtenberg, M. 2002. Patents, citations \& innovations: A window on the knowledge economy. Cambridge, MA: The MIT Press.

Jaffe, A. B., Trajtenberg, M., \& Fogarty, M. S. 2000. Knowledge spillovers and patent citations: Evidence from a survey of inventors. American Economic Review, 90: 215-218.

Jensen, M. 2008. The use of relational discrimination to manage market entry: When do social status and structural holes work against you? Academy of Management Journal, 51: 723-743.

Jurkovich, R. 1974. A core typology of organizational environments. Administrative Science Quarterly, 19: 380-394.

Kalaignanam, K., Shankar, V., \& Varadarajan, R. 2007. Asymmetric new product development alliances: Win-win or win-lose partnerships? Management Science, 53: 357-374. 
Kale, P., Dyer, J. H., \& Singh, H. 2002. Alliance capability, stock market response, and long-term alliance success: The role of the alliance function. Strategic Management Journal, 23: 747-767.

Kale, P. \& Puranam, P. 2004. Choosing equity stakes in technology-sourcing relationships. California Management Review, 46: 77-99.

Katila, R. \& Ahuja, G. 2002. Something old, something new: A longitudinal study of search behavior and new product inroduction. Academy of Management Journal, 45: 1183-1194.

Katila, R., Rosenberger, J. D., \& Eisenhardt, K. M., 2008. Swimming with sharks: Technology ventures, defense mechanisms and corporate relationships. Administrative Science Quarter$l y$, 53: 295-332.

Katila, R. \& Shane, S. 2005. When does lack of resources make new firms innovate? Academy of Management Journal, 48: 814-829.

Khanna, T., Gulati, R., \& Nohria, N. 1998. The dynamics of learning alliances: Competition, cooperation, and relative scope. Strategic Management Journal, 19: 193-210.

Kogut, B. 1988a. A study of the life cycle of joint ventures. In F. J. Contractor \& P. Lorange (Eds.), Cooperative Strategies in International Business: 169-186. Lexington, MA: Lexington Books.

Kogut, B. 1988b. Joint ventures: Theoretical and empirical perspectives. Strategic Management Journal, 9: 319-332.

Krishnan, V. \& Ulrich, K. T. 2001. Product development decisions: A review of the literature. Management Science, 47: 1-21.

Lane, P. J. \& Lubatkin, M. 1998. Relative absorptive capacity and interorganizational learning. Strategic Management Journal, 19: 461-477.

Laursen, K. \& Salter, A. 2006. Open for innovation: The role of openness in explaining innovation performance among U.K. manufacturing firms. Strategic Management Journal, 27: 131150 .

Lavie, D. 2006. The competitive advantage of interconnected firms: An extension of the resource-based view. Academy of Management Review, 31: 638-658.

Lavie, D. 2007. Alliance portfolios and firm performance: A study of value creation and appropriation in the U.S. software industry. Strategic Management Journal, 28: 1187-1212.

Lavie, D. \& Miller S. R. 2008. Alliance portfolio internationalization and firm performance. Organization Science, 19: 623-646.

Lavie, D. \& Rosenkopf L. 2006. Balancing exploration and exploitation in alliance formation. Academy of Management Journal, 49: 797-818.

Lavie, D. \& Singh, H. 2008. The evolution of alliance ego-networks: The case of Unisys. Working paper.

Lawrence, P. R. \& Lorsch, J. W. 1967. Differentiation and integration in complex organizations. Administrative Science Quarterly, 12: 1-47.

Leiblein, M. J., Reuer, J. J., \& Dalsace, F. 2002. Do make or buy decisions matter? The influence of organizational governance on technological performance. Strategic Management Journal, 23: 817-833.

Leiponen, A. \& Helfat, C. E. 2005. Innovation objectives, knowledge sources, and the benefits of breadth. Working paper.

Levinthal, D. A. \& March, J. G. 1993. The myopia of learning. Strategic Management Journal, 14: 95-112.

Lewin, A. Y. \& Stephens, C. U. 1994. CEO attitudes as determinants of organization design: An integrated model. Organization Studies, 15: 183-212.

Lincoln, J. R. 1984. Analyzing relations in dyads: Problems, models, and an application to interorganizational research. Sociological Methods \& Research, 13: 45-76. 
Lincoln, J. R., Gerlach, M. L., \& Takahashi, P. 1992. Keiretsu networks in the Japanese economy: A dyad analysis of intercorporate ties. American Sociological Review, 57: 561-585.

Mahnke, V., Overby, M. L., \& Nielsen, L. E. 2006. Portfolio management of R\&D collaborations in mobile commerce. In S. Klein \& A. Poulymenakau (Eds.), Managing Dynamic Networks: 113-123. Berlin/Heidelberg: Springer.

Manski, C. F. 1993. Identification problems in the social sciences. Sociological Methodology, 23: 156.

Merton, R. K. 1936. The unanticipated consequences of purposive social action. American Sociological Review, 1: 894-904.

Miles, R. E., Snow, C. C., Mathews, J. A., Miles, G., \& Coleman Jr., H. J. 1997. Organizing in the knowledge age: Anticipating the cellular form. Academy of Management Executive, 11: 7-20.

Miles, R. E., Snow, C. C., \& Pfeffer, J. 1974. Organization-environment: Concepts and issues. Industrial Relations, 13: 244-264.

Milliken, F. J. 1987. Three types of perceived uncertainty about the environment: State, effect, and response uncertainty. Academy of Management Review, 12: 133-143.

Mizruchi, M. S. \& Marquis, C. 2006. Egocentric, sociocentric, or dyadic? Identifying the appropriate level of analysis in the study of interorganizational networks. Social Networks, 28: 187-208.

Mohr, J. \& Spekman, R. 1994. Characteristics of partnership success. Strategic Management Journal, 15: 135-152.

Moon, H. 2001. Looking forward and looking backward: Integrating completion and sunk-cost effects within an escalation-of-commitment progress decision. Journal of Applied Psychology, 86: 104-113.

Mouw, T. 2006. Estimating the causal effect of social capital: A review of recent research. Annual Review of Sociology, 32: 79-102.

Mowery, D. C., Oxley, J. E., \& Silverman, B. S. 1996. Strategic alliances and interfirm knowledge transfer. Strategic Management Journal, 17: 77-91.

Munshi, K. 2003. Networks in the modern economy: Mexican migrants in the U.S. labor market. Quarterly Journal of Economics, 118: 549-597.

Munson, J. M. \& Spivey, W. A. 2006. Take a portfolio view of CRADAs. Research Technology Management, 49: 39-45.

Murray, M. P. 2006. Avoiding invalid instruments and coping with weak instruments. Journal of Economic Perspectives, 20: 111-132.

National Science Foundation 2006 (Division of Science Resources Statistics). Research and Development in Industry: 2003. NSF 07-314. Arlington, VA: National Science Foundation.

Nelson, R. R. 1961. Uncertainty, learning, and the economics of parallel research and development efforts. Review of Economics and Statistics, 42: 351-364.

Nelson, R. R. 1982. The role of knowledge in R\&D efficiency. Quarterly Journal of Economics, 97: 453-470.

Nelson, R. R. \& Winter, S. G. 1982. An evolutionary theory of economic change. Cambridge, MA: Harvard University Press.

Nutt, P. C. 1998. How decision makers evaluate alternatives and the influence of complexity. Management Science, 44: 1148-1166.

OECD 2002. Frascati manual. Paris: OECD.

Ouchi, W. G. 1979. A conceptual framework for the design of organizational control mechanisms. Management Science, 25: 833-848.

Oxley, J. E. 1997. Appropriability hazards and governance in strategic alliances: A transaction cost approach. Journal of Law, Economics, and Organization, 13: 387-409. 
Oxley, J. E. 2009. Alliances and performance. In J. A. Nickerson \& B. S. Silverman (Eds.), Economic Institutions of Strategy - Advances in Strategic Management Vol. 26: 147-164. Bingley, UK: JAI/Emerald Group.

Oxley, J. E. \& Sampson, R. C. 2004. The scope and governance of international R\&D alliances. Strategic Management Journal, 25: 723-749.

Oxley, J. \& Wada, T. 2009. Alliance structure and the scope of knowledge transfer: Evidence from US-Japan agreements. Management Science, 55: 635-649.

Pakes, A. 1985. On patents, R\&D, and the stock market rate of return. Journal of Political Econo$m y$, 93: 390-409.

Parayre, R. 1995. The strategic implications of sunk costs: A behavioral perspective. Journal of Economic Behavior and Organization, 28: 417-442.

Parise, S. \& Henderson, J. C. 2001. Knowledge resource exchange in strategic alliances. IBM Systems Journal, 40: 908-924.

Parise, S. \& Sasson, L. 2002. Leveraging knowledge management across strategic alliances. Ivey Business Journal, 66: 41-47.

Patel, P. \& Pavitt, K. 1997. The technological competencies of the world's largest firms: Complex and path-dependent, but not much variety. Research Policy, 26: 141-156.

Pennings, J. M. \& Harianto, F. 1992. Technological networking and innovation implementation. Organization Science, 3: 356-382.

Peri, G. 2005. Determinants of knowledge flows and their effect on innovation. Review of Economics and Statistics, 87: 308-322.

Pfeffer, J. \& Salancik, G. R. 1978. The external control of organizations. New York, NY: Harper \& Row Publishers Inc.

Pisano, G. P. 1989. Using equity participation to support exchange: Evidence from the biotechnology industry. Journal of Law, Economics, and Organization, 5: 109-126.

Pisano, G. P., Russo, M. V., \& Teece, D. J. 1988. Joint ventures and collaborative arrangements in the telecommunications equipment industry. In D. C. Mowery (Ed.), International Collaborative Ventures in U.S. Manufacturing: 23-70. Cambridge, MA: Ballinger Publishing Company.

Podolny, J. M. 1994. Market uncertainty and the social character of economic exchange. Administrative Science Quarterly, 39: 458-483.

Podolny, J. M. 2001. Networks as the pipes and prisms of the market. American Journal of Sociology, 107: 33-60.

Podolny, J. M. \& Page, K. L. 1998. Network forms of organization. Annual Review of Sociology, 24: 57-76.

Podolny, J. M., Stuart, T. E., \& Hannan, M. T. 1996. Networks, knowledge, and niches: Competition in the worldwide semiconductor industry, 1984-1991. American Journal of Sociology, 102: 659-689.

Powell, W. W. and Grodal, S. 2005. Networks of innovators. In J. Fagerberg, D. C. Mowery and R. R. Nelson (Eds.), The Oxford Handbook of Innovation: 56-85. Oxford, UK: Oxford University Press.

Powell, W. W., Koput, K., \& Smith-Doerr, L. 1996. Interorganizational collaboration and the locus of innovation: Networks of learning in biotechnology. Administrative Science Quarterly, 41: 116-145.

Powell, W. W., Koput, K., Smith-Doerr, L., \& Owen-Smith, J. 1999. Network position and firm performance: Organizational returns to collaboration, Research in the Sociology of Organizations Vol. 16: 129-159. Greenwich, CT: JAI Press. 
Powell, W. W., White, D. R., Koput, K. W., \& Owen-Smith, J. 2005. Network dynamics and field evolution: The growth of interorganizational collaboration in the life sciences. American Journal of Sociology, 110: 1132-1205.

Reagans, R. E., Zuckerman, E., \& McEvily, B. 2007. On firmer ground: The collaborative team as strategic research site for verifying network-based social-capital hypotheses. In J. E. Rauch (Ed.), The Missing Links: Formation and Decay of Economic Networks: 147-182. New York, NY: Russell Sage Foundation.

Reuer, J. J. \& Ragozzino, R. 2006. Agency hazards and alliance portfolios. Strategic Management Journal, 27: 27-43.

Ring, P. S. \& van de Ven, A. H. 1994. Developmental processes of cooperative interorganizational relationships. Academy of Management Review, 19: 90-118.

Roberts, K. \& Weitzman, M. L. 1981. Funding criteria for research, development, and exploration projects. Econometrica, 49: 1261-1288.

Robinson, D. T. \& Stuart, T. E. 2007. Network effects in the governance of strategic alliances. Journal of Law, Economics, and Organization, 23: 242-273.

Rosenkopf, L. \& Almeida, P. 2003. Overcoming local search through alliances and mobility. Management Science, 49: 751-766.

Rosenkopf, L. \& Schilling, M. A. 2007. Comparing alliance network structure across industries: Observations and explanations. Strategic Entrepreneurship Journal, 1: 191-209.

Rothaermel, F. T. \& Deeds, D. L. 2006. Alliance type, alliance experience and alliance management capability in high-technology ventures. Journal of Business Venturing, 21: 429-460.

Rowley, T., Behrens, D., \& Krackhardt, D. 2000. Redundant governance structures: An analysis of structural and relational embeddedness in the steel and semiconductor industries. Strategic Management Journal, 21: 369-386.

Salancik, G. R. 1995. WANTED: A good network theory of organization. Administrative Science Quarterly, 40: 345-349.

Sampson, R. C. 2004. The cost of misaligned governance in R\&D alliances. Journal of Law, Economics, and Organization, 20: 484-526.

Sampson, R. C. 2007. R\&D alliances and firm performance: The impact of technological diversity and alliance organization on innovation. Academy of Management Journal, 50: 364-386.

Santoro, M. D. \& McGill, J. P. 2005. The effect of uncertainty and asset co-specialization on governance in biotechnology alliances. Strategic Management Journal, 26: 1261-1269.

Sargan, J. D. 1958. The estimation of economic relationships using instrumental variables. Econometrica, 26: 393-415.

Sarkar, M. B., Aulakh, P. S., \& Madhok, A. 2009. Process capabilities and value generation in alliance portfolios. Organization Science, 20: 583-600.

Saxton, T. 1997. The effects of partner and relationship characteristics on alliance outcomes. Academy of Management Journal, 40: 443-461.

Scherer, F. M. 2007. Parallel R\&D paths revisited. John F. Kennedy School of Government working paper RWP07-040.

Schilling, M. A. 2009. Understanding the alliance data. Strategic Management Journal, 30: 233-260.

Schilling, M. A. \& Phelps, C. C. 2007. Interfirm collaboration networks: The impact of large-scale network structure on firm innovation. Management Science, 53: 1113-1126.

Schilling, M. A. \& Steensma, H. K. 2001. The use of modular organizational forms: An industrylevel analysis. Academy of Management Journal, 44: 1149-1169.

Schumpeter, J. A. 1934. The theory of economic development. London, UK: Oxford University Press.

Shan, W., Walker, G., \& Kogut, B. 1994. Interfirm cooperation and startup innovation in the biotechnology industry. Strategic Management Journal, 15: 387-394. 
Shaver, J. M. 1998. Accounting for endogeneity when assessing strategy performance: Does entry mode choice affect FDI survival? Management Science, 44: 571-585.

Shaver, J. M. 2008. Organizational significance. Strategic Organization, 6: 185-193.

Shimizu, K. \& Hitt, M. A. 2004. Strategic flexibility: Organizational preparedness to reverse ineffective strategic decisions. Academy of Management Executive, 18: 44-59.

Shipilov, A. V. 2006. Network strategies and performance of Canadian investment banks. Academy of Management Journal, 49: 590-604.

Silverman, B. S. \& Baum, J. A. C. 2002. Alliance-based competitive dynamics. Academy of Management Journal, 45: 791-806.

Simonin, B. L. 1999. Ambiguity and the process of knowledge transfer in strategic alliances. Strategic Management Journal, 20: 595-623.

Simsek, Z., Lubatkin, M. H., \& Floyd, S. W. 2003. Interfirm networks and entrepreneurial behaviour: A structural embeddedness perspective. Journal of Management, 29: 427-442.

Singh, J. 2005. Collaborative networks as determinants of knowledge diffusion patterns. Management Science, 51: 756-770.

Soh, P.-H. 2003. The role of networking alliances in information acquisition and its implications for new product performance. Journal of Business Venturing, 18: 727-744.

Sørensen, J. B. 2002. The strength of corporate culture and the reliability of firm performance. Administrative Science Quarterly, 47: 70-91.

Sørensen, J. B. \& Stuart, T. E. 2000. Aging, obsolescence, and organizational innovation. Administrative Science Quarterly, 45: 81-112.

Staw, B. M. 1981. The escalation of commitment to a course of action. Academy of Management Review, 6: 577-587.

Staw, B. M. \& Ross, J. 1978. Commitment to a policy decision: A multitheoretical perspective. Administrative Science Quarterly, 23: 40-64.

Staw, B. M. \& Ross, J. 1987. Knowing when to pull the plug. Harvard Business Review, MarchApril: 68-74.

Stinchcombe, A. L. 1987. Constructing social theories. Chicago, IL: University of Chicago Press.

Stuart, T. E. 1998. Network positions and propensities to collaborate: An investigation of strategic alliance formation in a high-technology industry. Administrative Science Quarterly, 43: 668-698.

Stuart, T. E. 2000. Interorganizational alliances and the performance of firms: A study of growth and innovation rates in a high-technology industry. Strategic Management Journal, 21: 791811.

Stuart, T. E. 2007. The formation of inter-organizational networks. In J. E. Rauch (Ed.), The Missing Links: Formation and Decay of Economic Networks: 79-99. New York, NY: Russell Sage Foundation.

Stuart, T. E., Hoang, H., \& Hybels, R. 1999. Interorganizational endorsements and the performance of entrepreneurial ventures. Administrative Science Quarterly, 44: 315-349.

Stuart, T. E. \& Podolny, J. M. 1996. Local search and the evolution of technological capabilities. Strategic Management Journal, 17: 21-38.

Stuart, T. E. \& Podolny, J. M. 1999. Positional consequences of strategic alliances in the semiconductor industry. In S. Andrews \& D. Knoke (Eds.), Research in the Sociology of Organizations Vol. 16: 161-182. Greenwich, CT: JAI Press.

Teece, D. J. 1992. Competition, cooperation, and innovation: Organizational arrangements for regimes of rapid technological progress. Journal of Economic Behavior and Organization, 18: 1-25. 


\section{Literature}

Teece, D. J., Pisano, G., \& Shuen, A. 1997. Dynamic capabilities and strategic management. Strategic Management Journal, 18: 509-533.

Thomke, S. H. 1997. The role of flexibility in the development of new products: An empirical study. Research Policy, 26: 105-119.

Tong, T. W., Reuer, J. J., \& Peng, M. W. 2008. International joint ventures and the value of growth options. Academy of Management Journal, 51: 1014-1029.

Tushman, M. L. \& Anderson, P. 1986. Technological discontinuities and organizational environments. Administrative Science Quarterly, 31: 439-465.

van de Ven, A. H. \& Polley, D. 1992. Learning while innovating. Organization Science, 3: 92-116.

van de Vrande, V., Vanhaverbeke, W., \& Duysters, G. 2009. External technology sourcing: The effect of uncertainty on governance mode choice. Journal of Business Venturing, 24: 62-80.

Venkatraman, N. \& Prescott, J. E. 1990. Environment-strategy coalignment: An empirical test of its performance implications. Strategic Management Journal, 11: 1-23.

Vishwanath, T. 1992. Parallel search for the best alternative. Economic Theory, 2: 495-507.

Walker, G. 2008. The rise of ecommerce as an epidemic in the small world of venture capital. In J. A. C. Baum \& T. J. Rowley (Eds.), Network Strategy - Advances in Strategic Management Vol. 25: 3-30. Bingley, UK: JAI/Emerald Group.

Wasserman, S. \& Faust, K. 1994. Social network analysis: Methods and applications. Cambridge, UK: Cambridge University Press.

Westphal, J. D., Gulati, R., \& Shortell, S. M. Customization or conformity? An institutional and network perspective on the content and consequences of TQM adoption. Administrative Science Quarterly, 42: 366-394.

Wheelwright, S. C. \& Clark, K. B. 1992. Revolutionizing product development: Quantum leaps in speed, efficiency, and quality. New York: The Free Press.

Williamson, O. E. 1991. Comparative economic organization: The analysis of discrete structural alternatives. Administrative Science Quarterly, 36: 269-296.

Winter, S. G. 1984. Schumpeterian competition in alternative technological regimes. Journal of Economic Behavior and Organization, 5: 287-320.

Wooldridge, J. M. 1999. Distribution-free estimation of some nonlinear panel data models. Journal of Econometrics, 90: 77-97.

Yayavaram, S. \& Ahuja, G. 2008. Decomposability in knowledge structures and its impact on the usefulness of inventions and knowledge-base malleability. Administrative Science Quarterly, 53: 333-362.

Zhang, J., Baden-Fuller, C., \& Mangematin, V. 2007. Technological knowledge base, R\&D organization structure and alliance formation: Evidence from the biopharmaceutical industry. Research Policy, 36: 515-528.

Ziedonis, R. H. 2004. Don't fence me in: Fragmented markets for technology and the patent acquisition strategies of firms. Management Science, 50: 804-820.

Zollo, M., Reuer, J. J., \& Singh, H. 2002. Interorganizational routines and performance in strategic alliances. Organization Science, 13: 701-713. 


\section{Nederlandse Samenvatting (Dutch Summary)}

\section{R\&D Allianties, Kennisstromen, en Innovatie: Drie Studies naar de Waarde van Samenwerking in R\&D}

Deze dissertatie presenteert drie empirische studies die ieder relaties bestuderen tussen verschillende deelaspecten van R\&D allianties (onderzoeks- en ontwikkelingsallianties) en zowel kennisstromen tussen samenwerkende bedrijven als innovatie op bedrijfsniveau.

Alle empirische analyses zijn gebaseerd op een steekproef van bedrijven die gedurende de periode 1975-1999 gebruik maakten van R\&D allianties in de informatietechnologie. De analyses houden zoveel mogelijk rekening met de belangrijkste alternatieve verklaringen die in de literatuur voor de getoetste relaties worden aangedragen.

De eerste studie onderzoekt hoe de R\&D allianties van een bedrijf gezamenlijk, als een portfolio, invloed hebben op de hoeveelheid technologische kennis die het bedrijf aantrekt van haar R\&D partners. De studie toetst twee ideeën. Ten eerste, enkele wetenschappers suggereren dat het uitvoeren van meerdere parallelle projecten (bv. R\&D allianties) vooral verstandig is wanneer exogene of endogene onzekerheden het moeilijk maken om de stand van de technologie te voorspellen. De empirische resultaten laten inderdaad zien dat de informatiewaarde van parallelle R\&D allianties afhangt van de onzekerheden gerelateerd aan deze allianties.

Ten tweede, behalve de aard van de R\&D allianties zal ook de aard van de partners een rol spelen in de hoeveelheid technologische kennis die een bedrijf aantrekt. Nieuwe partners-de partners waar een bedrijf nog niet eerder mee samenwerkte-genereren meestal meer informatie die nieuw is voor een bedrijf dan oude partners - de partners waar een bedrijf al mee samenwerkt(e). In tegenstelling tot oude partners zijn nieuwe partners echter minder vertrouwd en het zal dus minder gemakkelijk zijn om met nieuwe partners samen te werken. Deze overwegingen doen vermoeden dat een $R \& D$ alliantie portfolio de meeste ingaande kennisstromen genereert als deze zowel oude als nieuwe partners bevat. De empirische resultaten bevestigen dit vermoeden.

De tweede studie onderzoekt hoe de technologische kennis en de netwerkpositie van de R\&D partners van een bedrijf gezamenlijk invloed hebben op bedrijfsinnovatie - de productie van nieuwe technologische kennis. Bedrijven vormen R\&D allianties om toegang te krijgen tot de technologische kennis van andere bedrijven. Echter, dat de allianties die bedrijven met elkaar aangaan een netwerk vormen, lijkt hiervan slechts een onbelangrijk bijproduct te zijn dat geen verdere prestatieconsequenties heeft. Hoofdstuk 3 toont aan dat dit niet het geval is. De empirische resultaten laten ten eerste 
zien dat de technologische kennis van partners van invloed is op de innovatie van een bedrijf, zij het in afnemende mate. De netwerkpositie van deze zelfde partners is echter ook van belang. Als partners allianties onderhouden met andere bedrijven die ook direct onderling samenwerken, dan heeft dit een positief effect op bedrijfsinnovatie. De implicatie is dat het loont om, naast technologische kennis, ook te kijken naar de netwerkpositie van (potentiële) partners.

De derde en laatste studie onderzoekt een mogelijke tegenstrijdigheid in de alliantieliteratuur. Veel wetenschappers suggereren dat R\&D allianties het best presteren wanneer deze georganiseerd zijn als semiautonome bedrijven - als zogenaamde 'joint ventures'. Beschrijvende studies laten echter zien dat veruit de meeste R\&D allianties georganiseerd zijn als bilaterale projecten, voornamelijk in omgevingen waar exogene onzekerheden groot zijn. Deze ogenschijnlijke tegenstrijdigheid wekt de suggestie dat exogene onzekerheid van invloed is op de organisatiekeuzes die bedrijven maken. De empirische resultaten in deze laatste studie laten zien dat joint ventures het best presteren in omgevingen die langzaam en in voorspelbare richting veranderen, terwijl bilaterale contracten het best presteren in omgevingen die snel en in onvoorspelbare richting veranderen. Variaties in omgevingskenmerken verklaren dus wellicht waarom de literatuur schijnbaar tegenstrijdige bevindingen bevat. De resultaten in deze derde studie zijn consistent in verschillende modellen met alternatieve prestatiematen, te weten bilaterale kennisstromen, technologische impact, en de introductie van nieuwe producten.

De drie studies illustreren dat de prestaties van R\&D allianties afhangen van, ten minste, een aantal factoren op portfolio-, netwerk-, en relationeel niveau, wat implicaties heeft voor theorievorming en alliantiemanagement. De bevindingen in de drie studies kunnen leiden tot preciezere inzichten in de oorzaken van prestatieverschillen tussen allianties en, in bredere zin, tussen bedrijven. 


\section{Biographical Sketch}

Hans ([Johannes] Theresia Wilhelmus) Frankort was born on August 27, 1981 in Heerlen, the Netherlands. He attended Bernardinus College in Heerlen, where he graduated in 1999 (honorable mention). He subsequently started his studies at Eindhoven University of Technology, where he obtained his M.Sc. (cum laude) in Industrial Engineering and Management Science in 2005. During his studies, he was a visiting undergraduate student at the I. H. Asper School of Business at the University of Manitoba in Canada (2003). Also, he worked for the European Foundation for Management Development in Brussels, Belgium (2005).

In September 2005, Hans started his dissertation research at the Maastricht Research School of Economics of Technology and Organizations, within the department of Organization and Strategy. In 2007, he was a visiting doctoral researcher at the Institute of Management, Innovation and Organization at the Walter A. Haas School of Business at the University of California at Berkeley.

Hans was the recipient of the 2008 Robert J. Litschert Award provided by the Academy of Management's Business Policy and Strategy Division. Also, his research was selected for inclusion in the 2008 Academy of Management Best Paper Proceedings and published in Advances in Strategic Management (2008; joint with John Hagedoorn).

As for professional service, since 2009 Hans has served as a member of the Research Committee of the Academy of Management's Organization and Management Theory Division, and as paper discussant for the Business Policy and Strategy Division. Also, he regularly serves as a referee for three divisions of the Academy of Management (Business Policy and Strategy; Organization and Management Theory; and Technology and Innovation Management), and for the Academy of Management Journal, the Journal of Management Studies, and Long Range Planning.

As of September 2009, Hans works as a University Lecturer in Strategy at Sir John Cass Business School at City University London. 